UNIVERSIDADE DE SÃO PAULO

FFCLRP-DEPARTAMENTO DE FÍSICA

PROGRAMA DE PÓS-GRADUAÇÃO EM CIÊNCIAS

ÁREA DE CONCENTRAÇÃO: FÍSICA APLICADA À MEDICINA E BIOLOGIA

FERNANDA FERRETTI DE OLIVEIRA

\title{
CARACTERIZAÇÃO DE DOSÍMETROS SEMICONDUTORES E SUAS APLICAÇÕES EM TÉCNICAS ESPECIALIZADAS EM RADIOTERAPIA
}




\title{
CARACTERIZAÇÃO DE DOSÍMETROS SEMICONDUTORES E SUAS APLICAÇÕES EM TÉCNICAS ESPECIALIZADAS EM RADIOTERAPIA
}

\author{
Dissertação submetida ao programa de Pós- \\ Graduação em Física Aplicada a Medicina e \\ Biologia, da Faculdade de Filosofia, Ciências \\ e Letras de Ribeirão Preto, da Universidade \\ de São Paulo, como parte dos requisitos para \\ a obtenção do título de Mestre em Ciências - \\ Área de Concentração: \\ Física Aplicada à Medicina e Biologia. \\ Orientador:
}

Prof. Dr. Thomaz Ghilardi Netto

Ribeirão Preto 
Autorizo a reprodução e divulgação total ou parcial deste trabalho, por qualquer meio convencional ou eletrônico, para fins de estudo e pesquisa, desde que citada a fonte.

\section{FICHA CATALOGRÁFICA}

\section{Oliveira, Fernanda Ferretti}

Caracterização de dosímetros semicondutores e suas aplicações em técnicas especializadas em radioterapia. Ribeirão Preto-SP, 2012.

$$
101 \text { p. : il. ; } 30 \mathrm{~cm}
$$

Dissertação de Mestrado, apresentada à Faculdade de Filosofia, Ciências e Letras de Ribeirão Preto/USP. Área de concentração: Física Aplicada à Medicina e Biologia.

Orientador: Ghilardi Netto, Thomaz.

1. Radioterapia. 2. Controle da Qualidade.

3. Diodo Semicondutor. 4. Dosímetro Termoluminescente

5. Dosimetria IN VIVO. 
Nome: Oliveira, Fernanda Ferretti

Título: Caracterização de Dosímetros Semicondutores e suas Aplicações em Técnicas Especializadas em Radioterapia.

Dissertação submetida ao programa de PósGraduação em Física Aplicada a Medicina e Biologia, da Faculdade de Filosofia, Ciências e Letras de Ribeirão Preto, da Universidade de São Paulo, como parte dos requisitos para a obtenção do título de Mestre em Ciências Área de Concentração: Física Aplicada à Medicina e Biologia.

\section{Aprovado em:}

\section{Banca Examinadora}

Prof. Dr. Instituição:

Julgamento: Assinatura:

Prof. Dr. Instituição:

Julgamento: Assinatura:

Prof. Dr. Instituição:

Julgamento: Assinatura: 
“... A ignorância afirma ou nega veemente. A Ciência duvida..."

(Voltaire) 
Dedicatória 
A meus pais, Célio e Marilda, pais exemplares, por me apoiarem em todas as etapas da vida, e a meus irmãos Livia e João Lucas, pela compreensão, carinho, presença e incansável apoio ao longo do período de elaboração deste trabalho. 
Agradecimentos 
A Deus, pela minha vida e pelas oportunidades a mim concedidas.

A meus pais, Célio e Marilda, que sempre me deram suporte para tudo e que nunca me deixaram desistir, que me fizeram acreditar que vale a pena lutar por um sonho, mesmo sabendo da incerteza de realizá-lo e que contribuíram com meu caráter e me transformaram numa pessoa feliz e melhor.

Aos meus irmãos Lívia e João Lucas, por fazerem parte da minha vida, e me proporcionarem a maior felicidade do mundo.

Ao meu avô Francisco de Oliveira (in memoriam), que me ensinou o caminho da verdade, da honestidade e dignidade.

Aos meus avós Aparecido Ferretti, Eunice Ferretti e Maria de Lourdes Oliveira, pelo carinho, presença e incansável apoio ao longo do período de elaboração deste trabalho.

Ao meu namorado Camilo Lopes, por todo amor, amizade e companheirismo nos momentos de conquistas e perdas.

Ao meu amigo Wender Geraldelli por ser companheiro em todas as horas.

Ao meu orientador, Prof. Thomaz, pela valiosa orientação em todas as etapas deste trabalho.

Ao físico Leonardo Lira Amaral, por ter perdido tantas horas me ensinando, acompanhando e por ter sido fundamental na realização desse trabalho.

Ao Prof. Dr. Alessandro Martins Costa, pelo apoio, orientação e pelos inúmeros esclarecimentos e discussões.

Ao Prof. Dr. Martin Eduardo Poletti, por ter cedido um espaço em seu laboratório para que eu pudesse me dedicar a esse trabalho.

Ao Serviço de Radioterapia do HCFMRP, pela estrutura e condições adequadas para realização desse trabalho.

Aos professores do curso de pós-graduação em Física Aplicada à Medicina e Biologia, do Departamento de Física e Matemática da Faculdade de Filosofia Ciências e Letras de Ribeirão Preto, que contribuíram para minha formação.

Às secretárias do Departamento Física, em especial à Nilza, secretária do programa de pós-graduação em Física Aplicada à Medicina e Biologia por todo suporte durante o período de pós-graduação.

Ao CNPq e à FAPESP, pelo apoio que permitiu a realização do meu mestrado.

A todos que, de alguma forma, contribuíram direta ou indiretamente para este trabalho. 
Resumo

- 
Oliveira F.F. Caracterização de Dosímetros Semicondutores e suas Aplicações em Técnicas Especializadas em Radioterapia. Dissertação (Mestrado). Ribeirão Preto: Faculdade de Filosofia, Ciências e Letras de Ribeirão Preto, Universidade de São Paulo; 2012.101 páginas.

Introdução: A Radioterapia é frequentemente utilizada no tratamento do câncer, seja como uma modalidade simples ou em combinação com outras modalidades, tais como a cirurgia e a quimioterapia. Com o objetivo de eliminar células não desejadas no organismo humano, utiliza-se de radiações ionizantes para provocar a destruição de células tumorais pela absorção da energia da radiação incidente. A principal dificuldade encontrada em radioterapia é que as células tumorais não são tratadas isoladamente, isto é, o dano da radiação não é restrito somente às células tumorais, mas afeta também as células normais. Assim sendo, é essencial que a dose de radiação liberada nos tecidos normais seja tão baixa quanto possível para minimizar o risco de efeitos colaterais provocados pelos tratamentos radioterápicos. Objetivos: O objetivo deste trabalho é a caracterização de dosímetros semicondutores e dosímetros termoluminescentes e suas aplicações em técnicas não convencionais de Radioterapia. A partir da caracterização será possível a implementação dos dosímetros como sistema de dosimetria in vivo em teleterapia com feixe de fótons, visando atender as necessidades prementes do Serviço de Radioterapia do HCFMRP em implantar a técnica de irradiação de corpo inteiro e em realizar o controle de dose administrada ao paciente. Metodologia e Resultados: Diodos semicondutores foram caracterizados de acordo com o fator campo, angulação, taxa de dose, temperatura e fator bandeja, para obtenção dos fatores de correção. Verificou-se que a variação da resposta dos diodos com a temperatura, angulação e taxa de dose não foi significativa. Fatores campo foram calculados e registrados para campos de $3 \times 3 \mathrm{~cm}^{2}$ a $40 \times 40 \mathrm{~cm}^{2}$, onde se observou aumento na leitura do diodo com o aumento no campo. A resposta com a taxa de dose apresentou pouca variação (de $100 \mathrm{cGy} / \mathrm{min}$ para $300 \mathrm{cGy} / \mathrm{min}$ a variação foi menor que $1,2 \%$ ). O fator bandeja encontrado foi de $0,95 \pm 0,01$ demonstrando que a presença da bandeja provoca diminuição na resposta do detector. Após a caracterização, os diodos foram calibrados em setup TBI para determinação dos fatores de calibração para cada espessura simulada do paciente (DLL). A dosimetria in vivo foi realizada em 3 pacientes submetidos ao tratamento de TBI do HCFMRP. A diferença percentual máxima entre as medidas com diodo e o valor nominal de dose foi de $3,6 \%$, o que está de acordo com o recomendado pelo ICRU (+/- 5\%). Os resultados demonstram a viabilidade e confiabilidade da técnica de dosimetria com diodos semicondutores para Controle de Qualidade de dose em tratamento de TBI. Ainda, dosímetros termoluminescentes foram caracterizados quanto à homogeneidade do grupo e a linearidade. Os fatores de calibração individuais foram encontrados e os dosímetros foram aplicados em simulações em setup TBI. Os cálculos de dose das simulações realizadas com os termoluminescentes inseridos nos orifícios de um OSA demonstraram concordância com os valores nominais de dose. Para as regiões do tórax superior e inferior, onde os TLD receberam doses mais elevadas (>150cGy), recomendou-se a utilização de compensadores de dose, para a prática clínica.Uma câmara de ionização foi utilizada como dosímetro de referência em todas as etapas de calibração e caracterização dos diodos e termoluminescentes. Conclusões: Este estudo mostrou que, para tratamentos de irradiação de corpo inteiro, quando o paciente estiver sendo preparado para um transplante de medula óssea, e o planejamento necessitar de uma grande eficácia na distribuição de dose, a metodologia com aplicações de dosímetros semicondutores apresenta-se como uma alternativa viável, precisa e de grande importância para o controle dosimétrico. Assim, ficou evidenciada a importância da utilização do diodo para o Controle de Qualidade, na avaliação da dose a ser ministrada ao paciente, pelo menos em toda primeira fração de tratamento de TBI. Além disso, ficou demonstrada a aplicabilidade dos dosímetros termoluminescentes para controle dosimétrico, demonstrando o valor da dosimetria termoluminescente como um sistema de verificação de dose e sua eficácia como parte de um programa de garantia de qualidade em Radioterapia. A caracterização dos termoluminescentes evidenciou a possibilidade de aplicação da técnica TL em dosimetria in vivo.

Palavras-chave: Radioterapia, Controle de Qualidade, Diodo Semicondutor, Termoluminescência e Dosimetria IN VIVO. 
Abstract

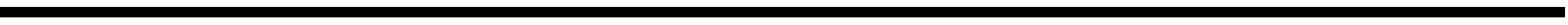


Oliveira F.F Characterization of Semiconductors Dosimeters and their Applications in Specialized Techniques in Radiation Therapy. Dissertation. Ribeirão Preto: Faculdade de Filosofia, Ciências e Letras de Ribeirão Preto, Universidade de São Paulo; 2012. 101 páginas.

Introduction: Radiation therapy is often used in cancer treatment, either as a single modality or in combination with other modalities, such as surgery and chemotherapy. Aiming to eliminate unwanted cells in the human body, radiation therapy uses ionizing radiation to cause destruction of tumor cells by absorbing the energy of the incident radiation. The main difficulty in radiation therapy is that tumor cells are not separately treated. The radiation damage is not restricted solely to tumor cells, but also affects normal cells. Therefore, it is essential that the radiation dose released in normal tissues is as low as possible to minimize the risk of side effects caused by radiotherapy treatments. Objectives: The objective of this work is the characterization of semiconductor dosimeters and thermoluminescent dosimeters and their applications in non-conventional radiotherapy techniques. After characterization it will be possible to implement the dosimeters as a system of in vivo dosimetry in radiotherapy with photon beam, to meet the pressing needs of the Radiotherapy Service of HCFMRP in deploying the technique of total body irradiation and make the control of dose administered to the patient. Methodology and Results: Semiconductor diodes were characterized according to the field factor, angle, dose rate, temperature and tray factor to obtain the correction factors. It was found that the variation of the response of the diodes with temperature, angle and dose rate was not significant. Field factors were calculated and recorded for fields from $3 \times 3 \mathrm{~cm}^{2}$ to $40 \times 40 \mathrm{~cm}^{2}$, where there was an increase in the reading of the diode with increasing field. The response with dose rate showed small variation (from $100 \mathrm{cGy} / \mathrm{min}$ to $300 \mathrm{cGy} / \mathrm{min}$ the variation was less than $1.2 \%$ ). The tray factor was $0.95 \pm 0.01$ demonstrating that the tray decreases detector response. After characterization, the diodes were calibrated in TBI setup for determining the calibration factors for each simulated patient thickness (latero-lateral distance). The in vivo dosimetry was performed in 3 patients undergoing TBI treatment in HCFMRP. The maximum percentage difference between the measurements and the diode nominal dose was $3.6 \%$, which is consistent with that recommended by ICRU $(+/-5 \%)$. The results demonstrate the feasibility and reliability of the dosimetry technique with semiconductor diodes for dose quality control in TBI treatments. Still, dosimeters were characterized by group homogeneity and linearity. The calibration factors were found and individual dosimeters were applied in simulations with TBI setup. The dose calculation of simulations performed with the thermoluminescent inserted in holes of the phantom showed agreement with the nominal dose. For regions of the upper and lower thorax where TLD received higher doses (> 150cGy) it was recommended the use of compensating dose in clinic. An ionization chamber dosimeter was used as reference in all stages of calibration and characterization of diodes and thermoluminescents. Conclusions: This study showed that, for total body irradiation treatments, when the patient is being prepared for a bone marrow transplant, and planning requires a great effect on the dose distribution, the methodology with semiconductor dosimeters presented a viable alternative, and has great importance for the dosimetric control. The study proved the importance of diode semiconductors for quality control, for evaluation of the dose to be administered to the patient, at least throughout the first fraction of TBI treating. Furthermore, it was demonstrated the applicability of TLD for control quality, demonstrating the value of thermoluminescent dosimetry as a dose verification system and its effectiveness as part of a program of quality assurance in radiotherapy. The characterization of thermoluminescent showed the possibility of applying the TL technique in in vivo dosimetry.

Keywords: Radiation Therapy, Control Quality, Semiconductor Diode, Thermoluminescent Dosimeter and In Vivo Dosimetry. 
Siglas e Abreviaturas 
AL: $\quad$ Acelerador Linear

DFS: $\quad$ Distância Fonte-Superfície

TBI: Total Body Irradiation

LNH: $\quad$ Linfoma Não-Hodgkin

LH: $\quad$ Linfoma Hodgkin

ICRU: International Comission on Radiation Units

TLD: $\quad$ Thermoluminescent Dosimeter

OSA: $\quad$ Objeto Simulador Antropomórfico

LH: $\quad$ Linfoma Hodgkin

TMO: $\quad$ Transplante de Medula Óssea

TCPH: Transplante de células progenitoras hematopoiético

PDP: $\quad$ Porcentagem de Dose Profunda

IAEA: International Atomic Energy Agency

MV: $\quad$ Megavoltage

MU: $\quad$ Monitors Unit

SSD: $\quad$ Source Skin Distance

HCFMRP: Hospital das Clínicas da Faculdade de Medicina de Ribeirão Preto

USP: $\quad$ Universidade de São Paulo

D: $\quad$ Dose Absorvida

TL: $\quad$ Termoluminescência

CIDRA: $\quad$ Centro de Instrumentação e Dosimetria

FC: $\quad$ Fator Campo

FB: $\quad$ Fator Bandeja

DLL: $\quad$ Distância Latero-Lateral

Dif \%: $\quad$ Diferença Percentual

CORR: $\quad$ Fator de calibração 
Lista de Figuras 
Figura 1- Porcentagem de dose profunda para diferentes feixes de radiação (ATTIX,1986) .....27 Figura 2- Representação da estrutura cristalina do semicondutor de Silício (VIEGAS, 2003) ...29 Figura 3-Representação da estrutura cristalina do material extrínseco tipo-p (VIEGAS, 2003)

Figura 4- Representação da estrutura cristalina do material extrínseco tipo-n (VIEGAS, 2003)

Figura 5- Para criar diodos tipo-p, um material tipo-p (a) com espessura $T$ e diâmetro $D$ é altamente dopado com material tipo-n (b). Em (c) L é a região de depleção e M é a espessura efetiva do detector. $C$ indica os conectores. ( $M)$ ) é o comprimento de difusão das cargas minoritárias (elétron em um detector de silício tipo-p).(RIKNER, G.; GRUSELL, E.).

Figura 6- Recombinações por armadilhas em material tipo-p. Após a irradiação, pares de elétron-buraco são criados. Portadores minoritários (elétrons) se moverão na banda de condução (a) até serem armadilhados (b) e ocuparem as armadilhas (c) antes de se recombinarem com os portadores majoritários $(d)$. Em (e) a recombinação está completa. (RIKNER, G.; GRUSELL, E.

Figura 7- Variação na sensibilidade com pré-irradiação de elétrons com $20 \mathrm{MeV}$ para diodos tipo-n ( $\odot$ ) diodos tipo-p (O) (de Rikner and Grusell 1983).

Figura 8- Objetos Simuladores: a) água Sólida, b) objeto simulador cúbico de água sólida, c)

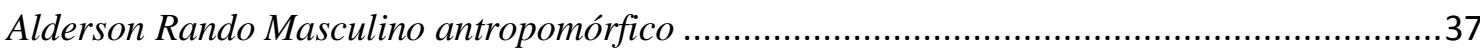

Figura 9- Conjunto dosimétrico: eletrômetro Dosel e câmara de ionização FC065 ……...........38

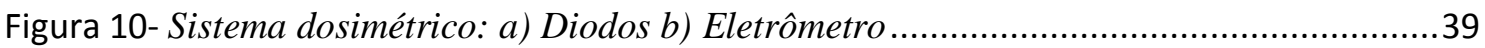

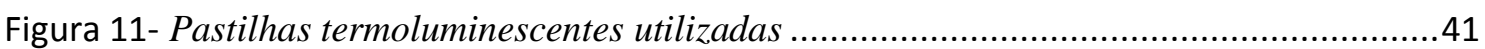

Figura 12- Arranjo experimental para a caracterização dos diodos .........................................41

Figura 13- Análise da dependência com a temperatura ..........................................................43

Figura 14- Setup utilizado para caracterização dos diodos no feixe de 6MV: a) dependência direcional, b) dependência com a distância

Figura 15- Setup para TBI montado para calibração dos diodos semicondutores posicionados na altura da pelve a) representa o posicionamento do gantry; b) representa a configuração do setup com os objetos simuladores representando o corpo de um paciente, c) detalhe para o posicionamento do diodo na altura da pelve do paciente e para a câmara de ionização posicionada dentro do objeto simulador cúbico.

Figura 16- Setup para TBI montado para verificação de dose com os diodos semicondutores posicionados na altura da cabeça

Figura 17- Setup para TBI utilizado na dosimetria com diodos semicondutores para validação do método

Figura 18- Setup montado para a calibração dos dosímetros termoluminescentes. a) e b)

representação da disposição do OSA na lateral direita enquanto c) representa o

posicionamento do lado esquerdo

Figura 19- Capas de buildup construídas para alojar cada dosímetro termoluminescente ........52

Figura 20- Gráfico do Fator Campo em função do campo para diodos utilizados em feixes do $A L$ de $6 M V$

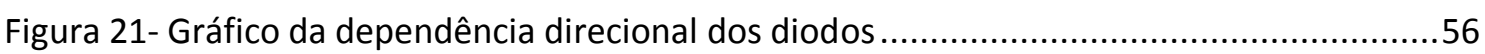

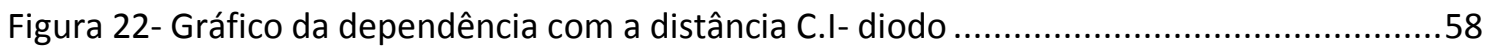

Figura 23- Gráfico da resposta TL em função da Dose ............................................................60 
Tabela 1- Principais regimes típicos de condicionamento pré-transplante de medula óssea .....22

Tabela 2- Especificações dos diodos Scanditronix Medical AB utilizados nesse trabalho ..........38

Tabela 3- Tipos de diodos utilizados e suas respectivas espessuras de buildup para cada faixa

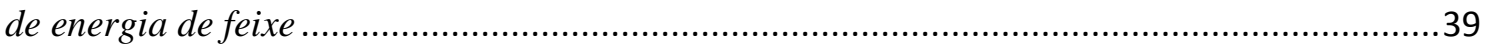

Tabela 4- Fator taxa de dose para diodos utilizados em feixes de acelerador linear de 6MV ...56

Tabela 5- Dependência dos diodos com a temperatura ..............................................................57

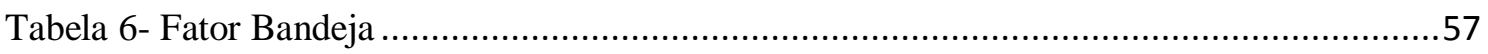

Tabela 7- Porcentagem de dose absorvida pelo diodo quando colocado sobre o objeto simulador, na mesma direção da C.I. .............................................................................58

Tabela 8- Parâmetros utilizados para calibração dos diodos semicondutores em setup para TBI

Tabela 9- Fatores de calibração dos diodos semicondutores para dosimetria TBI ...................63 Tabela 10- Diferença percentual de dose entre diodo e C.I, com diodo posicionado na cabeça do

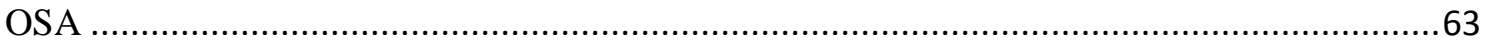

Tabela 11- Valores de doses obtidas com o diodo na simulação do tratamento de TBI..............64

Tabela 12- Leitura de referência com TLDs posicionados ao lado da câmara de ionização .....65

Tabela 13- Leitura do TLD na superfície de entrada do OSA ....................................................65

Tabela 14- Calibração dos dosímetros termoluminescentes no setup de TBI ............................68

Tabela 15- Valores de Dose para simulação com TLD em setup de TBI.................................69

Tabela 16-Leitura de dose dos TLD a partir da simulação TBI .....................................................71

Tabela 17- Parâmetros do tratamento de dosimetria in vivo TBI. ............................................. 72

Tabela 18- Valores de dosimetria in vivo em pacientes em tratamento de TBI........................72 
Sumário

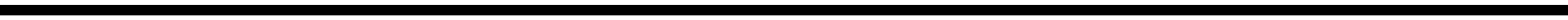




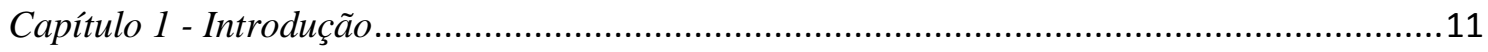

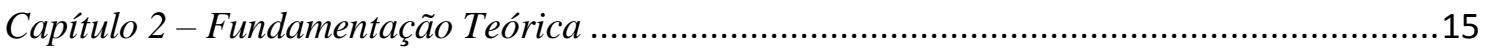

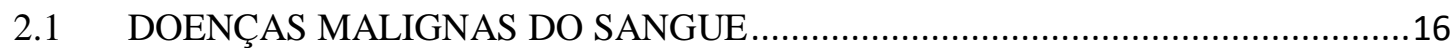

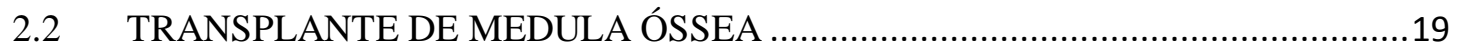

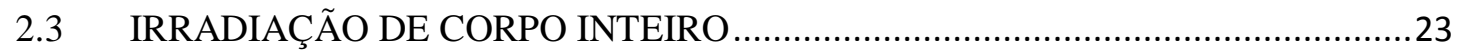

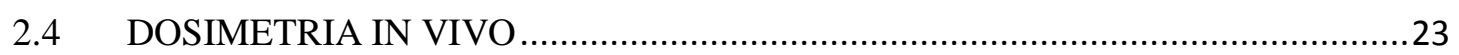

2.5 GRANDEZAS E PARÂMETROS DOSIMÉTRICOS ............................................25

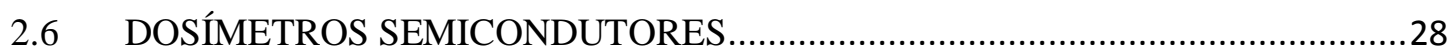

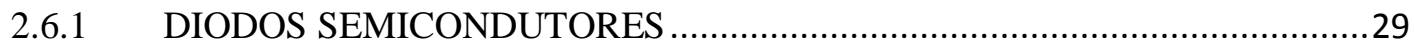

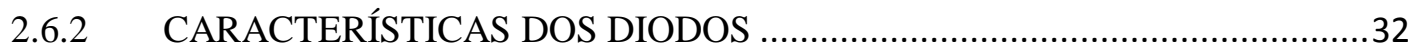

2.6.3 APLICAÇÃO DE DOSÍMETROS SEMICONDUTORES EM DOSIMETRIA 33

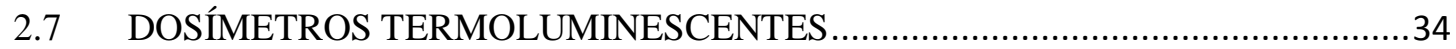

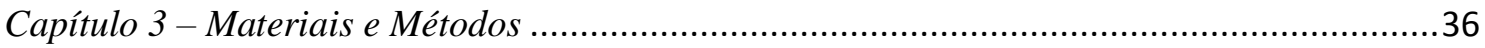

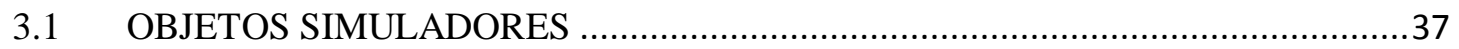

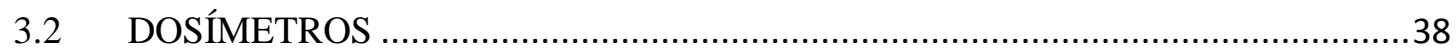

3.2.1 CÂMARA DE IONIZAÇÃO E ELETRÔMETROS ..........................................38

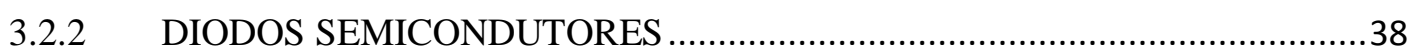

3.2.3 DOSÍMETROS TERMOLUMINESCENTES E SISTEMA DE LEITURA .......40

3.3 CARACTERIZAÇÃO DOS DIODOS SEMICONDUTORES …..............................41

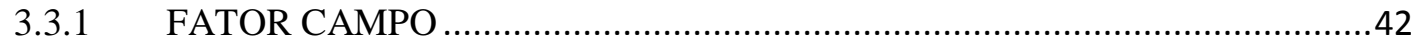

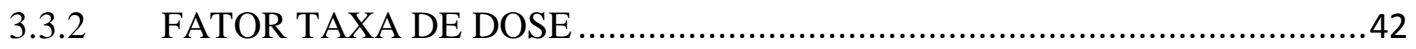

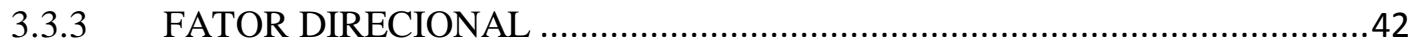

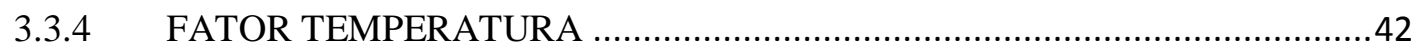

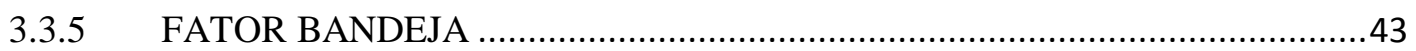

3.3.6 DEPENDÊNCIA COM A DISTÂNCIA …..................................................43

3.4 CARACTERIZAÇÃO DOS DOSÍMETROS TERMOLUMINESCENTES ..............44

3.4.1 PROCEDIMENTO DE INICIALIZAÇÃO......................................................45

3.4.2 HOMOGENEIDADE DO GRUPO …..................................................... 45

3.4.3 FATOR DE CORREÇÃO INDIVIDUAL …..............................................46

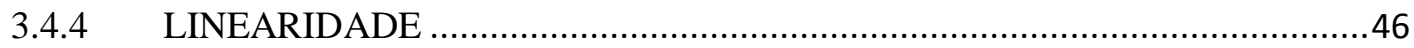

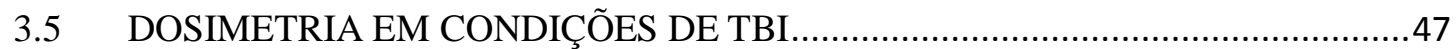

3.5.1 CALIBRAÇÃO DOS DIODOS NAS CONDIÇÕES DE TBI ............................48

3.5.2 CALIBRAÇÃO DOS TLD NAS CONDIÇÕES DE TBI...................................51 
3.6 SIMULAÇÃO DE TBI UTILIZANDO DIODOS E TLD.......................................52

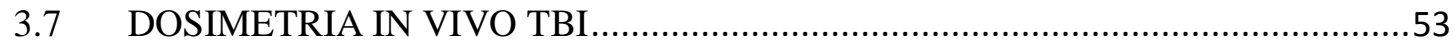

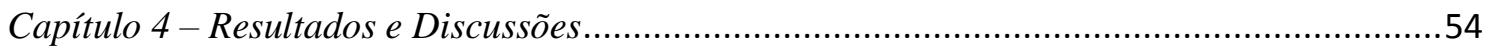

4.1 CARACTERIZAÇÃO DOS DIODOS SEMICONDUTORES …..............................55

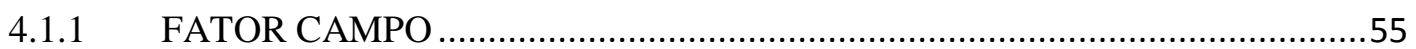

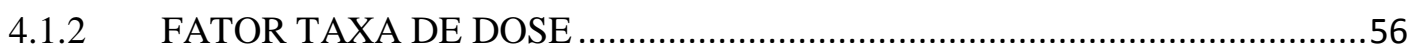

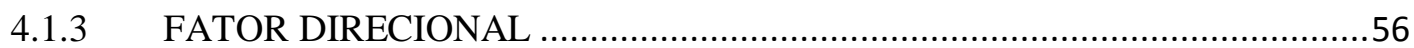

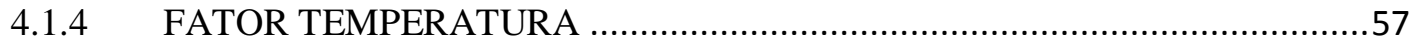

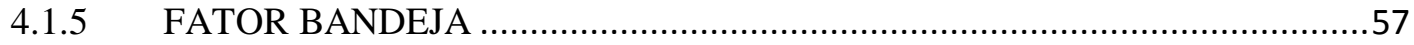

4.1.6 DEPENDÊNCIA COM A DISTÂNCIA …................................................

4.2 CARACTERIZAÇÃO DOS DOSÍMETROS TERMOLUMINESCENTES ..............59

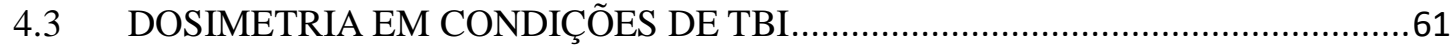

4.3.1 CALIBRAÇÃO DOS DIODOS NAS CONDIÇÕES DE TBI...........................61

4.3.2 CALIBRAÇÃO DOS TLD NAS CONDIÇÕES DE TBI..................................65

4.3.3 SIMULAÇÃO TBI UTILIZANDO DIODOS E TLD ........................................70

4.3.4 DOSIMETRIA IN VIVO TBI ................................................................... 71

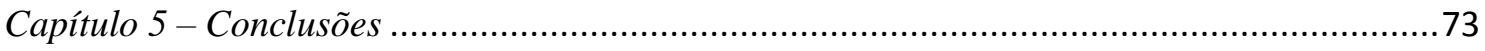

Capítulo 6 - Referências Bibliográficas .................................................................................. 
Capítulo 1 - Introdução 


\section{INTRODUÇÃO}

A radioterapia é frequentemente utilizada no tratamento do câncer, seja como uma modalidade simples ou em combinação com outras modalidades, tais como a cirurgia e a quimioterapia, utilizando radiações ionizantes e baseando-se na destruição das células tumorais pela absorção da energia da radiação incidente. $\mathrm{O}$ tratamento no qual a fonte de radiação é posicionada externamente ao paciente, chamada de teleterapia, é a forma mais comum de radioterapia, podendo ser convencional e não convencional, normalmente, sendo realizada com feixes de fótons de raios $\mathrm{X}$ de energias altas produzidos por aceleradores lineares (AL), com feixes de raios gama de unidades de cobalto, com raios $\mathrm{X}$ de energias menores, com tensões de até $250 \mathrm{kV}$, como também feixes de elétrons de megavoltagem produzidos por aceleradores lineares $\left[{ }^{1}\right]$.

Por Radioterapia convencional entendem-se tratamentos realizados em um conjunto de condições estabelecidas em protocolos clínicos e envolvendo parâmetros como: distância fonte-superfície (DFS), tamanho de campo, tipo de energia do feixe de radiação, além de outros. Os tratamentos não convencionais são todos aqueles que não conservam ou não cumprem as condições de referência.

Dentro da especialidade médica da Radioncologia, a Irradiação de Corpo Inteiro (TBI, do inglês Total Body Irradiation) é considerada um procedimento especial uma vez que se difere significativamente, das técnicas de tratamentos padrões utilizados em radioterapia. As diferenças são basicamente devido ao fato de que, os campos de tratamento para TBI excedem o tamanho do volume espalhador (o corpo inteiro) em todas as direções, e que o volume irradiado é altamente irregular em sua forma.

A TBI é uma técnica em teleterapia não convencional utilizada como um regime de preparação para a reconstituição da medula óssea, de pacientes com doenças malignas refratárias, incluindo leucemia, linfoma não-Hodgkin (LNH) e neuroblastoma. Estes regimes, tipicamente empregam doses supraletais de quimioterapia e radioterapia, podendo produzir uma maior toxicidade. Para evitar danos mais severos ou até mesmo, uma possível mortalidade, é importante garantir uma homogeneidade na distribuição da dose quando o corpo inteiro é irradiado $\left[{ }^{2}\right]$. A finalidade da TBI é destruir as células da medula óssea do paciente, com o intuito de imunossuprimí-la e prepará-la para receber a nova medula. Esta preparação normalmente é acompanhada por ciclos de quimioterapia

$\left[{ }^{3}\right]$. Adicionalmente, é essencial que os métodos de cálculo de dose para tratamentos 
TBI sejam confiáveis e sigam um protocolo padrão.

Inicialmente, a técnica de TBI era administrada como uma fração única de radiação. A toxicidade era influenciada pela taxa de dose e pela dose total do tratamento. A dose total era predominantemente limitada pela toxicidade pulmonar que, no caso de pneumonite intersticial poderia ser fatal ao paciente $\left[{ }^{4}\right]$. Posteriormente foram introduzidas técnicas de TBI de fracionamento e hiper-fracionamento, para melhorar os efeitos anti-leucêmicos, sem aumentar a toxicidade, baseados nos princípios da radiobiologia, ou seja, reparação dos tecidos normais com o fracionamento. Assim, um número significativo de estudos tem sugerido o uso da TBI fracionada na tentativa de redução da toxicidade $\left[{ }^{5,6}\right]$.

Atualmente existem várias técnicas em uso para administração da TBI $\left[{ }^{7}\right]$. Fatores que influenciam a escolha entre as técnicas atuais de TBI incluem homogeneidade de dose, entrega exata de dose, reprodutibilidade, facilidade do set up, tamanho de campo, tamanho da sala, entre outros.

Para relatar a homogeneidade de dose para TBI é necessário realizar extensas medições in vivo para cada fração do tratamento. A dosimetria in vivo monitora diretamente a dose de radiação liberada na superfície do paciente durante o tratamento radioterápico permitindo assim, uma comparação entre a dose prescrita e a dose liberada, promovendo um nível de qualidade e confiabilidade ao tratamento. Um bom programa de dosimetria in vivo oferece segurança adicional sem, no entanto, estender o tempo de tratamento $\left[{ }^{8}\right]$.

A diferença percentual entre as doses prescrita e recebida foi estipulada, pela Comissão Internacional sobre Unidades e Medidas em Radiação (ICRU, do inglês International Comission on Radiation Units and Measurements), em um máximo de $5 \%$ e $+7 \%$ para o volume de tratamento $\left[{ }^{9}\right]$. No entanto, em um tratamento de TBI, esse desvio percentual pode comprometer seriamente o pulmão do paciente levando-o ao desenvolvimento de pneumonitis radio-induzida $\left[{ }^{10}\right]$ além de aumentar a toxicidade gastrointestinal do paciente $\left[{ }^{11}\right]$.

Segundo a Organização Mundial da Saúde a avaliação do tratamento pela técnica de TBI deve ser realizada com sistemas de leitura em tempo real, como é caso dos diodos semicondutores, para que possíveis erros no posicionamento do paciente ou dosimetria do feixe possam ser corrigidos antes do tratamento $\left[{ }^{12}\right]$. No entanto, ainda podem ser utilizados outros tipos de dosímetros, que apresentam respostas adequadas para o controle da qualidade dos tratamentos em TBI, como os dosímetros 
termoluminescentes (TLD, do inglês Thermoluminescent Dosimeters) $\left[{ }^{13}\right]$. Dessa forma, a dosimetria in vivo é importante para garantir a acurácia necessária na administração da dose, tanto nos tratamentos convencionais como nos mais complexos, como é o caso do TBI.

O objetivo deste trabalho será a apresentação de um procedimento para implantação de um Programa de Controle de Qualidade utilizando diodos semicondutores à base de Silício, nas medidas in vivo durante o tratamento de TBI, no Serviço de Radioterapia do Hospital das Clínicas da Faculdade de Medicina de Ribeirão Preto (HCFMRP), bem como a caracterização de dosímetros termoluminescentes para serem utilizados nos estudos comparativos das respostas do detector quando submetido às condições clínicas do tratamento de TBI. 
Capítulo 2 - Fundamentação Teórica 


\section{FUNDAMENTAÇÃO TEÓRICA}

\subsection{DOENÇAS MALIGNAS DO SANGUE}

\section{O SANGUE}

O sangue, tecido conjuntivo líquido que circula o sistema vascular sanguíneo, é produzido na medula óssea vermelha e tem como função a manutenção da vida do organismo por meio do transporte de nutrientes, toxinas (metabólitos), oxigênio e gás carbônico. É formado por uma parte celular e uma parte líquida. A parte celular corresponde aos leucócitos (glóbulos Brancos), eritrócitos (glóbulos vermelhos ou hemácias) e as plaquetas. A parte celular é produzida por um processo chamado hematopoese no tecido mielóide (relativo a medula óssea) e no tecido linfóide (nodos linfático e baço). A parte líquida do sangue é composta pelo plasma $\left[{ }^{14}\right]$ :

Hemácias: são responsáveis pelo transporte de oxigênio e parte do gás carbônico através da hemoglobina. São estocadas no baço, que por sua vez tem duas funções: liberar hemácias sadias e destruir hemácias velhas, reciclando a hemoglobina.

Leucócitos: possuem função imunológica ou de defesa do organismo. São classificados em neutrófilos, monócitos, basófilos, eosinófilos e linfócitos, com funções diferentes de defesa e combate a agentes externos (bactérias, vírus, parasitas, entre outros). A deficiência de glóbulos brancos diminui a defesa do organismo contra infecções.

Plaquetas: são fragmentos de células da medula óssea em fase inicial de maturação. Tem como função realizar a coagulação sanguínea, prevenindo, portanto, a hemorragia.

> Plasma: responsável pelo transporte de hemácias, leucócitos, plaquetas e outras substância dissolvidas, como proteínas, nutrientes, excretas, hormônas, gases, entre outros. O plasma transporta essas substâncias por todo organismo, permitindo às células receber nutrientes e excretar e/ou secretar substâncias geradas pelo metabolismo. O plasma é composto por aproximadamente, $90 \%$ de água e 10\% de outras substâncias. 


\section{TIPOS DE DOENCAS MALIGNAS}

A leucemia, o linfoma, o mieloma múltiplo e a síndrome mielodisplásica, são as principais causas de câncer que acometem as células de defesa do sangue, os leucócitos.

\section{LEUCEMIA}

O termo leucemia corresponde a um conjunto de neoplasias malignas que atingem o sangue e possuem origem na medula óssea. Essas neoplasias malignas acometem os leucócitos presentes nos gânglios linfáticos e na corrente sanguínea, provocando a proliferação anormal dessas células na medula óssea, o que pode suprimir a produção de células normais, uma vez que as células leucêmicas podem substituir os elementos medulares normais. Consequentemente, a medula aspirada em outras áreas revelará o infiltrado leucêmico. A célula leucêmica também prolifera em outras áreas do sistema retículo endotelial como o baço, o fígado e os linfonodos. Além disso, podem invadir órgãos e tecidos não hematológicos tais como: meninges, trato-intestinal, rim e pele.

As leucemias são classificadas em $\left[{ }^{15}\right]$ :

> Agudas: quando as células malignas estão em uma fase muito imatura e se multiplicam rapidamente, causando uma enfermidade agressiva. Tem início e evolução rápidos e afeta a maioria das células primitivas, ainda não totalmente diferenciadas ou desenvolvidas.

Crônicas: quando a transformação maligna ocorre em células-tronco mais maduras. Nesse caso a instalação da doença é insidiosa, com complicações que podem levar meses ou anos para ocorrer.

Ainda de acordo com a linhagem celular comprometida são classificadas em:

Leucemias Linfóides: comprometimento da linhagem linfóide.

Leucemia Mielóides: comprometimento da linhagem mielóide.

\section{LINFOMA}

Os linfomas designam um grupo de diversas doenças neoplásicas do sistema linfóide que se originam da proliferação clonal de linfócitos B ou $\mathrm{T}$ em qualquer um de seus estágios de maturação e podem se estender a tecidos extranodais, tais como fígado 
e medula óssea. Os linfomas são classificados em dois grandes grupos: os linfomas $\underline{\operatorname{Hodgkin}(L H)}$ e os linfomas não-Hodgkin $($ LNH $)\left[{ }^{16}\right]$ :

$>L H$ : define-se como uma neoplasia maligna, comumente acometendo inicialmente, linfonodos. Originam-se de um tipo específico de célula linfóides, a célula de Reed-Stemberge. Estes linfomas podem se dividir em Linfoma de Hodgkin nodular linfócito predominante e Linfoma de Hodgkin clássico.

$>$ LNH: mais comuns que os linfomas de Hodgkin. É uma neoplasia do sistema linfático na qual as células linfáticas começam a se modificar, multiplicando-se sem controle, formando tumores. Pode ser indolente (de crescimento lento) ou agressivo (de crescimento rápido) ou possuir ambas as características. O linfoma de células B é o tipo mais comum e o linfoma de células $\mathrm{T}$ o menos comum.

\section{MIELOMA MÚLTIPLO}

O mieloma múltiplo é o câncer das células plasmáticas ou plasmócitos. Os plasmócitos têm origem nos linfócitos e são os responsáveis pela produção de anticorpos (imunoglobulinas ou gamaglobulinas).

No mieloma, mutações genéticas fazem com que o organismo perca o controle da produção de plasmócitos, que se multiplicam indefinidamente. Consequentemente, tem-se um acúmulo de células plasmáticas malignas na medula óssea e um excesso de anticorpos produzido pelas mesmas $\left[{ }^{17}\right]$.

\section{SÍNDROME MIELODISPLÁSICA}

O termo síndrome mielodisplásica refere-se a um grupo de doenças da medula óssea, caracterizadas por uma produção insuficiente de células sanguíneas sadias e que engloba as doenças neoplásicas mielóides e citopenias (anemia, leucopenia, trombocitopenia). As síndromes mielodisplásicas podem progredir para leucemia aguda. Todas as três linhas celulares da medula óssea podem estar envolvidas (série branca ou granulocítica, série vermelha ou eritrocítica e série plaquetária ou megacariocítica) $\left[{ }^{15}\right]$. As síndromes mielodisplásicas constituem um grupo de distúrbios sanguíneos caracterizados por:

Diminuição de todos os tipos de células sanguíneas no sangue periférico; 
Medula óssea com contagem normal ou aumentada de células, que apresentam anormalidades na forma e no tamanho, podendo ocorrer acúmulo de células da medula muito imatura, chamadas de blastos leucêmicos. A severidade da alteração das células da medula define a classificação da doença.

\subsection{TRANSPLANTE DE MEDULA ÓSSEA}

O Transplante de Medula Óssea (TMO) é uma modalidade terapêutica utilizada no tratamento de inúmeras doenças hematológicas, benignas ou malignas, hereditárias ou adquiridas. Consiste na infusão intravenosa de células progenitoras hematopoéticas com o objetivo de restabelecer a função medular nos pacientes com medula óssea danificada ou defeituosa $\left[{ }^{18}\right]$.

O primeiro relato de infusão intravenosa de medula óssea surgiu em 1939, quando um paciente recebeu $18 \mathrm{ml}$ de medula de seu irmão como tentativa de tratamento para aplasia de medula óssea $\left[{ }^{19}\right]$. No entanto, o desenvolvimento das bases científicas atuais da TMO ocorreu através de experiências com roedores. Nesse caso, observou-se que, após serem submetidos à radiação em doses letais, os roedores sobreviviam ao receber infusão posterior intravenosa de medula óssea $\left[{ }^{20}\right]$.

Nas décadas de 50 e 60, experimentos bem sucedidos com cães foi o principal modelo para o desenvolvimento da modalidade terapêutica em humanos. Os animais recebiam doses mieloablativas de irradiação corporal total, seguidas da infusão da medula de doadores aparentados $\left[{ }^{21,22}\right]$.

Em 1969, foi realizado em Seattle-EUA, pela equipe do Dr. E. Donnal Thomas, o primeiro TMO halogênico bem sucedido, dentro de um modelo que até hoje é utilizado. Um paciente com leucemia recebeu doses letais de irradiação corporal total, seguido da infusão de medula de seu irmão $\left[{ }^{23}\right]$.

O fundamento para o TMO baseia-se no fato de que todas as células maduras que circulam no sangue, glóbulos vermelhos, glóbulos brancos e plaquetas, provêm de uma única célula, contida na medula óssea, denominada célula progenitora ou "stem cell", as quais são definidas como células indiferenciadas que são capazes de (1) autorenovação, que é a produção de células iguais a elas, e (2) comprometimento, isto é, a produção de células que estão comprometidas em diferenciar-se. O corpo humano adulto contém uma variedade de diferentes tipos de stem cells que originam células especializadas dos órgãos nos quais elas são encontradas. Dessa forma, atualmente, o 
termo mais amplamente aceito é o de transplante de células progenitoras hematopoiético (TCPH) $\left[{ }^{24}\right]$.

O transplante consiste na substituição das células progenitoras doentes ou deficitárias, por células normais de medula óssea, com o objetivo de provocar a reconstituição da medula. Tais células estão localizadas em adultos, principalmente nos ossos chatos como bacia, esterno, costela e vértebras. O procedimento consiste em múltiplas aspirações das células progenitoras doentes, com agulhas especiais. As células progenitoras normais, infundidas na corrente sanguínea, se implantam na medula óssea dando início a reconstituição hematopoiética do paciente, após um regime de acondicionamento. Este transplante, ao contrário de muitos outros, não é mutilador. A quantidade de medula retirada do doador é apenas uma pequena porcentagem do total e, em curto prazo, essa quantidade será reposta pelo organismo do doador a reporá, sem que isto custe qualquer prejuízo para seu organismo.

A indicação ou não de um transplante de medula óssea depende de vários fatores, que devem ser analisados cuidadosamente pelo médico. A análise dos benefícios esperados, ponderação dos riscos, a idade e o sexo do paciente, o tipo de transplante, além do estádio da doença, são fatores a ser considerados previamente. Não são todos os pacientes portadores de alguma doença maligna do sangue que têm indicação para a realização do transplante. Os critérios para a realização do procedimento estão estabelecidos em protocolos aprovados pelos Comitês de Ética $\left[{ }^{23}\right]$.

\section{TIPOS DE TRANSPLANTE DE MEDULA ÓSSEA}

O transplante de medula óssea pode ser $\left[{ }^{15}\right]$ :

Alogênico: as células progenitoras provêm de um doador previamente selecionado por testes de compatibilidade, normalmente identificado entre os familiares ou em bancos de medula óssea.

> Autólogo ou autogênico: as células progenitoras provêm do próprio indivíduo transplantado (receptor).

> Singênico: as células progenitoras provêm de gêmeos idênticos (univitelinos). É a modalidade mais rara de transplante devido a pouca frequência de gêmeos idênticos na população. 


\section{ETAPAS DO TRANSPLANTE DE MEDULA ÓSSEA}

Anteriormente ao transplante de medula óssea, o paciente faz exames laboratoriais de controle, além de testes para que se possa selecionar um doador possível, ou seja, aquele que possui características geneticamente compatíveis com as dele $\left[{ }^{24}\right]$.

Posteriormente, o procedimento é dividido em etapas:

$>$ Coleta da medula óssea;

$>$ Condicionamento, $\mathrm{e}$

$>$ Pega e recuperação medular

\section{COLETA DA MEDULA ÓSSEA}

O procedimento é feito por meio de uma pequena cirurgia de aproximadamente 90 minutos, em que são realizadas múltiplas punções com agulhas especiais nos ossos posteriores da bacia, onde então a medula é aspirada. Usualmente uma quantidade estimada em $10 \mathrm{ml} / \mathrm{kg}$ de peso do receptor é retirada, que geralmente corresponde a um número adequado de células progenitoras suficiente para permitir a pega (engraftment) do enxerto, também denominada enxertia. A medula é então injetada em uma bolsa apropriada ou Becker contendo anticoagulante e, posteriormente, filtrada para a remoção de gorduras e espículas ósseas $\left[{ }^{25}\right]$.

\section{CONDICIONAMENTO}

O condicionamento pré-transplante tem a finalidade de erradicar a doença residual do paciente, assim como a de induzir uma imunossupressão que permita a pega das células infundidas. A irradiação corporal total foi utilizada isoladamente como agente de condicionamento para o TMO e logo depois a ciclofosfamida foi associada, sendo esta combinação utilizada até hoje. A escolha do melhor regime de condicionamento é feita de acordo com a doença de base do paciente. A Tabela 1 lista os principais regimes de condicionamento utilizados atualmente. 


\begin{tabular}{|c|c|c|}
\hline Regime & $\begin{array}{l}\text { Doenças mais } \\
\text { freqüentemente } \\
\text { tratadas com } \\
\text { o esquema }\end{array}$ & $\begin{array}{l}\text { Refe- } \\
\text { rência }\end{array}$ \\
\hline $\mathrm{TBI}(12 \mathrm{~Gy})+\mathrm{Cy}(120 \mathrm{mg} / \mathrm{kg})$ & $\begin{array}{l}\text { LLA, LMA, } \\
\text { LMC, AAG }\end{array}$ & 34 \\
\hline TBI (12 Gy $)+$ VP-16 (60mg/kg) & LLA & 35 \\
\hline $\mathrm{Bu}(16 \mathrm{mg} / \mathrm{kg})+\mathrm{Cy}(120 \mathrm{mg} / \mathrm{kg})$ & $\mathrm{LMC}, \mathrm{LMA}$ & 32 \\
\hline $\mathrm{Bu}(4 \mathrm{mg} / \mathrm{kg})+\mathrm{Cy}(200 \mathrm{mg} / \mathrm{kg})$ & $\mathrm{AAG}$ & 47 \\
\hline $\mathrm{Bu}(16 \mathrm{mg} / \mathrm{kg})+\mathrm{Mel}(140 \mathrm{mg} / \mathrm{kg})$ & $\begin{array}{l}\text { LMA, LMC, } \\
\text { tumores sólidos }\end{array}$ & 48 \\
\hline Cy $(200 \mathrm{mg} / \mathrm{kg})$ & $\mathrm{AAG}$ & 49 \\
\hline TBI $(12 \mathrm{~Gy})+\mathrm{Ara}-\mathrm{C}\left(36 \mathrm{~g} / \mathrm{m}^{2}\right)$ & LLA & 50 \\
\hline $\begin{array}{l}\text { BEAM - BCNU }\left(300 \mathrm{mg} / \mathrm{m}^{2}\right) \\
+ \text { VP-16 }\left(800 \mathrm{mg} / \mathrm{m}^{2}\right) \\
+ \text { Ara-c }\left(800 \mathrm{mg} / \mathrm{m}^{2}\right) \\
+\operatorname{Mel}\left(140 \mathrm{mg} / \mathrm{m}^{2}\right)\end{array}$ & $\begin{array}{l}\text { Linfomas } \\
\text { Hodgkin } \\
\text { e não Hodgkin }\end{array}$ & 39 \\
\hline
\end{tabular}

Bu: Bussulfan, TBI: Irradiação corporal total ( Total bo dy irradiation), Cy: Ciclofosfamida, VP-16: Etoposide, Mel: Melfalan, Ara-C: Citos ina-arabinosídeo

Tabela 1- Principais regimes típicos de condicionamento pré-transplante de medula óssea ( de CASTRO JR, C.G, GREGIANIN L.J, BRUNETTO, A.L.)

\section{PEGA E RECUPERAÇÃO MEDULAR}

Após ser submetido aos tratamentos acima citados, que tem por finalidade destruir a medula doente do receptor e abrir "espaço" para as novas células progenitoras, o paciente recebe então a medula sadia como se estivesse sendo submetido a uma transfusão de sangue. Uma vez na corrente sanguínea, as células progenitoras novas circulam e se alojam na medula óssea, voltando a se proliferar. Durante o período em que estas células ainda não são capazes de produzir glóbulos brancos, vermelhos e plaquetas em quantidade suficiente para manter as taxas dentro da normalidade, o paciente fica mais exposto a episódios infecciosos e ou hemorragias. Por essa razão, o paciente geralmente é mantido preferencialmente internado, em regime de isolamento. Após a recuperação da medula, a produção de hemácias, leucócitos e plaquetas vai alcançando a normalidade. Ainda assim, o paciente continua a receber tratamento, em regime ambulatorial, sendo necessário, por vezes, o comparecimento diário ao hospital. Exames feitos pela equipe médica irão avaliar, posteriormente, o sucesso do transplante $\left.{ }^{24}\right]$. 


\subsection{IRRADIAÇÃO DE CORPO INTEIRO}

A TBI é uma técnica de radioterapia não convencional, que usa fótons de alta energia sendo frequentemente utilizada para preparar os pacientes para transplante de medula óssea, vítima das doenças malignas do sangue (leucemia, linfomas, mielomas, entre outros) e pode ser associada à quimioterapia na etapa de condicionamento do TMO $\left[{ }^{26}\right]$.

A finalidade da TBI é auxiliar na destruição das células da medula, imunossuprimindo o paciente para que este possa receber a nova medula óssea.

Nos serviços de Radioterapia, a TBI é administrada com diferentes prescrições de dose e fracionamento de dose. O fracionamento de dose para técnica de TBI foi proposto como forma de reduzir a toxicidade em órgãos críticos do paciente, tais como pulmão e trato gastrointestinal.

As doses totais do tratamento são, geralmente, de $12 \mathrm{~Gy}$, com taxas de dose de até alguns poucos décimos de grays por minuto. São empregados campos extensos, em média $150 \times 150 \mathrm{~cm}^{2}$, posicionando-se o paciente em grandes distâncias da fonte de radiação, sendo tais distâncias, em média, de $\left.350 \mathrm{~cm} \mathrm{[}{ }^{27}\right]$.

A técnica de TBI é considerada complexa, uma vez que a combinação de taxas de doses baixas, campos extensos e grandes distâncias fonte-superfície levam a um aumento na dificuldade do tratamento. Incertezas na determinação da taxa de dose nas condições de irradiação, na determinação da dose em profundidade, no posicionamento do paciente entre frações e na definição da homogeneidade da dose, são fatores que contribuem para a complexidade do tratamento. A não homogeneidade da dose, no volume de tratamento, devido a não homogeneidade dos tecidos presentes no campo de radiação, ao contorno irregular do paciente e à energia do feixe, pode comprometer os órgãos de risco do tratamento, como pulmão, podendo levar ao desenvolvimento de pneumonitis radio-induzida ou a síndrome gastrointestinal $\left[{ }^{28,29}\right]$.

\subsection{DOSIMETRIA IN VIVO}

Entre as etapas de planejamento e execução dos tratamentos em Radioterapia são introduzidas incertezas individuais que contribuem para a incerteza total na dose absorvida pelo paciente. A exatidão na distribuição de dose pode ser menor que o desejável: erros sistemáticos podem surgir devido à influência dos contornos, dos 
movimentos, variação de anatomia interna do paciente e inomogeneidades $\left[{ }^{30}\right]$. Além disso, incertezas podem ser introduzidas durante a transferência de dados do sistema de planejamento do tratamento ou do simulador para o acelerador, por erros nos parâmetros da unidade de tratamento, no posicionamento do paciente ou dos modificadores de feixe $\left[{ }^{31,32}\right]$. A verificação final da dose real distribuída a um paciente somente pode ser realizada pela dosimetria in vivo. Sendo assim, é extremamente necessário quantificar a incerteza total.

A dosimetria in vivo pode ser realizada colocando-se dosímetros sobre a pele ou em cavidades naturais do paciente. Doses de entrada e de saída podem ser obtidas posicionando-se os dosímetros sobre a pele. Da combinação das doses de entrada e saída pode-se obter a dose no interior do paciente a partir de várias relações [ $\left.{ }^{33,34,35}\right]$.

As determinações de dose de entrada são usadas para verificar a calibração da unidade de tratamento, a exatidão do posicionamento do paciente e dos modificadores de feixe e o cálculo do número de unidades monitoras. Enquanto que, as determinações de dose de saída são usadas para verificar o alinhamento do feixe, determinar o tamanho e densidade do paciente e verificar a influência das variações de forma. Após essas determinações é necessário aplicar fatores de correção para então, calcular a dose esperada no ponto de interesse, e compará-la com a dose medida pelo sistema de detecção.

Se existir uma diferença significativa, todos os parâmetros do tratamento devem ser verificados. A concordância do planejamento com a unidade monitora calculada deve ser verificada, bem como todos os modificadores de feixe. Feitas as devidas correções, uma segunda medida deve ser feita a fim de se confirmar a concordância da dose esperada com a dose medida. Uma elevada acurácia pode ser obtida, num procedimento de dosimetria in vivo, se os devidos fatores de correção forem corretamente aplicados. Nesse caso, este procedimento pode levar à detecção de problemas com o equipamento de calibração e a erros sistemáticos.

A dosimetria termoluminescente e a dosimetria com detectores semicondutores são as duas técnicas mais bem estabelecidas utilizadas para dosimetria in vivo $\left[{ }^{36,37,38,39}\right]$. Detectores semicondutores, mais especificamente os diodos de silício, em virtude do seu tamanho diminuto, da alta resolução espacial, e da razão constante entre os stopping powers do $\mathrm{Si}$ e da para energias entre 5 e $20 \mathrm{MeV}$, dispensam fatores de correção, e devido a isto, estão sendo amplamente utilizados em determinações de dose absorvida em tratamentos radioterápicos $\left[{ }^{36}\right]$. 
As câmaras de ionização apresentam dificuldades nos procedimentos, por serem volumosas e frágeis, tornando-as não apropriadas para a dosimetria in vivo e, devido a isto, não são rotineiramente usadas em pacientes. Além disso, requerem uma conexão a um eletrômetro e consequentemente, a aplicação de uma alta voltagem, que pode ser um risco de choque elétrico para o paciente. Dessa forma, para o caso específico de tratamento TBI, as câmaras possuem aplicação limitada $\left[{ }^{37}\right]$.

Cada instituição deve ter meios para garantir que, a qualidade do serviço de radioterapia a ser oferecido se mantenha dentro dos limites admitidos internacionalmente e que disponha dos mecanismos necessários para corrigir os desvios que possam levar ao detrimento do paciente. A maioria das instituições brasileiras segue o Protocolo de Garantia de Qualidade TECDOC - $1151\left[{ }^{38}\right]$ e os protocolos de dosimetria publicados pela Agência Internacional de Energia Atômica (IAEA, do inglês International Atomic Energy Agency) [ ${ }^{39]}$.

O ICRU recomenda uma diferença percentual entre as doses prescrita e administrada entre $-5 \%$ e $+7 \%$. Especificamente em tratamentos de irradiação de corpo inteiro TBI, que empregam distâncias fonte-superfície extensas e campos largos de radiação apresentando assim, um grau de complexidade elevada quando comparada com os procedimentos convencionais, ainda não há um protocolo bem estabelecido para o cálculo da dose absorvida. Os efeitos colaterais severos associados ao tratamento de TBI fazem com que seja necessário um controle rigoroso das doses administradas ao paciente. Dessa forma, um programa de verificação do tratamento, através da dosimetria in vivo é imprescindível [ [ ].

\subsection{GRANDEZAS E PARÂMETROS DOSIMÉTRICOS}

As grandezas dosimétricas são derivadas das grandezas radiométricas, que caracterizam os campos de radiação, e de coeficientes de interação, que caracterizam os processos de interação da radiação com a matéria. Algumas grandezas dosimétricas são a exposição, a taxa de exposição, o kerma, e a dose absorvida, sendo esta última a mais importante em radioterapia por estar relacionada com a deposição de dose nos tecidos do paciente.

Os parâmetros dosimétricos são utilizados para relacionar uma dada grandeza dosimétrica em diferentes condições de irradiação ou posições do paciente e são 
utilizados em sistemas de cálculo do tratamento e na verificação das doses em profundidade. Alguns parâmetros dosimétricos são a porcentagem de dose profunda (PDP), a razão tecido-máximo (TMR, do inglês Tissue Maximum Rate) e a correção pela lei do inverso do quadrado da distância.

\section{DOSE ABSORVIDA}

A dose absorvida é definida pelo ICRU como a razão entre o valor esperado da energia cedida para o meio por partículas diretamente ionizantes, $d \varepsilon$, por unidade de massa do meio, $d m$, em um diferencial de volume. Assim, a dose absorvida (D), é definida como:

$$
D=\frac{d \varepsilon}{d m}
$$

Equação 1

A unidade de dose absorvida no Sistema Internacional é o Gray (Gy), sendo 1 Gy igual a $1 \mathrm{~J} / \mathrm{kg}\left[{ }^{40,41}\right]$.

A IAEA define o formalismo para determinação, de uma forma prática, da taxa de dose de referência para feixes clínicos em condições de referência. Para feixes de um acelerador linear, as condições de referência são: profundidade de 10,0 cm em água, campo de $10 \times 10 \mathrm{~cm}^{2}$, distância fonte-superfície de $100 \mathrm{~cm}$. Com base neste formalismo a dose absorvida no ponto efetivo de medida é dada por:

$$
D_{W}=M N_{D, W}(G y)
$$

Equação 2

Onde $M$ é a leitura corrigida do dosímetro no ponto de referência e $N_{D, W}$ é o fator de calibração do dosímetro em dose absorvida na água e na energia do fóton em questão.

\section{PORCENTAGEM DE DOSE PROFUNDA}

A PDP é definida como a quantidade que expressa a porcentagem de dose absorvida em uma profundidade de interesse, $D_{d}$, em relação à dose na profundidade de máxima dose, $D_{m}$. A PDP caracteriza então a distribuição da dose em profundidade em ralação à dose em uma profundidade de referência.

$$
P D P(d)=\frac{D_{d}}{D_{m}} x 100 \%
$$

A PDP depende da profundidade de medida, da largura do campo de radiação, 
da distância fonte-superfície e do feixe de radiação $\left[{ }^{41}\right]$. Através das porcentagens de dose obtidas em várias profundidades pode-se obter a curva de PDP para diferentes qualidades de feixe de radiação, como mostrada na Figura 1.

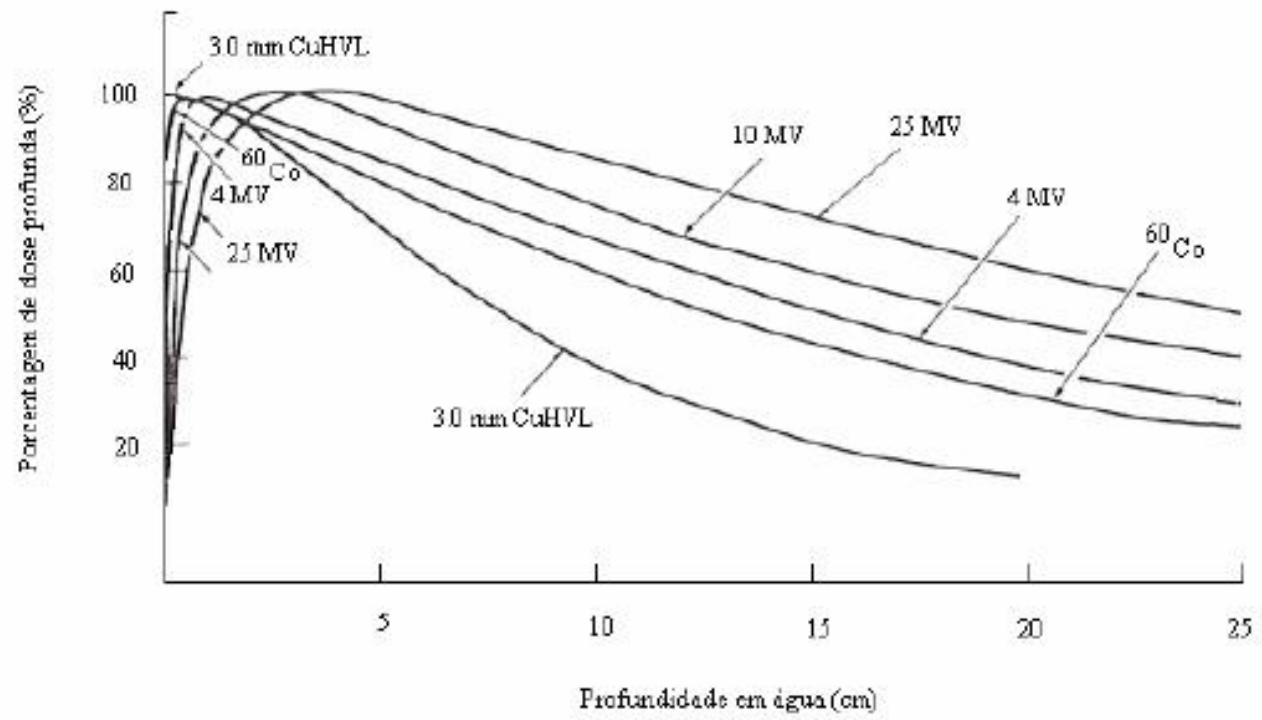

Figura 1- Porcentagem de dose profunda para diferentes feixes de radiação (ATTIX,1986)

Através das curvas da Figura 1, observa-se que, a partir da superfície do material irradiado, a PDP, inicialmente aumenta até alcançar 100\% na profundidade de máxima dose (buildup), onde o feixe de radiação alcança o equilíbrio eletrônico dentro do material. A espessura de buildup varia em função da energia do feixe, portanto com aumento da energia a espessura aumenta. A partir da camada de buildup, a PDP diminui com o aumento da profundidade devido à atenuação do feixe primário pelo material.

\section{LEI DO INVERSO DO OUADRADO DA DISTÂNCIA}

A lei do inverso do quadrado da distância define a variação da fluência dos fótons de uma fonte de radiação à medida que a distância da fonte aumenta, sendo independente da energia da fonte de radiação. Nesse caso, a atenuação do feixe não é considerada. Considerando-se a fonte de radiação como uma fonte pontual (como as fontes que são utilizadas na Radioterapia externa), a lei do inverso do quadrado da distância relaciona as doses nos ponto X e Y no espaço livre $\left[{ }^{41}\right]$, como é mostrado na Equação 4.

$$
D_{y}=D_{x}\left(\frac{d_{y}}{d_{x}}\right)^{2}
$$


onde $D_{Y}$ e $D_{X}$ são as doses nos pontos $X$ e $Y$, localizados a uma distância $d_{Y}$ e $d_{X}$ em relação a fonte de radiação, respectivamente.

\section{EXPOSICÃ̃}

A exposição descreve os feixes de raios-X em termos de sua capacidade de ionizar o ar. A exposição (X) é definida como o valor absoluto da carga de íons de um sinal $\mathrm{d}_{\mathrm{q}}$, produzido no ar quando todos os elétrons liberados por fótons no ar, de massa $\mathrm{d}_{\mathrm{m}}$, são completamente freados $\left[{ }^{41}\right]$.

$$
X=\frac{d_{q}}{d_{m}}
$$

A exposição é usualmente medida em Coulomb por quilogramas $(\mathrm{C} / \mathrm{kg})$.

\subsection{DOSÍMETROS SEMICONDUTORES}

\section{MATERIAIS CRISTALINOS}

Os materiais cristalinos apresentam três bandas de energia em relação à condutividade de elétrons: a banda de valência, a banda de condução e uma banda proibida. Esta última representa uma região onde os elétrons são impedidos de permanecer.

Os elétrons que se encontram nas camadas mais externas, ou de valência, são considerados praticamente livres dentro do cristal, como se não pertencessem a nenhum átomo em particular. A região onde estes elétrons se localizam é chamada banda de valência. Elétrons da banda de valência podem ser acelerados por um campo elétrico externo e passar para a região denominada banda de condução. Quando um elétron passa para a banda de condução, em seu lugar fica uma ausência de elétron, que é chamada de lacuna ou simplesmente buraco. Na banda de condução, a população de elétrons dependerá da natureza e da temperatura do cristal. Por elevação de temperatura, os elétrons da banda de valência podem adquirir energia suficiente para saltar a banda proibida e chegar à banda de condução.

A largura em energia da banda proibida é o que caracteriza os materiais em isolantes, semicondutores ou condutores. Nos materiais chamados isolantes, a banda proibida é muito larga, da ordem de $5 \mathrm{eV}$ à temperatura ambiente, de modo que mesmo na ausência de excitação térmica, a banda de condução permanece vazia e a banda de 
valência, completa. Mesmo com um campo elétrico externo não se consegue fazer com que o elétron mude de banda. Nos materiais condutores, a banda proibida é muito pequena, de modo que as bandas de valência e de condução se superpõem. Para os materiais cuja energia de separação entre as bandas de valência e de condução é da ordem de $1 \mathrm{eV}$ à temperatura ambiente, assim uma pequena quantidade de excitação térmica é suficiente para causar a migração de elétrons para a banda de condução, proporcionando uma alta condutividade, o suficiente para o material ser classificado como semicondutor.

\subsubsection{DIODOS SEMICONDUTORES}

Diodos são dispositivos eletrônicos capazes de transformar corrente elétrica alternada em contínua. São constituídos de material semicondutor tetravalente como o Germânio (Ge) ou Silício ( $\mathrm{Si}$ ), sendo este último o mais usado. A Figura 2 mostra um esquema da estrutura cristalina do semicondutor de Silício.

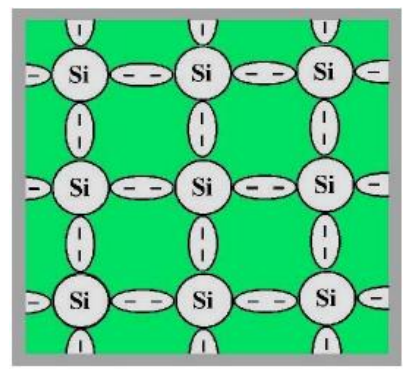

Figura 2- Representação da estrutura cristalina do semicondutor de Silício (VIEGAS,2003)

Ao semicondutor em seu estado puro, conhecido como semicondutor intrínseco, geralmente adiciona-se Boro (B) ou Fósforo (P), formando materiais tipo- $p$ e tipo- $n$, dependendo, respectivamente, se o material adicionado é do Grupo III ou V. Essa adição de materiais, ou adição de impurezas, é um processo conhecido como dopagem. O semicondutor dopado passa a ser denominado extrínseco $\left[{ }^{42}\right]$.

Para obter-se um material tipo-p, adiciona-se um elemento que tenha somente três elétrons na última camada, como o Boro (B) ou o Alumínio ( $\mathrm{Al}$ ), ou seja, adicionase um elemento trivalente, o material passa a ter uma característica receptiva. Dessa forma, existirá um elétron a menos na ligação, o que corresponde a uma lacuna ou buraco. Na Figura 3, observam-se as três ligações completas de elétrons e uma quarta ligação incompleta, originando uma lacuna ou íon negativo fixo à estrutura do cristal. Nesse caso, o material precisa atrair um elétron para completar sua quarta ligação. As 
lacunas aqui representam a maioria e por isso são denominadas majoritárias. No entanto, existirão elétrons como portadores de carga minoritários que surgirão devido ao rompimento de uma ligação covalente, provocadas pelo fornecimento de energia ao material.

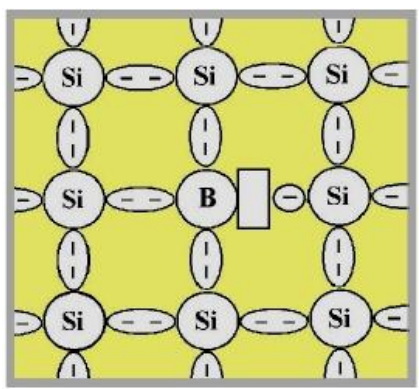

Figura 3- Representação da estrutura cristalina do material extrínseco tipo-p (VIEGAS, 2003)

Para obter-se um material tipo- $n$, adiciona-se um elemento pentavalente, no caso o fósforo, dando ao material característica doadora. Essa dopagem faz com que agora, os portadores de carga majoritários sejam os elétrons e, as lacunas, os minoritários (Figura 4).

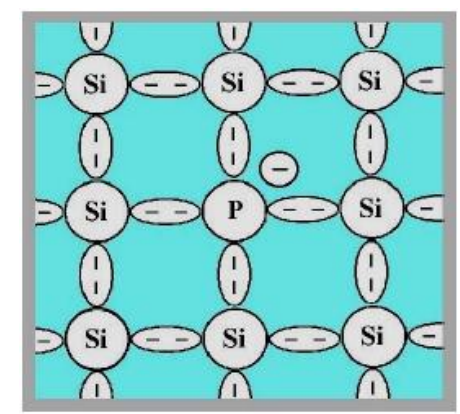

Figura 4- Representação da estrutura cristalina do material extrínseco tipo-n (VIEGAS, 2003)

Observa-se na Figura 4, a existência de quatro ligações completas, um elétron livre por região do material e um íon positivo fixo à estrutura do cristal.

Por mais de 30 anos, os diodos semicondutores de silício têm sido utilizados como detectores de radiação. A densidade do silício e a baixa energia necessária para formação de um par elétron-buraco resultam em uma densidade de corrente de radiação, a qual é aproximadamente 18.000 vezes maior que aquela produzida no ar permitindo assim que, o diodo apresente um pequeno volume (aproximadamente $10^{-2}-10^{-1} \mathrm{~mm}^{3}$ ) e que consiga facilmente medir corrente. Consequentemente, os diodos apresentam uma alta sensibilidade, definida como quantidade de carga coletada por unidade de dose, quando comparados a uma câmara de ionização. A energia necessária para a formação

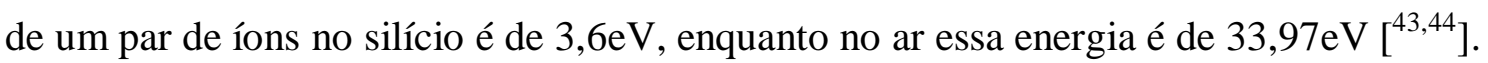


Dessa forma, seu pequeno volume, simplicidade mecânica e a leitura em tempo real, fazem dos diodos, dosímetros atrativos para dosimetria in vivo.

Diodos de silício podem ter dimensões pequenas, largura $(T)$ (Figura 5(a)) inferior a $1 \mathrm{~mm}$ e um diâmetro $(D)$ de dezenas de milímetros até alguns centímetros e podem ser de tipo- $n$ ou tipo-p quando dopados corretamente. O nível de dopagem é definido como a quantidade de átomos de dopagem por unidade de volume no cristal de silício. Para obter se diodos tipo-p, mostrado na Figura 5(a) é necessário dopar uma parte do material tipo-p com um material tipo- $n$, a fim de se obter uma junção $p$ - $n$, mostrado na Figura 5(b). O nível de dopagem no lado $n$ é alto o que acarreta uma baixa eficiência de portadores de cargas. Dessa forma, levam-se em consideração apenas eventos de ionização no lado $p$. Entre os lados $p$ e $n$ do diodo, existe uma região de depleção pela qual uma tensão de $0,7 \mathrm{~V}$ é criada a uma distância de alguns micrômetros indicado por $L$ na Figura 5(c). Durante a irradiação, pares de elétron-buraco são criados e o sinal observado é devido aos portadores de carga criados na região de depleção e aos portadores minoritários (elétrons em materiais tipo-p e buracos nos materiais tipo-n), criados no material base e difundidos pela região de depleção, mostrado na Figura 5(c). A espessura do volume efetivo, mostrado em $M$ na Figura 5(c) é determinado pelo tempo de vida dos portadores minoritários, o qual é da ordem de alguns microssegundos.

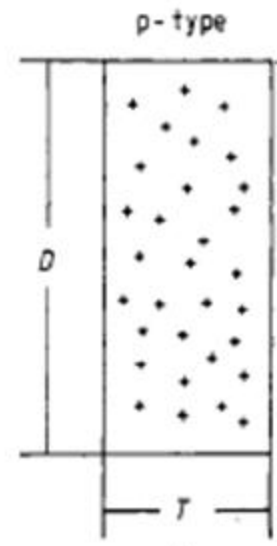

$|a|$

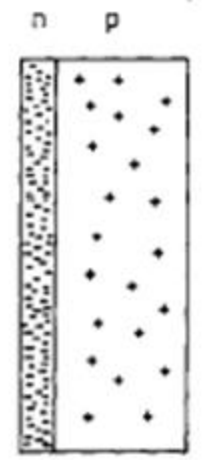

(b)

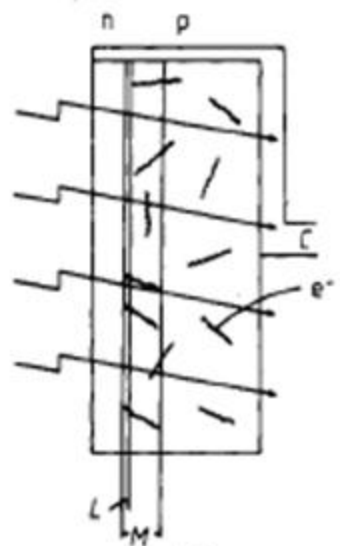

$(c)$

Figura 5- Para criar diodos tipo-p, um material tipo-p (a) com espessura T e diâmetro D é altamente dopado com material tipo-n (b). Em (c) L é a região de depleção e M é a espessura efetiva do detector. $C$ indica os conectores. ( $M$ ) é o comprimento de difusão das cargas minoritárias (elétron em um detector de silício tipo-p).(RIKNER, G.; GRUSELL, E.)

O tempo de vida finito dos portadores é devido aos centros de recombinação e às armadilhas do cristal. As armadilhas consistem em imperfeições na estrutura cristalina 
do material e são induzidas pela radiação ionizante. $O$ efeito de recombinação pode ser observado na Figura 6.

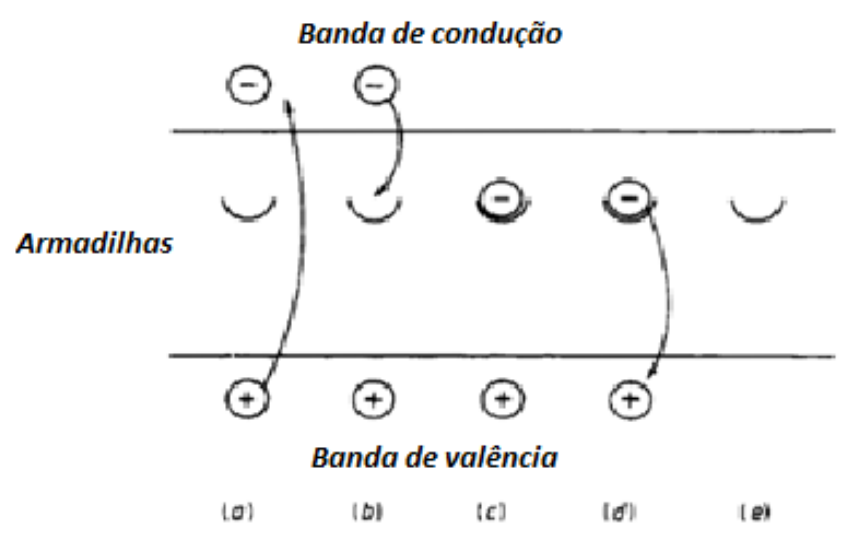

Figura 6- Recombinações por armadilhas em material tipo-p. Após a irradiação, pares de elétronburaco são criados. Portadores minoritários (elétrons) se moverão na banda de condução (a) até serem armadilhados $(b)$ e ocuparem as armadilhas $(c)$ antes de se recombinarem com os portadores majoritários (d). Em (e) a recombinação está completa. (RIKNER, G.; GRUSELL, E.)

\subsubsection{CARACTERÍSTICAS DOS DIODOS}

Quando exposto a doses de radiação o diodo pode apresentar imperfeições, defeitos e impurezas o que contribui para uma perda de sua sensibilidade. A variação da sensibilidade aumenta com o aumento da energia do feixe que, por sua vez, aumenta a probabilidade de causar danos no material. Além disso, a sensibilidade diminui com o aumento da dose acumulada.

De acordo com o aumento da temperatura, observa-se um aumento na sensibilidade do diodo, o que pode ser atribuído a mudanças na mobilidade dos portadores de carga e no número de armadilhas disponíveis no cristal detector. A variação da sensibilidade com a temperatura também depende da dose acumulada recebida pelo diodo. Basicamente, a sensibilidade crescerá com a temperatura em torno de $0,1 \%$ por ${ }^{\circ} \mathrm{C}$, no caso de diodos pouco irradiados. Entretanto, após uma dose de $6 \mathrm{kGy}$ com elétrons de $20 \mathrm{MeV}$, ela pode aumentar até de $0,4 \%$ por ${ }^{\circ} \mathrm{C}$. Esta dependência necessita ser avaliada anteriormente, uma vez que na dosimetria in vivo, o diodo fica em contato com o paciente e, dessa forma, sua temperatura pode subir até $10{ }^{\circ} \mathrm{C}$ em relação à temperatura ambiente, no intervalo de 2 a 3 minutos, antes de se estabilizar [ $\left.{ }^{43}\right]$.

Detectores tipo- $n$ e tipo- $p$ se comportam de maneira diferente uma vez que, os portadores minoritários são buracos e elétrons, respectivamente. Em relação à 
sensibilidade após irradiação foi notado em experimentos uma diferença significativa na resposta desses dois tipos de detectores. Detectores tipo-p possuem menor queda de sensibilidade quando comparados aos do tipo- $n\left[{ }^{43}\right]$, conforme mostra a Figura 7.

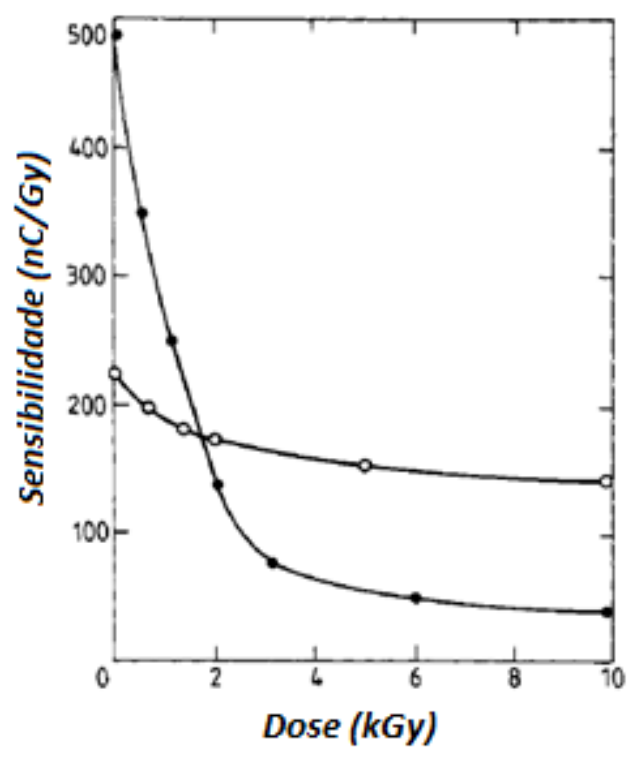

Figura 7- Variação na sensibilidade com pré-irradiação de elétrons com 20MeV para diodos tipo-n ( e diodos tipo-p $(\mathrm{O}) \quad$ (de Rikner and Grusell 1983).

Em virtude dos efeitos descritos acima, a determinação real da dose verificada com os diodos, depende fortemente de parâmetros geométricos, ou seja, da distância fontesuperfície (SSD), do tamanho do campo, da presença de bandejas e blocos presentes durante o tratamento radioterápico. Por essa razão, os fatores de correção devem ser determinados. Por outro lado, as medidas in vivo são realizadas com os diodos localizados na superfície do paciente ou no objeto simulador, o que promove uma avaliação diferente da dose de radiação espalhada quando comparada com a medida de dose de entrada no paciente, definida como a profundidade de máxima dose. Dessa forma, para minimizar os fatores de correção e garantir uma acurácia maior nas medidas de dose é preferível que os diodos tenham uma capa de build-up com espessura igual à profundidade de máxima dose $\left[{ }^{45}\right]$.

\subsubsection{APLICAÇÃO DE DOSÍMETROS SEMICONDUTORES EM DOSIMETRIA}

Detectores tipo diodo, à base de Silício, podem ser utilizados na dosimetria in 
vivo com feixes clínicos de fótons e elétrons. Estes detectores quando acompanhados de um bom eletrômetro oferecem uma combinação única e portátil, de leitura imediata, fácil manuseio, independente de fonte de tensão externa e elevada precisão e acurácia. Isto se deve ao fato de suas dimensões poderem ser mantidas muito menores que as dos detectores gasosos equivalentes, porque a densidade dos sólidos é da ordem de 1000 vezes maior que a dos gases. Eles apresentam maior quantidade de portadores de cargas elétricas, para um dado evento radioativo, do que qualquer outro tipo de detector. Esses portadores são "os pares elétron-buraco" criados ao longo da trajetória da radiação incidente $\left[{ }^{46}\right]$.

\subsection{DOSÍMETROS TERMOLUMINESCENTES}

A dosimetria termoluminescente (TL) é fundamentada no princípio de que alguns cristais podem absorver e armazenar a energia da radiação ionizante, que é reemitida na forma de radiação eletromagnética, principalmente na região de comprimento de onda visível, quando estes cristais são aquecidos. Tais cristais são chamados de dosímetros termoluminescentes. A luz emitida é então detectada por uma fotomultiplicadora e correlacionada à dose absorvida recebida pelo material TL $\left[{ }^{47}\right]$.

O fenômeno de termoluminescência é explicado com a utilização do modelo de bandas de energia. Ao expor o cristal à radiação, os elétrons do cristal pertencentes à banda de valência recebem energia suficiente para atravessar a banda proibida e chegar à banda de condução, assim formando pares de elétrons-buracos. Os elétrons livres se deslocam através do cristal, na banda de condução, por um tempo curto, até serem capturados em estados metaestáveis de energia, localizados na banda proibida (as chamadas armadilhas) ou se recombinarem radiativamente (fluorescência) ou não com os buracos na banda de valência, ou serem capturados em centros de luminescência (armadilhas muito profundas em relação à banda de condução, já ativados por buracos devido à irradiação, com a emissão de luz (radioluminescência)). Os buracos criados pela radiação ionizante na estrutura do cristal comportam-se de maneira semelhante aos elétrons.

Os elétrons podem ficar armadilhados por longos períodos, o que confere ao método TL a vantagem de armazenar informação. Para coletar a informação, o cristal deve ser aquecido a uma temperatura que depende da sua natureza. A energia sob a forma de calor é absorvida pelos elétrons que escapam das armadilhas indo novamente 
para a banda de condução. Nessa etapa, os elétrons podem ser rearmadilhados, ou se recombinarem radiativamente ou não com os buracos na banda de valência, ou se recombinarem radiativamente em centros de luminescência ativados por buracos. A luz emitida por este último processo é a termoluminescência.

Um sistema de leitura, chamado de leitora TL, realiza o aquecimento e a detecção de luz. A quantidade de luz emitida depende da temperatura e do número de elétrons armadilhados. O número de elétrons armadilhados depende da dose absorvida no cristal.

Dessa forma, a quantidade de luz emitida também depende da dose absorvida no cristal. Na maioria dos materiais TL há mais que, um tipo de armadilha. Estas armadilhas têm diferentes profundidades em relação à banda de condução e, portanto, serão desocupadas em diferentes temperaturas. O grande número de armadilhas leva a uma função complicada da intensidade da luz contra a temperatura que é chamada de curva de emissão TL. Essa curva consiste de diferentes picos TL, cada pico correspondendo a um diferente estado de energia no cristal. Estes picos podem ser instáveis -decaindo mais ou menos rapidamente com o tempo de acordo com o material TL considerado- ou estáveis. Um dosímetro TL sempre contém picos instáveis e estáveis, sendo que os picos estáveis são utilizados em dosimetria e assim, são chamados de picos dosimétricos.

Após a leitura, o material TL poderá estar completamente em seu estado original, e, neste caso, estará pronto para ser reutilizado, caso contrário precisará de um tratamento térmico especial para restaurar o seu estado original $\left[{ }^{48}\right]$. 
Capítulo 3 -Materiais e Métodos 


\section{MATERIAIS E MÉTODOS}

Neste capítulo são apresentados os materiais utilizados e os métodos empregados para a caracterização dos dosímetros semicondutores e termoluminescentes para aplicação em dosimetria in vivo TBI.

As irradiações foram realizadas no Acelerador Linear Oncor, marca Siemens, com feixe de $6 \mathrm{MV}$, do Hospital das Clínicas da Faculdade de Medicina de Ribeirão Preto da Universidade de São Paulo (HCFMRP-USP).

\subsection{OBJETOS SIMULADORES}

Neste trabalho foram utilizadas várias combinações diferentes de placas de água sólida, um objeto simulador cúbico de água sólida e um OSA-Alderson Rando masculino. As 20 placas de água sólida possuem dimensões de $30 \times 30 \times 1 \mathrm{~cm}^{3}$ cada e densidade de $1 \mathrm{~g} / \mathrm{cm}^{3}$. O objeto simulador cúbico de água sólida possui dimensões de 18 x 18 x $18 \mathrm{~cm}^{3}$ e o OSA representa um homem adulto sem extremidades. Os materiais do OSA são: o isocyanate que simula o tecido mole, resina epoxy que simula o pulmão, o esqueleto humano simulando um homem de $1,73 \mathrm{~m}$ da cabeça ao torso e de peso 73,5 $\mathrm{kg}$. O OSA é composto por fatias em secções transversais de $2,5 \mathrm{~cm}$ cada e contendo orifícios, de, aproximadamente, $0,5 \mathrm{~cm}$ de diâmetro, distribuídos em diferentes profundidades. Os objetos simuladores são mostrados na Figura 8.

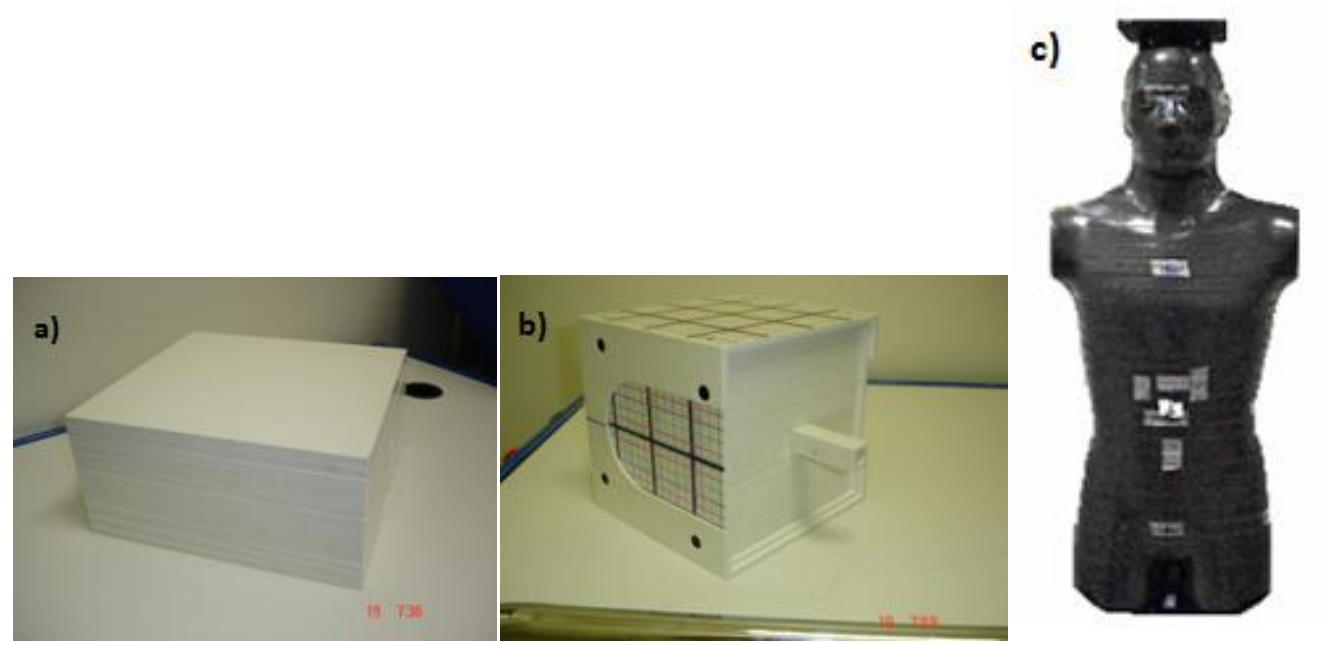

Figura 8- Objetos Simuladores: a) água Sólida, b) objeto simulador cúbico de água sólida, c) Alderson Rando Masculino antropomórfico 


\subsection{DOSÍMETROS}

Para detecção da radiação foram usados três tipos de dosímetros: câmara de ionização, diodos semicondutores e dosímetros termoluminescentes. A câmara de ionização foi usada com um eletrômetro da IBA, dose1.

\subsubsection{CÂMARA DE IONIZAÇÃO E ELETRÔMETROS}

O conjunto formado pela câmara de ionização e o eletrômetro foi usado, como dosímetro de referência, nas determinações de dose durante a caracterização e calibração dos sistemas dosimétricos, para posterior aplicação e validação da técnica de dosimetria in vivo aplicada em tratamentos de TBI. Em todos os casos foi utilizado o mesmo eletrômetro Dose1 da marca IBA. A câmara de ionização utilizada foi a FC065, de volume sensível de $0,65 \mathrm{~cm}^{3}$, marca IBA, conforme mostra a Figura 9.

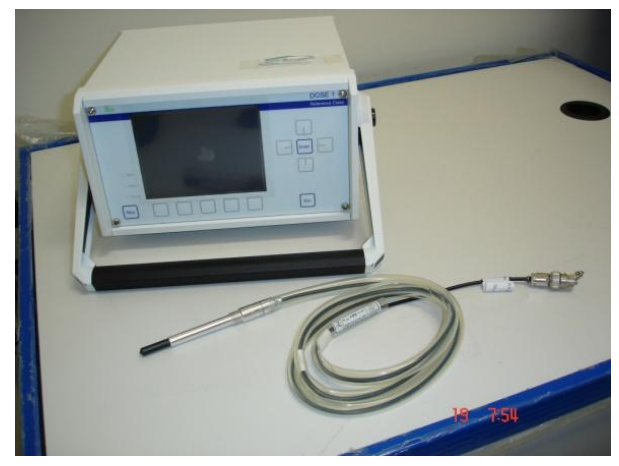

Figura 9- Conjunto dosimétrico: eletrômetro Dosel e câmara de ionização FC065

\subsubsection{DIODOS SEMICONDUTORES}

Os diodos utilizados nos experimentos foram diodos tipo-p, IBA Dosimetry DPD-3, da empresa Scanditronix Medical AB - Germany. Para cada energia de feixe, um conjunto de 2 diodos é disponibilizado, com exceção para o modelo EDP-5, onde um conjunto de 3 diodos é disponibilizado pelo fabricante, uma vez que podem ser aplicados em dosimetria com elétrons e $\mathrm{Co}^{60}$. As especificações dos dosímetros são mostradas nas Tabela 2 e Tabela 3.

\begin{tabular}{|c|c|}
\hline Scanditronix Medical AB/ Diodos EDP & \\
\hline Tipo & $p$ \\
\hline Sensibilidade (nC/Gy) & 10 a 70 \\
\hline Degradação da Sensibilidade (\%/kGy) & 1 \\
\hline Degradação da Sensibilidade com Temperatura $\left(\% /^{\circ} \mathrm{C}\right)$ & 0,4 \\
\hline
\end{tabular}

Tabela 2- Especificações dos diodos Scanditronix Medical AB utilizados nesse trabalho 


\begin{tabular}{|c|c|c|}
\hline Modelo & $\begin{array}{c}\text { Aplicação/ } \\
\text { Faixa Energia }\end{array}$ & $\begin{array}{c}\text { Material Buildup/Espessura } \\
\text { equivalente em água }\end{array}$ \\
\hline EDD-2 & Entrada - Saída/ Elétrons & $2 \mathrm{~mm}$ \\
\hline EDP-5 & Elétrons e Co-60 & $5 \mathrm{~mm}$ \\
\hline EDD-5 & $\begin{array}{c}\text { Órgãos de risco (fora do } \\
\text { feixe primário) }\end{array}$ & poliestireno/5mm \\
\hline EDP-0 & Dose na pele & \\
\hline EDP-10 & $4-8 \mathrm{MV}$ & aço inoxidável/10mm \\
\hline EDP-15 & $6-12 \mathrm{MV}$ & aço inoxidável/15mm \\
\hline EDP-20 & $10-20 \mathrm{MV}$ & aço inoxidável/20mm \\
\hline EDP-30 & $16-25 \mathrm{MV}$ & tântalo/30mm \\
\hline
\end{tabular}

Tabela 3- Tipos de diodos utilizados e suas respectivas espessuras de buildup para cada faixa de energia de feixe

A resposta do diodo é obtida através de um eletrômetro DPD-3 IBA Dosimetry, também da empresa Scanditronix Medical AB, que indica a corrente produzida quando os diodos são expostos a irradiações ionizantes. Nesse trabalho foram caracterizados os modelos EDP-5 e EDP-15, respectivamente utilizados para feixes de radiação de $\mathrm{Co}^{60} \mathrm{e}$ de 6MV. O modelo EDP-15 foi calibrado com o auxílio dos objetos simuladores descritos em no item 3.1, para dosimetria in vivo em TBI.
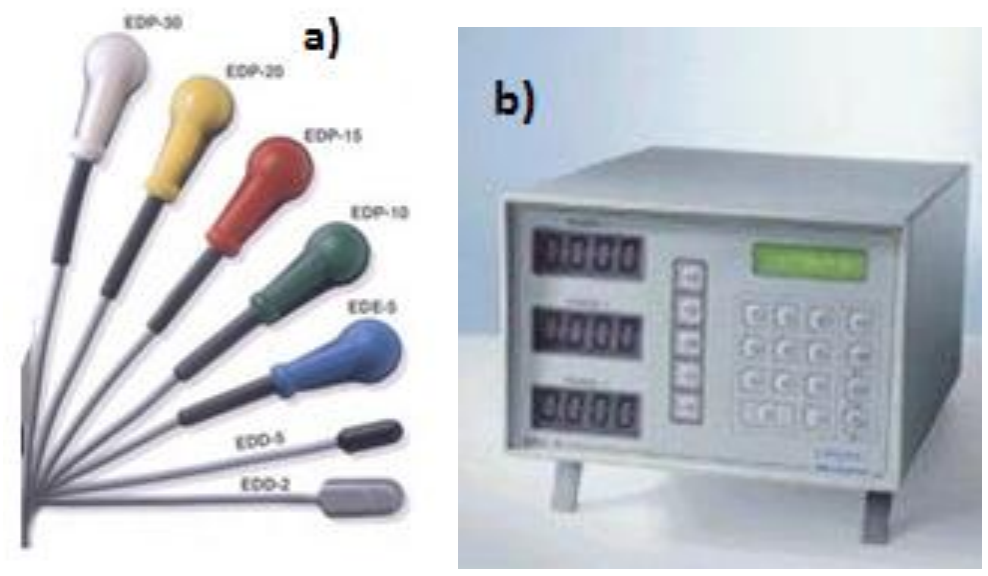

Figura 10-Sistema dosimétrico: a) Diodos b) Eletrômetro

Antes de serem utilizados para a determinação de doses, os diodos foram caracterizados e calibrados e determinados os respectivos fatores de correção individuais $\left(C F_{i}\right)$. O valor da dose de entrada, em uma situação clínica, é calculado a partir do valor determinado pelo diodo, que é igual ao produto da leitura do dosímetro ( $L_{\text {entr,diodo }}$ ) pelos fatores de calibração $\left(F_{c a l}\right)$ e de correção (Equação 6). O fator de calibração é definido como a razão da dose obtida com a câmara de ionização $\left(D_{C . I}\right)$ pela leitura obtida com o diodo $\left(L_{\text {diodo }}\right)$, medida em uma geometria de referência (Equação 7). 


$$
\begin{gathered}
D_{\text {entr }}=L_{\text {entr,diodo }} * \boldsymbol{F}_{c a l} * \prod C \boldsymbol{F}_{\boldsymbol{i}} \\
\boldsymbol{F}_{\text {cal }}=\left(\frac{D_{C . I}}{L_{\text {diodo }}}\right)_{\text {cond.ref }}
\end{gathered}
$$

Os diodos foram calibrados utilizando uma câmara de ionização secundária devidamente calibrada. Para a determinação do fator de calibração, o diodo foi posicionado na superfície de um objeto simulador de calibração. A câmara de ionização foi posicionada no interior do objeto simulador, no eixo central e na profundidade de referência. Essa profundidade, de acordo com a definição de dose de entrada, é a profundidade de máxima dose. A distância de referência (DFS) é geralmente de $100 \mathrm{~cm}$ para aceleradores lineares e com um campo de referência de $10 \times 10 \mathrm{~cm}^{2}$.

Em relação à caracterização dos diodos, uma série de fatores de correção foi estabelecida para compensar as variações na resposta do diodo, em situações que poderiam se diferir das condições de referência. Os fatores que influenciam a resposta podem ser o tamanho do campo, DFS, taxa de dose, variação angular do gantry, temperatura, presença de modificadores de feixe, tais como filtros, bandejas e blocos, entre outros (Equação 8).

$C F_{i}=C F_{\text {tamanho campo }}, C F_{S S D}, C F_{\text {bandeja }}, C F_{\text {taxadedose }}, C F_{\text {angulo }}, C F_{\text {temperatura }}$ Equação 8

Os fatores de correção são determinados através da razão entre a leitura obtida pela câmara de ionização e a leitura obtida com o diodo semicondutor em uma situação clínica de irradiação normalizada pela mesma razão para a situação de referência (Equação 9).

$$
\boldsymbol{C F}=\frac{\left(\boldsymbol{L}_{C . I} / \boldsymbol{L}_{\text {diodo }}\right)_{\text {condição clinica }}}{\left(\boldsymbol{L}_{C . I} / \mathbf{L}_{\text {diodo }}\right)_{\text {condição referencia }}}
$$

Equação 9

Dessa forma, a dose medida pelos diodos semicondutores, dependerá fortemente das condições de medida durante os procedimentos radioterápicos e das situações adversas às condições de referência.

\subsubsection{DOSÍMETROS TERMOLUMINESCENTES E SISTEMA DE LEITURA}

Os TLDs são compostos de fluoreto de lítio dopados com Magnésio e Titânio (LiF:Mg,Ti), Harshaw TLD-100, em forma de pastilhas, com dimensões de 0,9x3,1×3,1 $\mathrm{mm}^{3}$, massa de 23,40 mg e número atômico efetivo de 8,2. Utilizou-se um conjunto de 70 dosímetros, onde cada TL foi marcado por números com traços bem finos de grafite.

Para as leituras das pastilhas termoluminescentes, sempre realizadas após vinte e 
quatro horas da irradiação, se empregou uma leitora Harshaw, modelo 200-B do Centro de Instrumentação, Dosimetria e Radioproteção (CIDRA), da Universidade de São Paulo (USP). O sistema de leitura constitui-se de um sistema de aquecimento, tubo fotomultiplicador e circuitos eletrônicos associados. A leitora possui uma entrada de gás na câmara de avaliação TL, o que permite um fluxo constante e a formação de uma atmosfera de nitrogênio durante a leitura, reduzindo as emissões espúrias. Com uma taxa de aquecimento constante de $8^{\circ} \mathrm{C} / \mathrm{s}$, cada ciclo de avaliação durou 25 segundos e a temperatura variou entre $50^{\circ} \mathrm{C}$ e $250^{\circ} \mathrm{C}$. A estabilidade da leitora era testada antes de cada leitura dos grupos.

Os dosímetros foram analisados quanto à repetitividade e linearidade com a dose, para que, posteriormente, pudessem ser utilizados na dosimetria em TBI.

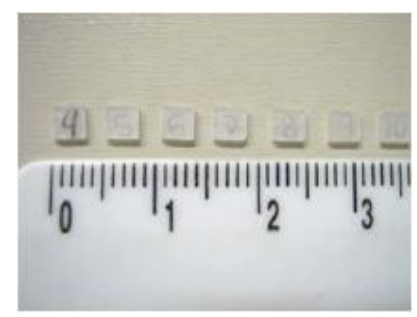

Figura 11- Pastilhas termoluminescentes utilizadas

\subsection{CARACTERIZAÇÃO DOS DIODOS SEMICONDUTORES}

Os diodos semicondutores, modelo EDP-15, foram caracterizados no feixe de 6MV do AL Oncor, do HCFMRP, onde foram verificados os fatores campo, taxa de dose e bandeja, bem como a dependência direcional e dependência com a temperatura. Nesse caso, as condições de referência foram: DSS=100 cm, campo $10 \times 10 \mathrm{~cm}^{2}$. A câmara de ionização foi colocada a $5 \mathrm{~cm}$ de profundidade. $\mathrm{O}$ arranjo experimental é representado na Figura 12 e o setup experimental na Figura 14. Durante os procedimentos foi realizado o monitoramento da temperatura e pressão da sala de tratamento.

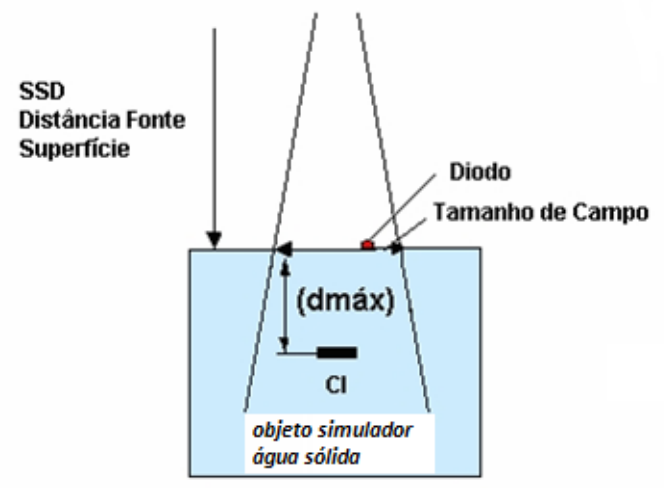

Figura 12- Arranjo experimental para a caracterização dos diodos 


\subsubsection{FATOR CAMPO}

Com os diodos posicionados no setup indicado na

Figura 12, realizaram-se medidas variando o campo de $3 \times 3 \mathrm{~cm}^{2}$ a $40 \times 40 \mathrm{~cm}^{2}$. Tomou-se como medida de referência o campo $10 \times 10 \mathrm{~cm}^{2}$ e calculou-se o fator campo (FC), dado por:

$$
F C=\frac{D_{C}}{D_{\text {ref }}}
$$

Equação 10

Onde $D_{C}$ é a dose no campo arbitrário e $D_{\text {ref }}$ é a dose calculada nas condições de referência.

\subsubsection{FATOR TAXA DE DOSE}

A influência da taxa de dose na sensibilidade do diodo foi obtida variando-se a taxa de dose do feixe do AL. As taxas de dose verificadas foram de 100, 200 e 300 cGy/min, mantendo-se um campo fixo de $10 \times 10 \mathrm{~cm}^{2}$ na superfície do objeto simulador homogêneo.

\subsubsection{FATOR DIRECIONAL}

Para determinar a dependência direcional, o diodo foi posicionado sobre o objeto simulador homogêneo e com as medidas sendo realizadas com a posição do gantry do AL nas seguintes angulações: $30^{\circ}, 60^{\circ}, 90^{\circ}, 270^{\circ}, 300^{\circ}, 330^{\circ}$, conforme mostra a Figura 14.

\subsubsection{FATOR TEMPERATURA}

Para analisar a variação da sensibilidade dos diodos com a temperatura utilizouse uma cuba de acrílico, onde se colocou água a temperaturas diferentes. A temperatura foi monitorada com o auxílio de um termômetro. Os diodos foram fixados na lateral externa da cuba, com fita adesiva. Após a colocação da água foi esperado um tempo de aproximadamente 1 minuto para permitir que o equilíbrio térmico fosse atingido. 


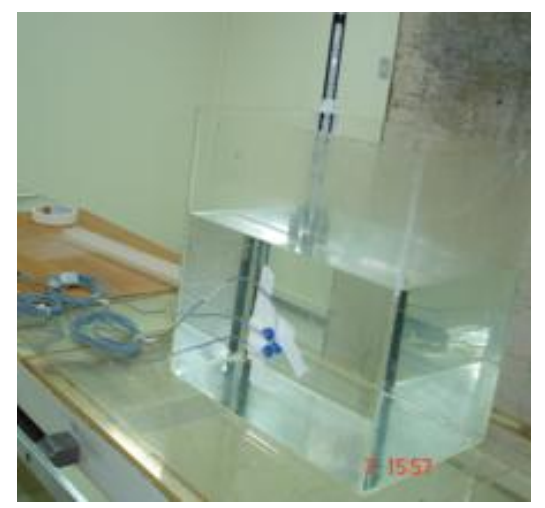

Figura 13- Análise da dependência com a temperatura

Com os resultados obtidos nessa etapa estabeleceu-se que os diodos fossem utilizados dentro de uma estrutura de isopor, para isolá-lo para evitar a influência da temperatura nas medidas, uma vez que tais diodos serão utilizados na dosimetria em TBI. No caso do TBI, os diodos ficariam em contato com a superfície do corpo do paciente, logo, bruscas variações de temperatura poderiam ter influência nas avaliações dosimétricas.

\subsubsection{FATOR BANDEJA}

Com os diodos posicionados, no setup indicado na Figura 14, realizou-se uma medição de referência nas condições de referência (sem bandeja) e posteriormente, nas mesmas condições, porém com a bandeja. Calculou-se então o fator bandeja (FB), dado por:

$$
F B=\frac{D_{b}}{D_{\text {ref }}}
$$

Onde $D_{b}$ é a dose calculada na situação com bandeja e $D_{r e f}$ é a dose calculada nas condições de referência, sendo DFS $=100 \mathrm{~cm}$ e com um campo $10 \mathrm{x} 10 \mathrm{~cm}^{2}$.

\subsubsection{DEPENDÊNCIA COM A DISTÂNCIA}

Para a verificação da variação da sensibilidade do diodo com a distância a câmara de ionização, fixou-se um campo $10 \times 10 \mathrm{~cm}^{2}$ com o gantry a $0^{0}$, e colocou-se a câmara de ionização a $100 \mathrm{~cm}$ da fonte. O diodo manteve-se na superfície do objeto simulador e variou-se a distância da câmara de ionização em relação ao mesmo. A distância de $5 \mathrm{~cm}$ foi tomada como referência. O objetivo nessa etapa era testar a 
variação na resposta do diodo através da variação da distância entre ele e a C.I a fim de que pudesse ser feita uma calibração prévia para as medidas posteriores de TBI.

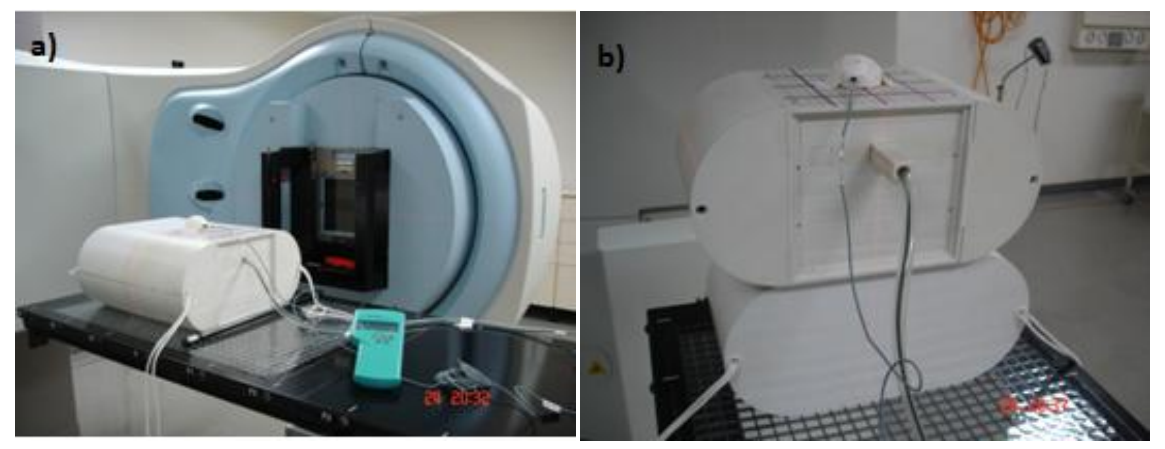

Figura 14- Setup utilizado para caracterização dos diodos no feixe de 6MV: a) dependência direcional, b) dependência com a distância

\subsection{CARACTERIZAÇÃO DOS DOSÍMETROS TERMOLUMINESCENTES}

Para que fosse possível a caracterização dos dosímetros, primeiramente os TLDs foram submetidos a um tratamento térmico pré-irradiação para eliminar qualquer sinal pré-existente no detector. Assim, antes de cada irradiação, os TLDs foram aquecidos a $400^{\circ} \mathrm{C}$ por 60 minutos no forno, seguindo-se um ciclo de aquecimento de 120 minutos a $100^{\circ} \mathrm{C}$ na estufa pertencente ao CIDRA na FFCLRP-USP.

O procedimento de caracterização visa avaliar a qualidade do grupo de dosímetros a fim de torná-lo viável para a utilização na dosimetria clínica. O primeiro procedimento realizado foi o procedimento de inicialização. Em seguida, foi avaliada a homogeneidade do grupo, que visa verificar a coerência entre as respostas do grupo. $\mathrm{O}$ índice de homogeneidade revela, percentualmente, a maior dispersão entre as medidas dentro do grupo. Para diminuir a flutuação da sensibilidade entre os dosímetros do grupo, foi calculado o fator de correção individual de cada dosímetro. Recalculando o índice de homogeneidade e o coeficiente de variação do procedimento de homogeneidade verificou-se a importância do fator de correção individual para as medidas, pois tais índices diminuíram significativamente. Por último, foram realizados os procedimentos que avaliaram a linearidade do grupo.

A análise de dependência energética não foi realizada uma vez que a calibração do grupo foi feita na mesma energia utilizada na dosimetria clínica.

Um grupo de 70 dosímetros foi utilizado. Dos 70 dosímetros, 65 TLs foram irradiados no Acelerador Linear Oncor, de 6MV. Para o set-up de calibração dos dosímetros foram utilizadas placas do objeto simulador de água sólida. Os diodos foram 
dispostos sobre as placas e acima deles foi colocada uma espessura de $1,3 \mathrm{~cm}$ com placas de acrílico, referente à espessura de buildup de acrílico para o feixe de 6MV. A DSS utilizada foi de $100 \mathrm{~cm}$, em um campo $10 \times 10 \mathrm{~cm}^{2}$. Uma dose equivalente a $150 \mathrm{cGy}$ (150 MU) foi administrada. Os dosímetros foram irradiados três vezes. Sendo que 5 dosímetros do grupo não foram irradiados e foram utilizados como leitura de referência para avaliação do sinal de fundo.

\subsubsection{PROCEDIMENTO DE INICIALIZAÇÃO}

Objetivo: garantir a reprodutibilidade do sinal de fundo e da sensibilidade.

Método- Tratar todos os dosímetros do grupo ao mesmo tempo conforme a literatura $\left[{ }^{47}\right]$ :

1) Avaliar o sinal de fundo de cada dosímetro em uma leitora TL.

2) Calcular a média e o coeficiente de variação (CV\%) do grupo.

$$
C V(\%)=100 \cdot \frac{\sigma}{\bar{L}}
$$

Equação 12

Onde $\bar{L}$ é a média e $\sigma$ o desvio padrão das medidas.

3) Repetir os itens anteriores mais duas vezes.

4) Se a média não se mantiver estável ou o coeficiente de variação não se manter dentro do recomendado (menor que 30\%), repetir os itens acima até que as duas condições citadas sejam atingidas.

\subsubsection{HOMOGENEIDADE DO GRUPO}

Objetivo: verificar a coerência entre as medidas de um mesmo grupo.

Método:

1) Irradiar todos os dosímetros do grupo com um mesmo valor de dose.

2) Avaliar a resposta de cada dosímetro, $\mathrm{L}$.

3) Tratar termicamente o grupo.

4) Avaliar o sinal de fundo de cada dosímetro, $\mathrm{L}_{0}$.

5) Calcular o índice de homogeneidade do grupo $\Delta_{\max }$.

$$
\Delta_{\max }=\frac{\left(L-L_{0}\right)_{\max }-\left(L-L_{0}\right)_{\min }}{\left(L_{-} L_{0}\right)_{\min }} .100<30 \%
$$

Equação 13 
sendo $\left(\mathrm{L}-\mathrm{L}_{0}\right)_{\max }$ e $\left(\mathrm{L}-\mathrm{L}_{0}\right)_{\min }$ iguais aos valores máximos e mínimos de $\mathrm{L}-\mathrm{L}_{0}$, que é a resposta líquida de cada dosímetro.

6) Repetir os itens anteriores mais duas vezes.

7) Se o índice de homogeneidade for maior que 30\%, deve ser descartados alguns dosímetros do grupo até que o índice seja aceitável.

\subsubsection{FATOR DE CORREÇÃO INDIVIDUAL}

\section{Objetivo: amenizar as flutuações de sensibilidade do grupo.}

\section{Método:}

1) Irradiar todos os dosímetros do grupo com um mesmo valor de dose.

2) Avaliar a resposta de cada dosímetro, L.

3) Tratar termicamente o grupo.

4) Avaliar o sinal de fundo de cada dosímetro, $\mathrm{L}_{0}$.

5) Calcular um fator de correção individual, $S_{i}$, para cada dosímetro.

$$
S_{i}=\frac{\overline{L-L_{0}}}{L-L_{o}}
$$

Equação 14

Onde $\overline{L-L_{0}}$ é a resposta líquida média.

6) Repetir os itens anteriores mais duas vezes.

7) Calcular o fator de correção individual médio de cada dosímetro.

$$
S_{i, \text { médio }}=\frac{\sum_{i=1}^{n} S_{i}}{n}
$$

\subsubsection{LINEARIDADE}

\section{Objetivo: testar a linearidade do grupo.}

Método:

1) Dividir o grupo em subgrupos e irradiar cada um deles com uma dose diferente.

2) Avaliar a resposta de cada dosímetro.

3) Tratar termicamente o grupo.

4) Avaliar o sinal de fundo de cada dosímetro.

5) Calcular a resposta líquida de cada dosímetro e multiplicar pelo seu fator de correção individual.

6) Calcular a média da resposta líquida de cada subgrupo. 
7) Construir o gráfico da curva da resposta líquida média em função da dose. $O$ coeficiente linear é o sinal de fundo intrínseco e o inverso do coeficiente angular é a sensibilidade absoluta do grupo (Fator de calibração).

Nessa etapa de linearidade, o grupo de dosímetros foi dividido em 12 subgrupos de 5 dosímetros cada. Cada subgrupo foi irradiado com uma dose diferente no acelerador linear Oncor $6 \mathrm{MV}$. Iniciou-se com uma dose de 0,25 Gy para irradiar o primeiro subgrupo e aumentou-se a dose até atingir o valor de 3,0 Gy, variando-se de 0,25 Gy.

Os dosímetros termoluminescentes apresentam linearidade com a dose até 1Gy e dessa forma, uma correção para a supralinearidade foi utilizada para corrigir a leitura dos TLDs em doses acima de $1 \mathrm{~Gy}\left[{ }^{49}\right]$. A forma de correção utilizada foi:

$$
C_{\text {supra }}=\left(1+0,00278 D-0,000265 D^{2}\right)^{-1}
$$

Onde $D$ é o valor de dose nominal, em Gy.

A partir das leituras obtidas e após a correção para supralinearidade, foi plotado um gráfico da resposta TL (em $\mu \mathrm{C}$ ) em função da Dose (em Gy) para se determinar o fator de calibração do grupo.

\subsection{DOSIMETRIA EM CONDIÇÕES DE TBI}

A dosimetria em condições de TBI foi realizada com feixes de fótons de 6MV do AL Oncor do HCFMRP. As avaliações foram realizadas à uma distância fonteisocentro de $393 \mathrm{~cm}$. O tamanho do campo foi de $40 \mathrm{x} 40 \mathrm{~cm}^{2}$, no isocentro, reproduzindo na parede um campo de $186 \times 186 \mathrm{~cm}^{2}$. O gantry foi angulado a $270^{\circ}$ e o colimador a $45^{0}$, projetando no campo luminoso toda a dimensão do paciente. A taxa de dose durante a irradiação foi de $100 \mathrm{MU} / \mathrm{min}$. O paciente foi colocado sobre a mesa de TBI, e as irradiações foram realizadas lateralmente ao corpo do paciente. Para homogeneizar a dose ao longo do corpo, uma espessura de $4 \mathrm{~mm}$ de chumbo foi fixada a bandeja, próxima ao gantry, em uma posição que pudesse blindar parte da radiação incidente na cabeça do paciente, uma vez que essa região possui uma espessura latero-lateral (DLL) menor que a restante do corpo e por isso, poderia estar sujeita a maiores níveis de dose. Nessas condições foram aplicadas doses de 150 cGy duas vezes ao dia, por um período de 4 dias, correspondendo a uma dose total de 1200cGy.

Para preparar os dosímetros semicondutores e os termoluminescentes para futuras aplicações na dosimetria in vivo, foi realizada uma calibração, em um setup de TBI, utilizando-se o OSA, o qual possui um contorno irregular, similar ao do corpo 
humano, e é formado por diferentes materiais, simulando diferentes tecidos humanos.

Em tratamentos de TBI é necessário que seja estabelecido um plano de referência para avaliação da homogeneidade da dose. O plano geralmente empregado é o plano coronal médio, utilizado neste trabalho. A profundidade do plano coronal médio nas regiões anatômicas da cabeça, fúrcula, mediastino e pélvis foram obtidos mesurando-se as distâncias laterais do OSA nessas regiões.

\subsubsection{CALIBRAÇÃO DOS DIODOS NAS CONDIÇÕES DE TBI}

Os diodos foram calibrados no setup de TBI, nas condições mostradas na Figura 15. Nesse caso, foram obedecidas as condições de TBI citadas em 3.5. Objetos simuladores de água sólida foram utilizados e colocados sobre a mesa de tratamento para simular um paciente. A câmara de ionização foi inserida na linha média do simulador, que é a profundidade de referência do tratamento de TBI, uma vez que não existe um volume alvo definido (o volume alvo nesse caso seria o corpo todo do paciente). O diodo foi colocado dentro do isopor e fixado na lateral do objeto simulador, na altura que simulava a pelve do paciente.

Para se determinar os fatores de calibração ia-se variando, lateralmente, a profundidade da câmara de ionização dentro do objeto simulador de água sólida, enquanto que o diodo era mantido em uma posição fixa, ou seja, variava-se a distância da câmara em relação ao diodo. O objetivo nesse caso era simular várias espessuras DLL, onde o diodo assumia fatores de calibração diferentes, de acordo com a dose verificada com a câmara em cada profundidade. Uma vez que os pacientes candidatos ao tratamento TBI podem ser de qualquer idade, obteve-se fatores de calibração para distâncias de $4 \mathrm{~cm}$ a 23,5 cm. Para cada distância DLL considerada, o sistema dosimétrico fornecia um fator de correção que era alocado na unidade dosimétrica. Isso permitia que, no momento da dosimetria in vivo, o DLL do paciente fosse medido e então o fator de correção correspondente aquele valor, e já previamente calculado na simulação, fosse acessado.

Ainda, foi realizada uma verificação da dosimetria, fixando-se o diodo na região da cabeça, conforme mostra a Figura 16. Considerando-se que o DLL da cabeça é muito menor que da pelve, foi necessário uma verificação de dose adicional para essa região. Ainda, nessa etapa a câmara de ionização foi inserida dentro do simulador cúbico de água sólida com e o diodo fixado na altura da cabeça em sua superfície externa. A profundidade da C.I em relação ao diodo foi variada, de modo a simular os diferentes 
DLL da cabeça de um paciente. Os fatores de calibração utilizados foram aqueles previamente obtidos com a calibração feita para a o diodo posicionado na altura da pelve, para as profundidades de $4 \mathrm{~cm}, 6 \mathrm{~cm}, 9 \mathrm{~cm}$ e $11 \mathrm{~cm}$. Nessas condições foi administrada uma dose total de 150 cGy. O objetivo nessa etapa era comprovar que uma calibração adicional para a região da cabeça não seria necessária. Dessa forma, os fatores de calibração, já calculados, foram utilizados para confirmar a leitura do diodo com a leitura da C.I em cada profundidade. Ao longo dos procedimentos eram monitoradas a temperatura e a pressão.
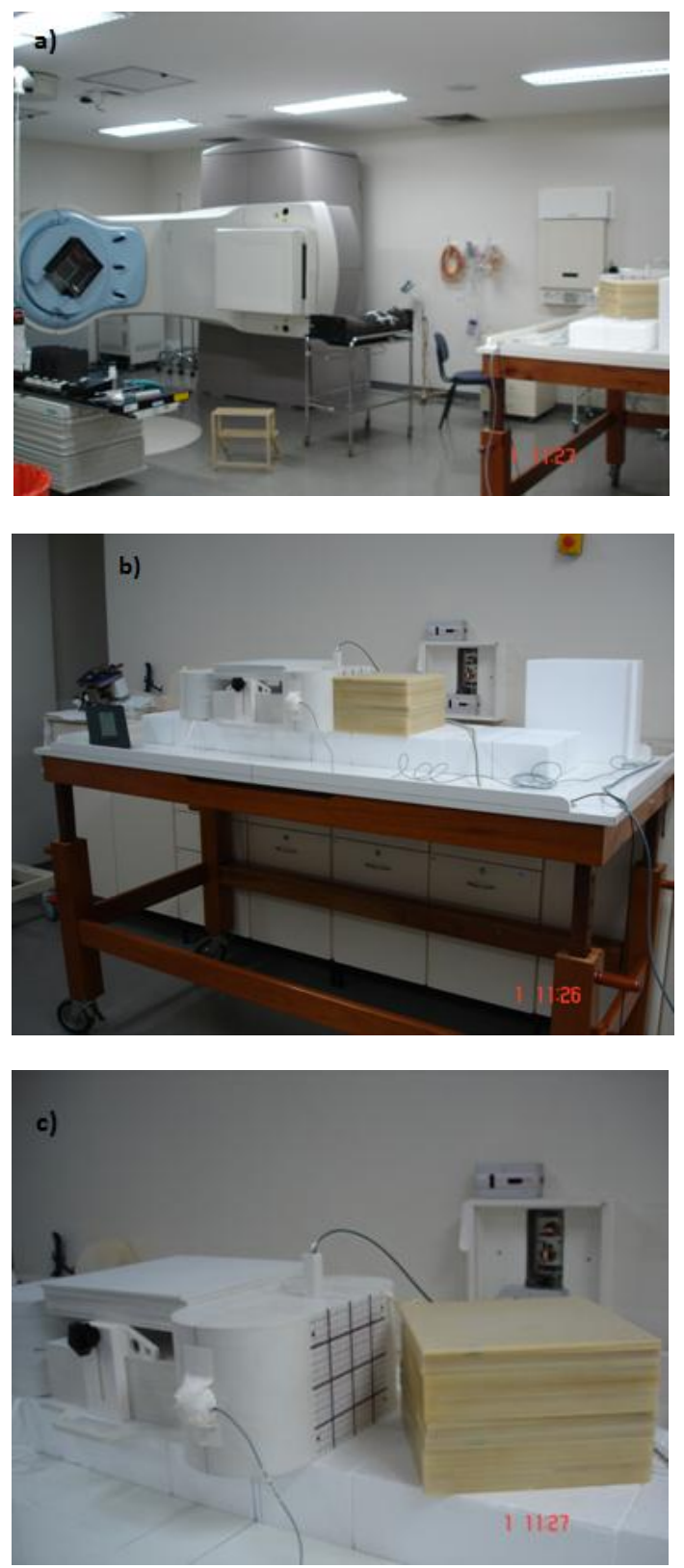

Figura 15- Setup para TBI montado para calibração dos diodos semicondutores posicionados na altura da pelve a) representa o posicionamento do gantry; b)representa a configuração do setup com os objetos simuladores representando o corpo de um paciente, $c$ ) detalhe para o posicionamento do diodo na altura da pelve do paciente e para a câmara de ionização posicionada dentro do objeto simulador cúbico. 


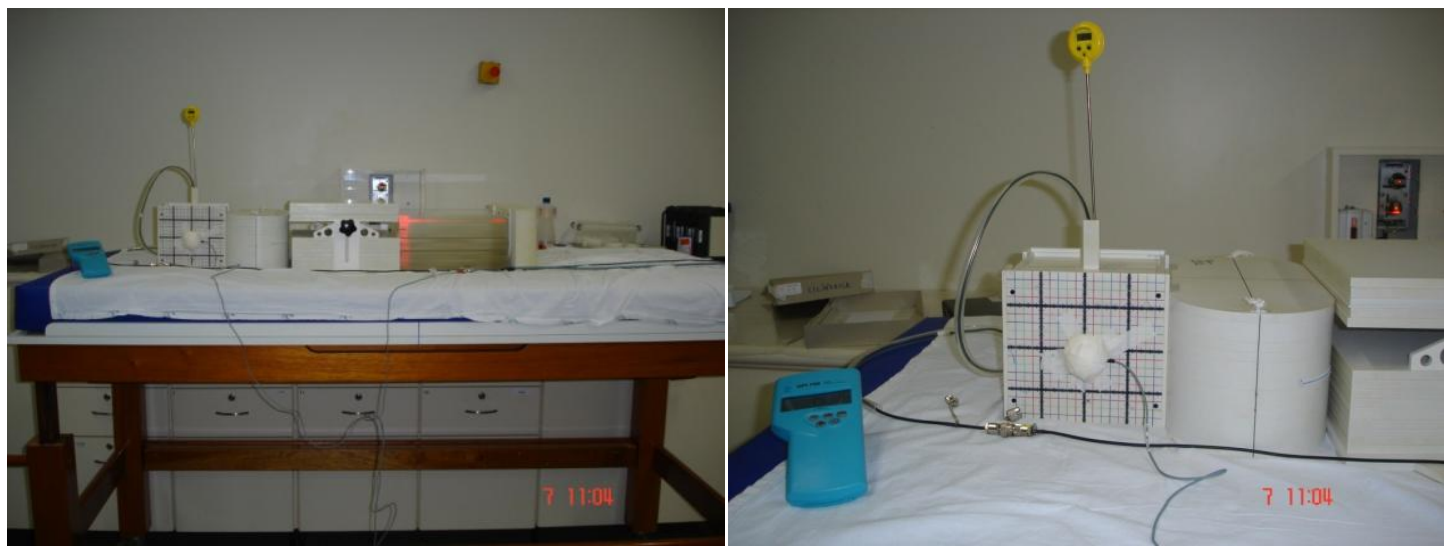

Figura 16- Setup para TBI montado para verificação de dose com os diodos semicondutores posicionados na altura da cabeça

\subsubsection{SIMULAÇÃO DO SETUP PARA TBI COM DIODOS}

Após a calibração dos diodos semicondutores procurou-se validar o método de dosimetria utilizando o OSA, a partir de uma simulação do tratamento de TBI. Para isso, o OSA foi colocado sobre a mesa de TBI a uma distância de $393 \mathrm{~cm}$ em relação ao gantry. O gantry foi colocado a $270^{\circ}$ e o colimador a $45^{\circ}$. O diodo foi inserido dentro do isopor e fixado na superfície externa do OSA, na altura da pelve. O DLL do OSA foi medido e encontrado o valor de $31,0 \mathrm{~cm}$ na altura da pelve. Dessa forma, prescreveu-se uma dose de 50 cGy na profundidade de $15,5 \mathrm{~cm}$, referente a metade do DLL. Nessa etapa, não foi utilizada a câmara de ionização. A representação do setup pode ser vista na Figura 17.

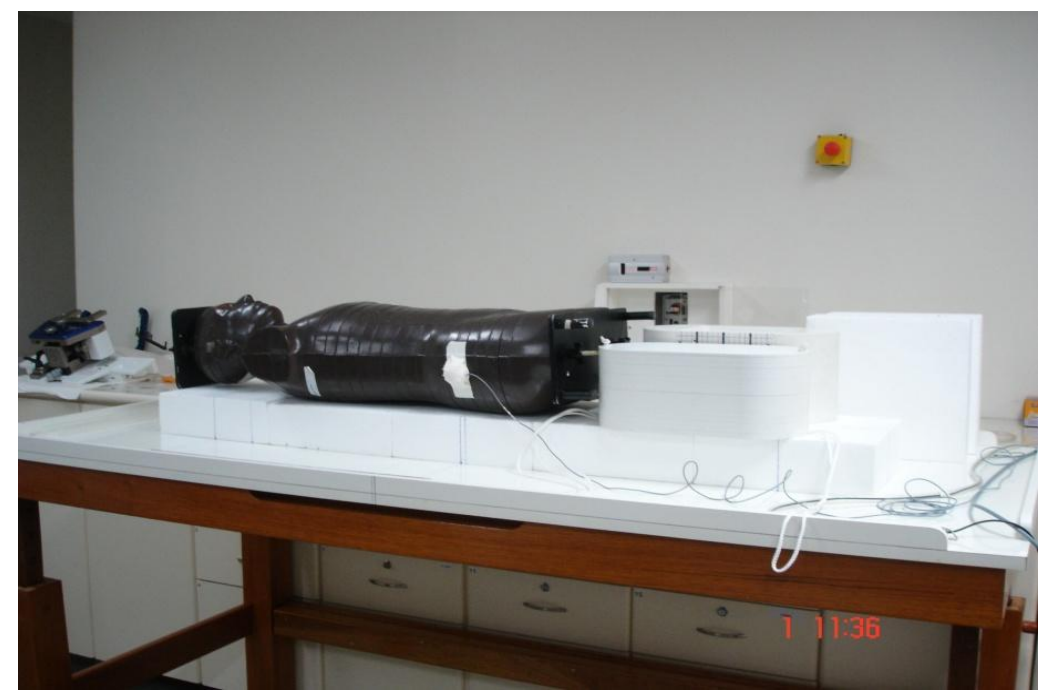

Figura 17- Setup para TBI utilizado na dosimetria com diodos semicondutores para validação do método 


\subsubsection{CALIBRAÇÃO DOS TLD NAS CONDIÇÕES DE TBI}

Os TLDs foram também calibrados no setup de TBI, de acordo com as condições estabelecidas em 3.5. Para tal, um total de 5 TLDs foram colocados no interior do objeto simulador de água sólida, ao lado da câmara de ionização, a uma profundidade de $9,0 \mathrm{~cm}$, conforme mostrado na figura 18 . O objetivo de se calibrar os dosímetros no setup de TBI era para evitar que fatores de correção tivessem que ser determinados e aplicados na determinação da dose durante a realização da dosimetria in vivo. Uma dose de 75 cGy nominal foi administrada para a irradiação, lateralmente, do objeto simulador. Posteriormente, girando-se a mesa de $180^{\circ}$ e mantendo-se o isocentro irradiou-se, novamente, a outra lateral do OSA com 75 cGy nominal, conforme mostra a Figura $18 \mathrm{c}$. Adicionalmente, os TLDs foram fixados na superfície externa do OSA, na altura da pelve, ao lado do diodo. Dessa forma, para que fosse possível a calibração dos TLDs colocados na superfície externa do OSA, foram obtidas as medidas de dose de entrada. Para os casos em que os TLDs não possuíssem capas de buildup intrínsecas, como ocorrem com os diodos, foram construídas capas de buildup, na oficina mecânica do Departamento de Física, conforme mostra Figura 19. Uma dose nominal total de 150 cGy foi liberada.
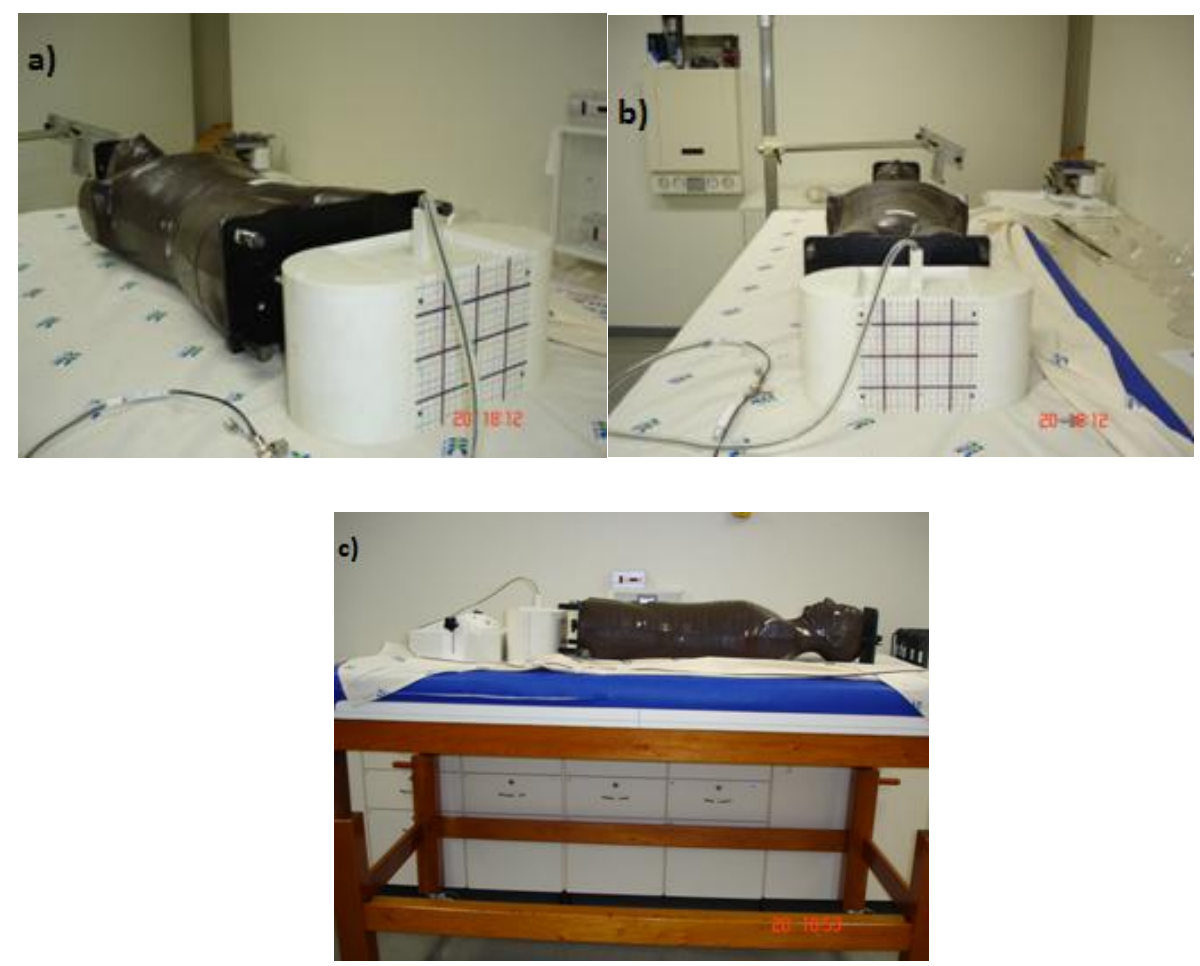

Figura 18- Setup montado para a calibração dos dosímetros termoluminescentes. a) e b) representação da disposição do OSA na lateral direita enquanto c) representa o posicionamento do lado esquerdo 

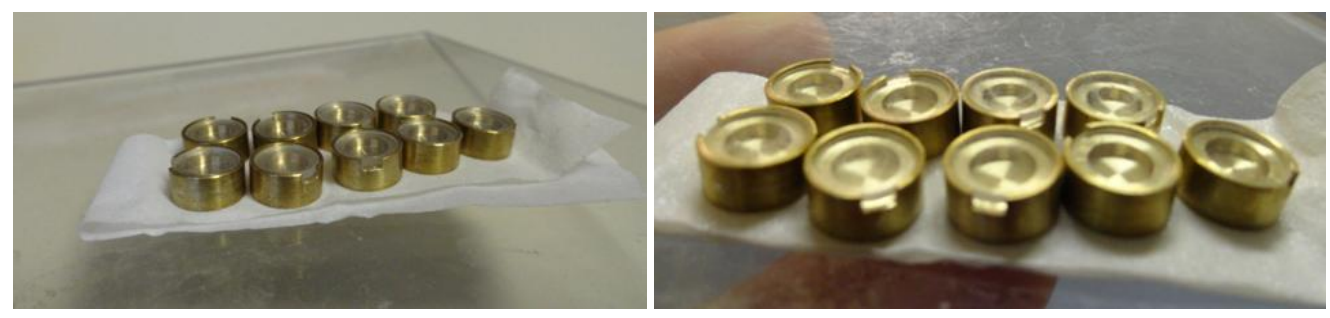

Figura 19- Capas de buildup construídas para alojar cada dosímetro termoluminescente

\subsubsection{1}

\section{SIMULAÇÃO COM TLD NO SETUP PARA TBI}

Durante a calibração dos TLDs em setup de TBI, realizou-se uma simulação do tratamento de TBI, com o auxílio do OSA. Como o OSA é composto por fatias numeradas em secções transversais e com orifícios de aproximadamente $0,5 \mathrm{~cm}$ de diâmetro, distribuídos em diferentes profundidades, as pastilhas de TLD puderam ser inseridas nesses orifícios. As pastilhas eram inseridas, três a três, nos orifícios das fatias, correspondentes, para as diferentes profundidades. A localização da pastilha em cada fatia é mostrada na Tabela 14. O OSA foi irradiado nas condições de TBI. Uma dose nominal de 75 cGy foi administrada na primeira irradiação, na lateral direita e, após girar-se a mesa de $180^{\circ}$ e mantendo-se o isocentro, irradiou-se a lateral esquerda do OSA com mais $75 \mathrm{cGy}$, conforme mostra a Figura 18. Para garantir a homogeneidade na distribuição da dose durante a irradiação, fixaram-se duas plaquinhas de chumbo, cada uma com $2 \mathrm{~mm}$ de espessura, em uma bandeja, posicionada no gantry do AL para compensar a dose. Esses compensadores de dose eram fixados na bandeja, de maneira que cobrissem o campo na região da cabeça do OSA. Isso foi importante, pois, uma vez que a DLL do OSA na região da cabeça é bem menor, quando comparada ao restante do corpo, esta região receberia uma dosagem maior e, como o intuito do tratamento TBI é o de irradiar uniformemente o corpo todo, ou o volume alvo, o compensador poderia garantir que aproximadamente, os 150 cGy nominais, devidamente calculados, fossem liberados na região da cabeça.

\subsection{SIMULAÇÃO DE TBI UTILIZANDO DIODOS E TLD}

A fim de validarmos a dosimetria, com dosímetros semicondutores e termoluminescentes, realizou-se uma simulação em um setup para TBI, utilizando o 
OSA, o qual foi colocado, sobre a mesa de TBI, a distância de $393 \mathrm{~cm}$ em relação ao gantry. O gantry foi ajustado a $270^{\circ}$ e com o colimador a $45^{\circ}$. Nessas condições, o diodo foi inserido dentro do isopor e fixado na superfície externa do OSA, na altura da cabeça. As pastilhas de TLD foram inseridas nos orifícios do OSA, nas mesmas posições descritas na Tabela 14. Nessas condições, mediu-se o DLL do OSA na altura da cabeça onde foi determinado o valor de $16 \mathrm{~cm}$. Dessa forma, prescreveu-se uma dose de 150 cGy, sendo 75cGy em cada lateral, na profundidade de referência (linha média do OSA15,5cm). Nessa etapa não foi utilizada a câmara de ionização. Para a obtenção da dose com o diodo foi utilizado o fator de correção referente à profundidade de $9 \mathrm{~cm}$ (CORR 17, disponibilizado na Tabela 9 da seção 4.21 ) e foi também realizada uma interpolação para corrigir a profundidade para $8 \mathrm{~cm}$ (metade do DLL da cabeça do OSA).

O objetivo nessa etapa era estabelecer o sistema dosimétrico, para que os dosímetros semicondutores e TLDs fossem utilizados na verificação da dose prescrita aos pacientes indicados para o tratamento de TBI, no Serviço de Radioterapia do HCFMRP.

A fixação do diodo na região da cabeça se justifica, uma vez que essa região tem um DLL menor que o da pelve e, por isso, poderá ser submetidos a doses maiores de radiação. Para compensar a variação de dose, blocos absorvedores de chumbo de $4 \mathrm{~mm}$ são fixados no gantry na altura da cabeça. Pela unidade de terapia, verificou-se que, com essa espessura de chumbo, a dose entregue a cabeça seria de 147 cGy, ao invés de 150 cGy (nominal).

\subsection{DOSIMETRIA IN VIVO TBI}

A dosimetria in vivo, como verificação rotineira, pode ser praticada em cada paciente em um Serviço de Radioterapia. No entanto, afim de reduzir a carga de trabalho, pode-se optar por verificar a dose somente para uma parte dos pacientes. Tal escolha deve ser selecionada aleatoriamente para evitar qualquer tipo de tendência.

Dessa forma, utilizando os diodos previamente calibrados, realizou-se a dosimetria in vivo em três pacientes candidatos ao tratamento de TBI do Serviço de Radioterapia do HCFMRP.

A ausência de candidatos ao tratamento de TBI do HCFMRP justifica o número pequeno de pacientes no qual a dosimetria in vivo foi verificada e confirmada. 
Capítulo 4-Resultados e Discussões 


\section{RESULTADOS E DISCUSSÕES}

Neste capítulo são apresentados os resultados adquiridos na caracterização e calibração dos dosímetros semicondutores e TLD assim como os resultados da simulação para TBI e os resultados da dosimetria in vivo utilizando os diodos semicondutores.

\subsection{CARACTERIZAÇÃO DOS DIODOS SEMICONDUTORES}

Os valores de temperatura e pressão registrados foram, respectivamente, $19,0^{\circ} \mathrm{C}$ e $94,36 \mathrm{kPa}$.

\subsubsection{FATOR CAMPO}

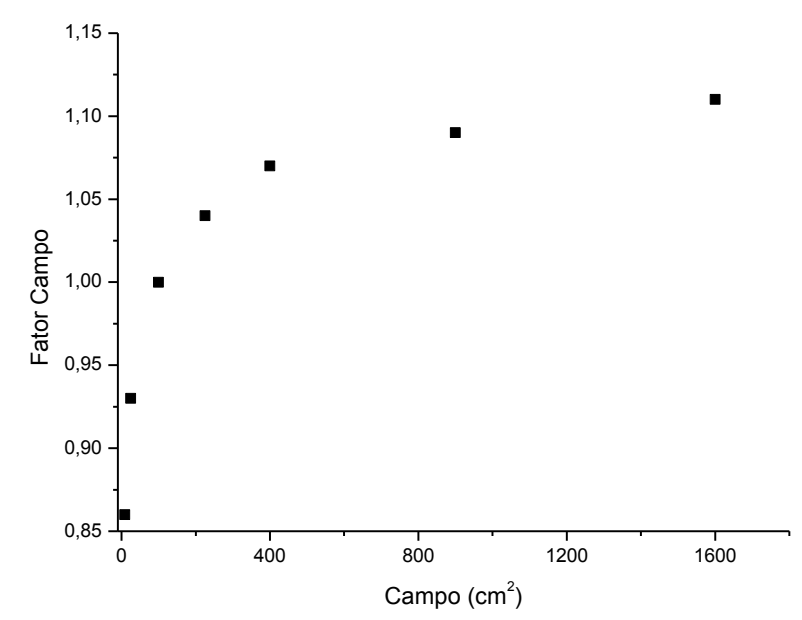

Figura 20- Gráfico do Fator Campo em função do campo para diodos utilizados em feixes do AL de 6MV

Pelos resultados pode-se observar um aumento no valor de leitura dos diodos, com o aumento no tamanho do campo. Esses resultados são justificados uma vez que campos maiores provocam maior espalhamento da radiação, causando um aumento na dose determinada pelos diodos. Além do que, pode ser notado que para campos aproximadamente acima de $800 \mathrm{~cm}^{2}$, demonstra uma tendência dos valores permanecerem constantes, uma vez que, com o aumento da dimensão do campo, a possibilidade da radiação espalhada pelo paciente atingir o detector tende a não aumentar, devido à absorção do próprio tecido. Conclui-se que não há aumento na contribuição do feixe primário com o aumento do campo, mas sim, aumento da radiação espalhada que não alcança o eixo central e não contribui para a dose. 


\subsubsection{FATOR TAXA DE DOSE}

A taxa de dose de referência foi de 300 cGy/min.

\begin{tabular}{|c|c|c|c|}
\hline \multicolumn{4}{|c|}{ Fator Taxa de Dose } \\
\hline $\begin{array}{c}\text { Taxa de Dose } \\
\text { (cGy/min) }\end{array}$ & $\mathrm{L}_{\mathbf{D}}(\mathbf{c G y})$ & $\mathbf{L}_{\text {C.I }}(\mathbf{c G y})$ & $\mathbf{F}_{\text {dose }}$ \\
\hline 100 & $83,97 \pm 0,06$ & $84,01 \pm 0,01$ & $1,01 \pm 0,01$ \\
\hline 200 & $83,97 \pm 0,06$ & $84,01 \pm 0,01$ & $1,01 \pm 0,01$ \\
\hline 300 & $82,98 \pm 0,08$ & $83,04 \pm 0,01$ & $1,00 \pm 0,01$ \\
\hline
\end{tabular}

Tabela 4- Fator taxa de dose para diodos utilizados em feixes de acelerador linear de 6MV

Pelos resultados da Tabela 4, observa-se que os diodos apresentam baixa dependência com a taxa de dose para a energia de 6MV. Esses resultados já foram observados na literatura. No entanto, caso os diodos recebam várias frações de dose, por um longo período de tempo, a sensibilidade diminuirá e dessa forma a variação com a taxa de dose pode ocorrer de maneira acentuada $\left[{ }^{50}\right]$.

\subsubsection{FATOR DIRECIONAL}

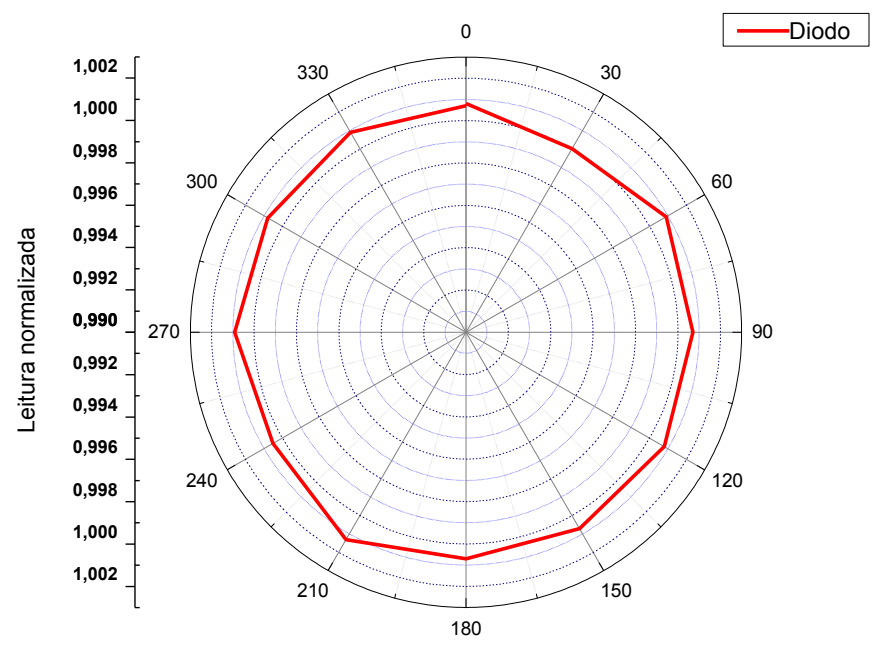

Figura 21- Gráfico da dependência direcional dos diodos

A variação da sensibilidade do diodo em relação à angulação do gantry é causada, em parte, pela construção do detector incluindo a transmissão através da espessura de buildup e a diferença de material nos lados $p$ e $n$ da junção e, em parte, pelo retroespalhamento do paciente ou do objeto simulador.

Verifica-se que os diodos não apresentam significativa variação de sensibilidade com a angulação do gantry. No entanto, nas situações em que os diodos foram 
empregados para dosimetria, os mesmo eram posicionados de maneira que o feixe primário de radiação incidia perpendicularmente ao volume sensível do dosímetro.

\subsubsection{FATOR TEMPERATURA}

\begin{tabular}{|c|c|}
\hline \multicolumn{2}{|c|}{ Dependência com a Temperatura } \\
\hline Temp $\left.\mathbf{(}^{\mathbf{0}} \mathbf{C}\right)$ & $\mathbf{L}_{\text {diodo }}$ (cGy/min) \\
\hline $26,5 \pm 0,5$ & $41,71 \pm 0,35$ \\
\hline $31,0 \pm 0,5$ & $42,14 \pm 0,35$ \\
\hline $35,7 \pm 0,5$ & $42,31 \pm 0,35$ \\
\hline $36,5 \pm 0,5$ & $42,40 \pm 0,35$ \\
\hline $38,8 \pm 0,5$ & $42,63 \pm 0,35$ \\
\hline
\end{tabular}

Tabela 5- Dependência dos diodos com a temperatura

Os resultados indicaram uma baixa dependência térmica dos diodos, o que está de acordo com outros resultados da literatura $\left[{ }^{51}\right]$. No entanto, a fim de evitar variações de leitura devido à temperatura - quando os mesmos fossem colocados em contato com o paciente, como é o caso do tratamento de TBI, onde os diodos são fixados na superfície da pele do paciente - foi utilizado isopor, na forma de meia esfera, que envolviam os diodos para que não sofressem influência do calor do corpo.

\subsubsection{FATOR BANDEJA}

\begin{tabular}{|c|c|c|c|}
\cline { 2 - 4 } \multicolumn{1}{c|}{} & \multicolumn{3}{c|}{ Fator Bandeja } \\
\cline { 2 - 4 } \multicolumn{1}{c|}{} & $\mathbf{L}_{\mathbf{D}} \mathbf{( \mathbf { c G y } )}$ & $\mathbf{L}_{\mathbf{C . I}}(\mathbf{c G y})$ & $\mathbf{F}_{\mathbf{b}}$ \\
\hline Sem Bandeja & $83,02 \pm 0,04$ & $83,09 \pm 0,01$ & \\
\hline Com Bandeja & $79,02 \pm 0,02$ & $79,06 \pm 0,01$ & $0,95 \pm 0,01$ \\
\hline
\end{tabular}

Tabela 6- Fator Bandeja

Da Tabela 6, observa-se que a leitura da dose do diodo diminui com a colocação da bandeja, uma vez que a mesma absorve parte da radiação incidente. Uma redução de $4,8 \%$ ocorreu com a bandeja posicionada.

Para medidas dosimétricas, na qual a bandeja será utilizada, é necessário multiplicarmos a leitura do diodo pelo fator de correção bandeja. 


\subsubsection{DEPENDÊNCIA COM A DISTÂNCIA}

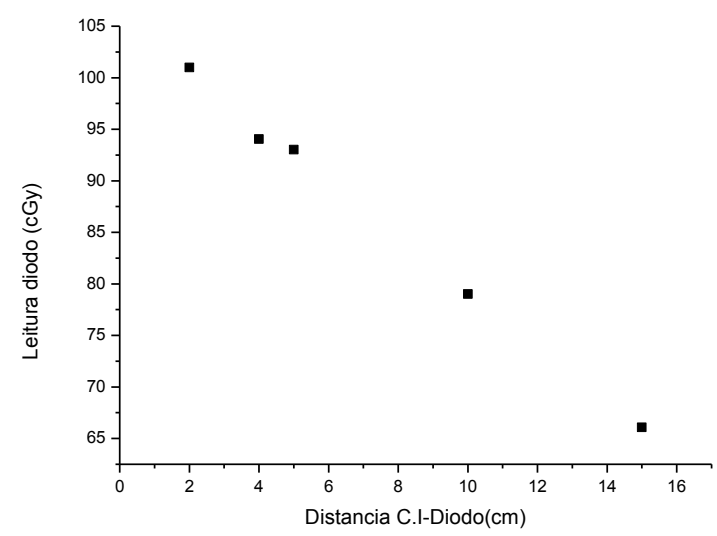

Figura 22- Gráfico da dependência com a distância C.I- diodo

A Figura 22 indica a diminuição na leitura do diodo com o aumento da distância do mesmo em relação à câmara de ionização o que demonstra estar de acordo com a lei do quadrado do inverso da distância. No entanto, esta etapa não foi utilizada como calibração para tratamento TBI, pois a configuração do TBI tem espalhamento diferente e a energia entregue na profundidade de máxima dose é diferente daquela entregue nesta configuração apresentada.

Posteriormente, retirou-se o diodo da superfície do objeto simulador e mediu-se a dose apenas com a câmara de ionização. O objetivo nessa etapa era verificar a porcentagem de dose que o diodo absorvia, quando colocado na superfície do objeto simulador, ou seja, na frente da câmara de ionização. Os resultados são apresentados na Tabela 7.

\begin{tabular}{|c|c|c|c|}
\cline { 2 - 3 } \multicolumn{1}{c|}{} & \multicolumn{3}{c|}{ Porcentagem de dose absorvida pelo diodo } \\
\cline { 2 - 3 } \multicolumn{1}{c|}{} & $\mathbf{L}_{\mathbf{D}}(\mathbf{c G y})$ & $\mathbf{L}_{\mathbf{C . I}}(\mathbf{c G y})$ & $\%$ \\
\hline Sem Diodo & & $86,02 \pm 0,01$ & \multirow{2}{*}{3,44} \\
\hline Com Diodo & $83,02 \pm 0,06$ & $83,06 \pm 0,01$ & \\
\hline
\end{tabular}

Tabela 7- Porcentagem de dose absorvida pelo diodo quando colocado sobre o objeto simulador, na mesma direção da C.I.

Pela Tabela 7 observa-se uma porcentagem considerável de dose absorvida pelo diodo, o que contribui para que a dose registrada pela câmara de ionização seja menor do que a nominal (100 cGy). Esse resultado é importante, uma vez que para a dosimetria em setup de TBI, o diodo será fixado na superfície externa do objeto simulador, na altura da pelve e na frente da câmara de ionização.

Convém ressaltar que, embora não tenha sido necessário a utilização dos fatores de correção, uma vez que a calibração foi realizada nas mesmas condições da simulação 
e da dosimetria in vivo - tamanho do campo, taxa de dose, DFS, angulação do gantryesses fatores de correção foram corretamente calculados para que possam ser aplicados em condições que exijam suas aplicações para a obtenção da dose final.

\subsection{CARACTERIZAÇÃO DOS DOSÍMETROS TERMOLUMINESCENTES}

Posteriormente ao tratamento térmico dos TLDs foi realizada a leitura do sinal de fundo. Esse procedimento foi realizado três vezes. Após a leitura do sinal de fundo, o grupo foi irradiado nas condições mencionadas no item 3.4, com uma dose total de 150 cGy. Os dosímetros foram irradiados três vezes e as leituras em carga foram obtidas após cada irradiação. Através desse procedimento, as etapas de inicialização, análise de homogeneidade do grupo e obtenção do fator de correção individual foram realizadas e, a partir dos resultados, alguns dosímetros foram descartados do grupo. Os resultados estão apresentados no Apêndice, item 7.1.

As células em amarelo nas Tabelas 19, 20 e 21 apresentadas no Apêndice, item 7.1 indicam a ausência de sinal durante a leitura. Nesses casos, os valores de fator de correção $\left(\mathrm{S}_{\mathrm{i}}\right)$ não foram calculados. Pelos resultados encontrados verificou-se que 5 dosímetros deveriam ser descartados do grupo pois estavam contribuindo, no cálculo final, para um coeficiente de homogeneidade maior que $30 \%$, sendo que o recomendado é um coeficiente menor que 30\%. Dessa forma, os TLDs de número 4, 9, 23, 38 e 46 foram retirados do grupo e novamente os cálculos foram realizados para a obtenção do coeficiente de homogeneidade que, dessa vez, ficaram dentro do recomendado.

Para cada TLD, calculou-se um fator de correção individual médio que foi utilizado na correção da leitura de cada TLD, nas etapas de análise da linearidade e na simulação do tratamento de TBI a partir da dosimetria com TL. Os fatores de correção individual são mostrados na Tabela 22 do Apêndice.

Os resultados da análise da linearidade encontram-se na Tabela 23. As leituras foram corrigidas para doses acima de $1 \mathrm{~Gy}$. As células marcadas em vermelho representam os TLDs descartados do grupo. Apenas 65 dosímetros foram irradiados sendo que os outros 10 não foram expostos e foram tomados como referência. Onde

$$
\begin{array}{clrl}
L_{\text {corr }} & =L * S_{i, \text { médio }} & & \text { Equação 17 } \\
L_{\text {corr }, \text { supra }} & =L_{\text {corr,média }} * C_{\text {supra }} & & \text { Equação 18 }
\end{array}
$$


A partir dos resultados da Tabela 23, construiu-se o gráfico apresentado na Figura 23.

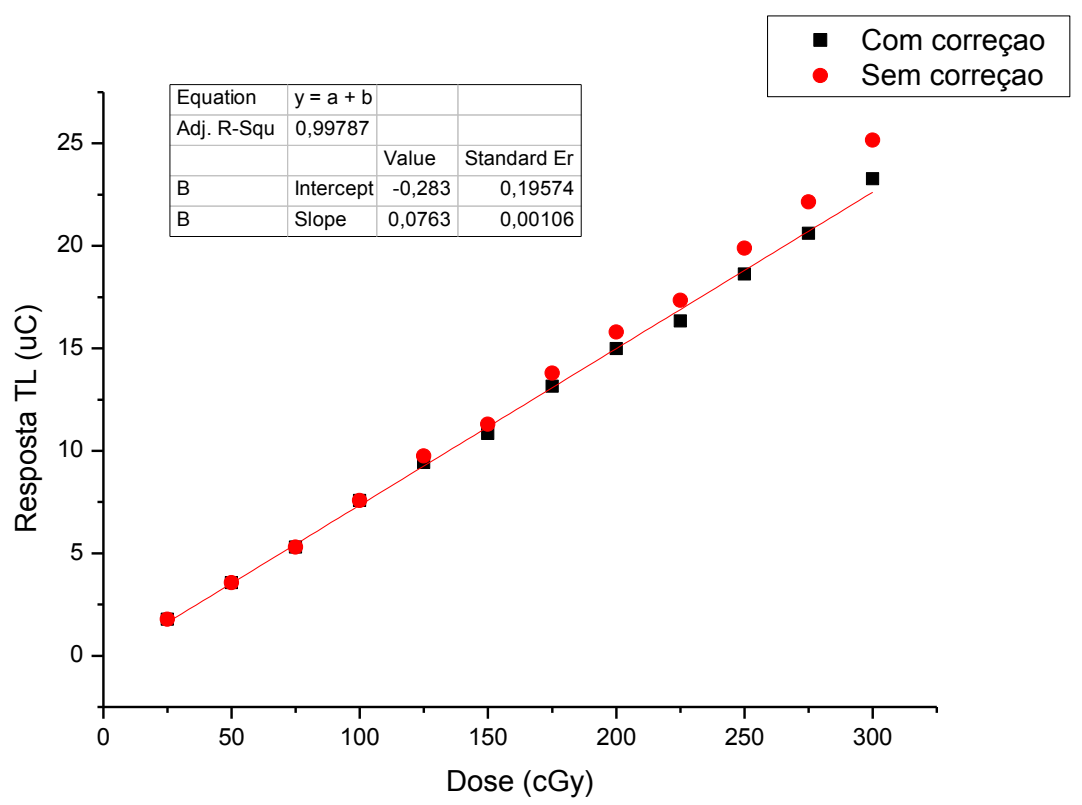

Figura 23- Gráfico da resposta TL em função da Dose

Pelo gráfico pode-se observar que a correção para a supralinearidade foi bem aplicada e corrigindo também os pontos que se dispersaram da reta. Os pontos em vermelho representam a leitura sem correção para supralinearidade, indicando a região de supralinearidade. Do gráfico obtém-se o fator de calibração para o grupo de dosímetros, dado pelo inverso do coeficiente angular encontrado.

$$
F_{c a l}=13,11 \pm 0,33 c G y / \mu C
$$

Embora seja possível a determinação do fator de calibração do grupo a partir do gráfico da linearidade, o mesmo não será utilizado para o cálculo da dose final obtida pelos TLDs, na etapa de simulação do tratamento. Isso é devido às flutuações inerentes associadas à calibração do grupo como um todo. Dessa forma, o fator de calibração será obtido na etapa de calibração com o setup de TBI, onde a calibração e a dosimetria com o OSA serão feitas simultaneamente. Nesse caso, 5 dosímetros serão colocados próximos a C.I, na profundidade de $15,5 \mathrm{~cm}$. A leitura de dose obtida com a câmara de ionização será utilizada como referência para o cálculo do fator de calibração. Isso evitará imprecisão na leitura dos TLs, devido a erros do sistema de leitura. Os 5 dosímetros usados como referência, juntamente com o restante do grupo utilizado para a dosimetria no OSA, serão lidos no mesmo dia, evitando assim as flutuações inerentes do 
sistema de leitura, que ocorrem quando a leitura do grupo de referência é feita em dias diferentes do restando do grupo.

\subsection{DOSIMETRIA EM CONDIÇÕES DE TBI}

\subsubsection{CALIBRAÇÃO DOS DIODOS NAS CONDIÇÕES DE TBI}

Os parâmetros utilizados nessa etapa são apresentados na Tabela 8. Uma dose nominal de 20 cGy foi prescrita na profundidade de $18,5 \mathrm{~cm}$, na qual a câmara de ionização foi colocada inicialmente. Variaram-se as profundidades da C.I em relação ao diodo e, para cada uma, calculou-se os fatores de correção que foram alocados no parâmetro CORR do sistema de dosimetria, especificado na Tabela 9. Para todas as medidas foi determinado o sinal de fundo dos diodos, anteriormente a realização da dosimetria, e não corresponderam a valores significativos. Para todos os DLL considerados, o ponto de prescrição de dose era calculado na metade do valor DLL, ponto de referência para prescrição de dose em tratamento de TBI.

\begin{tabular}{|l|}
\hline \multicolumn{1}{|c|}{ Calibração dos Diodos Semicondutores } \\
\hline Setup TBI \\
\hline Acelerador Oncor 6MV \\
\hline Diodo utilizado: EDP-15 3G,4m DEC 712-2801 (Canal 1) \\
\hline Campo : 40 x $40 \mathrm{~cm}^{2}$ \\
\hline Gantry: $270^{\circ}$ \\
\hline Colimador: $45^{\circ}$ \\
\hline C.I colocada a $18,5 \mathrm{~cm}$ de profundidade (centro da pelve) \\
\hline Dose na C.I : $20 \mathrm{cGy}$. \\
\hline Distância Fonte-Superfície $=393 \mathrm{~cm}$ \\
\hline Taxa de Dose: $12 \mathrm{cGy} / \mathrm{min}$ \\
\hline $\mathrm{T}=18,0^{\circ} \mathrm{C}$ \\
\hline $\mathrm{P}=94,8 \mathrm{kPa}$ \\
\hline
\end{tabular}

Tabela 8- Parâmetros utilizados para calibração dos diodos semicondutores em setup para TBI

\begin{tabular}{|c|c|c|c|c|}
\hline \multicolumn{5}{|c|}{$D L L=8,00 \pm 0,05 \mathrm{~cm}$} \\
\hline $\begin{array}{c}\text { Ponto Presc. } \\
\text { Dose }(\mathrm{cm})\end{array}$ & $\mathbf{L}_{\mathbf{C . I}}(\mathbf{c G y})$ & $\mathbf{L}_{\text {diodo }}$ (u.a) & $\begin{array}{c}\text { Fator } \\
\text { Calibração } \\
\left(\mathbf{c G y /} \mathbf{L}_{\text {diodo }}\right)\end{array}$ & CORR \\
\hline $4,00 \pm 0,05$ & $13,65 \pm 0,01$ & $12,0 \pm 0,1$ & $1,14 \pm 0,01$ & 15 \\
\hline \multicolumn{5}{|c|}{ DLL $=12,00 \pm 0,05 \mathrm{~cm}$} \\
\hline $\begin{array}{c}\text { Ponto Presc. } \\
\text { Dose (cm) }\end{array}$ & $\mathbf{L}_{\text {C.I }}(\mathbf{c G y})$ & $\mathbf{L}_{\text {diodo }}$ (u.a) & $\begin{array}{c}\text { Fator } \\
\text { Calibração } \\
\left(\mathbf{c G y /} \mathbf{L}_{\text {diodo }}\right)\end{array}$ & CORR \\
\hline $6,00 \pm 0,05$ & $11,65 \pm 0,01$ & $12,0 \pm 0,1$ & $0,97 \pm 0,01$ & 16 \\
\hline \multicolumn{5}{|c|}{$D L L=18,00 \pm 0,05 \mathrm{~cm}$} \\
\hline
\end{tabular}




\begin{tabular}{|c|c|c|c|c|}
\hline $\begin{array}{c}\text { Ponto Presc. } \\
\text { Dose }(\mathrm{cm})\end{array}$ & $\mathbf{L}_{\text {C.I }}(\mathbf{c G y})$ & $\mathbf{L}_{\text {diodo }}($ u.a) & 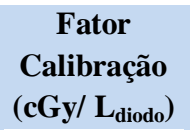 & CORR \\
\hline $9,00 \pm 0,05$ & $10,54 \pm 0,01$ & $12,2 \pm 0,1$ & $0,87 \pm 0,01$ & 17 \\
\hline \multicolumn{5}{|c|}{$D L L=22,00 \pm 0,05 \mathrm{~cm}$} \\
\hline $\begin{array}{c}\text { Ponto Presc. } \\
\text { Dose }(\mathrm{cm})\end{array}$ & $\mathbf{L}_{\text {C.I }}(\mathbf{c G y})$ & $\mathbf{L}_{\text {diodo }}$ (u.a) & $\begin{array}{c}\text { Fator } \\
\text { Calibração } \\
\left(\mathbf{c G y /} \mathbf{L}_{\text {diodo }}\right)\end{array}$ & CORR \\
\hline $11,00 \pm 0.05$ & $9,88 \pm 0,01$ & $12,2 \pm 0,1$ & $0,81 \pm 0,01$ & 18 \\
\hline \multicolumn{5}{|c|}{$D L L=23,00 \pm 0,05 \mathrm{~cm}$} \\
\hline $\begin{array}{c}\text { Ponto Presc. } \\
\text { Dose }(\mathrm{cm})\end{array}$ & $\mathbf{L}_{\text {C.I }}(\mathbf{c G y})$ & $\mathbf{L}_{\text {diodo }}$ (u.a) & $\begin{array}{c}\text { Fator } \\
\text { Calibração } \\
\left(\mathbf{c G y /} \mathbf{L}_{\text {diodo }}\right)\end{array}$ & CORR \\
\hline $11,50 \pm 0.05$ & $19,56 \pm 0,01$ & $23,7 \pm 0,1$ & $0,83 \pm 0,01$ & 2 \\
\hline \multicolumn{5}{|c|}{$D L L=25,00 \pm 0,05 \mathrm{~cm}$} \\
\hline $\begin{array}{c}\text { Ponto Presc. } \\
\text { Dose }(\mathbf{c m})\end{array}$ & $\mathbf{L}_{\mathbf{C . I}}(\mathbf{c G y})$ & $\mathbf{L}_{\text {diodo }}$ (u.a) & $\begin{array}{c}\text { Fator } \\
\text { Calibração } \\
\left(\mathbf{c G y /} \mathbf{L}_{\text {diodo }}\right)\end{array}$ & CORR \\
\hline $12,50 \pm 0.05$ & $18,98 \pm 0,01$ & $23,7 \pm 0,1$ & $0,81 \pm 0,01$ & 3 \\
\hline \multicolumn{5}{|c|}{$D L L=27,00 \pm 0,05 \mathrm{~cm}$} \\
\hline $\begin{array}{c}\text { Ponto Presc. } \\
\text { Dose }(\mathrm{cm})\end{array}$ & $\mathbf{L}_{\text {C.I }}(\mathbf{c G y})$ & $\mathbf{L}_{\text {diodo }}$ (u.a) & $\begin{array}{c}\text { Fator } \\
\text { Calibração } \\
\left(\mathbf{c G y /} \mathbf{L}_{\text {diodo }}\right)\end{array}$ & CORR \\
\hline $13,50 \pm 0.05$ & $18,40 \pm 0,01$ & $23,7 \pm 0,1$ & $0,77 \pm 0,01$ & 4 \\
\hline \multicolumn{5}{|c|}{$D L L=29,00 \pm 0,05 \mathrm{~cm}$} \\
\hline $\begin{array}{c}\text { Ponto Presc. } \\
\text { Dose }(\mathrm{cm})\end{array}$ & $\mathbf{L}_{\text {C.I }}(\mathbf{c G y})$ & $\mathbf{L}_{\text {diodo }}$ (u.a) & $\begin{array}{c}\text { Fator } \\
\text { Calibração } \\
\left(\mathbf{c G y /} \mathbf{L}_{\text {diodo }}\right)\end{array}$ & CORR \\
\hline $14,50 \pm 0.05$ & $17,85 \pm 0,01$ & $23,8 \pm 0,1$ & $0,75 \pm 0,01$ & 5 \\
\hline \multicolumn{5}{|c|}{$D L L=31,00 \pm 0,05 \mathrm{~cm}$} \\
\hline $\begin{array}{c}\text { Ponto Presc. } \\
\text { Dose }(\mathrm{cm})\end{array}$ & $\mathbf{L}_{\mathbf{C . I}}(\mathbf{c G y})$ & $\mathbf{L}_{\text {diodo }}$ (u.a) & $\begin{array}{c}\text { Fator } \\
\text { Calibração } \\
\left(\mathbf{c G y /} \mathbf{L}_{\text {diodo }}\right)\end{array}$ & CORR \\
\hline $15,50 \pm 0.05$ & $17,32 \pm 0,01$ & $23,9 \pm 0,1$ & $0,72 \pm 0,01$ & 6 \\
\hline \multicolumn{5}{|c|}{$D L L=33,00 \pm 0,05 \mathrm{~cm}$} \\
\hline $\begin{array}{c}\text { Ponto Presc. } \\
\text { Dose }(\mathbf{c m})\end{array}$ & $\mathbf{L}_{\text {C.I }}(\mathbf{c G y})$ & $\mathbf{L}_{\text {diodo }}$ (u.a) & $\begin{array}{c}\text { Fator } \\
\text { Calibração } \\
\left(\mathbf{c G y /} \mathbf{L}_{\text {diodo }}\right)\end{array}$ & CORR \\
\hline $16,50 \pm 0.05$ & $16,75 \pm 0,01$ & $24,0 \pm 0,1$ & $0,70 \pm 0,01$ & 7 \\
\hline \multicolumn{5}{|c|}{$D L L=35,00 \pm 0,05 \mathrm{~cm}$} \\
\hline $\begin{array}{c}\text { Ponto Presc. } \\
\text { Dose (cm) }\end{array}$ & $\mathbf{L}_{\text {C.I }}(\mathbf{c G y})$ & $\mathbf{L}_{\text {diodo }}$ (u.a) & $\begin{array}{c}\text { Fator } \\
\text { Calibração } \\
\left(\mathbf{c G y /} \mathbf{L}_{\text {diodo }}\right)\end{array}$ & CORR \\
\hline $17,50 \pm 0.05$ & $16,20 \pm 0,01$ & $24,0 \pm 0,1$ & $0,67 \pm 0,01$ & 8 \\
\hline \multicolumn{5}{|c|}{$D L L=37,00 \pm 0,05 \mathrm{~cm}$} \\
\hline $\begin{array}{c}\text { Ponto Presc. } \\
\text { Dose }(\mathrm{cm})\end{array}$ & $\mathbf{L}_{\text {C.I }}(\mathbf{c G y})$ & $\mathbf{L}_{\text {diodo }}$ (u.a) & $\begin{array}{c}\text { Fator } \\
\text { Calibração } \\
\left(\mathbf{c G y /} \mathbf{L}_{\text {diodo }}\right)\end{array}$ & CORR \\
\hline $18,50 \pm 0.05$ & $15,70 \pm 0,01$ & $24,1 \pm 0,1$ & $0,65 \pm 0,01$ & 9 \\
\hline \multicolumn{5}{|c|}{$\mathrm{DLL}=39,00 \pm 0,05 \mathrm{~cm}$} \\
\hline
\end{tabular}




\begin{tabular}{|c|c|c|c|c|}
\hline $\begin{array}{c}\text { Ponto Presc. } \\
\text { Dose }(\mathrm{cm})\end{array}$ & $\mathbf{L}_{\mathbf{C . I}}(\mathbf{c G y})$ & $\mathbf{L}_{\text {diodo }}$ (u.a) & 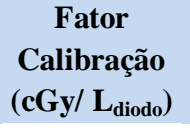 & CORR \\
\hline $19,50 \pm 0.05$ & $15,21 \pm 0,01$ & $24,2 \pm 0,1$ & $0,63 \pm 0,01$ & 10 \\
\hline \multicolumn{5}{|c|}{ DLL $=41,00 \pm 0,05 \mathrm{~cm}$} \\
\hline $\begin{array}{c}\text { Ponto Presc. } \\
\text { Dose }(\mathrm{cm})\end{array}$ & $\mathbf{L}_{\text {C.I }}(\mathbf{c G y})$ & $\mathbf{L}_{\text {diodo }}(\mathbf{u} . \mathbf{a})$ & $\begin{array}{c}\text { Fator } \\
\text { Calibração } \\
\left.\text { (cGy/ } \mathbf{L}_{\text {diodo }}\right)\end{array}$ & CORR \\
\hline $20,50 \pm 0.05$ & $14,76 \pm 0,01$ & $24,3 \pm 0,1$ & $0,61 \pm 0,01$ & 11 \\
\hline \multicolumn{5}{|c|}{ DLL $=43,00 \pm 0,05 \mathrm{~cm}$} \\
\hline $\begin{array}{c}\text { Ponto Presc. } \\
\text { Dose }(\mathrm{cm})\end{array}$ & $\mathbf{L}_{\mathbf{C . I}}(\mathbf{c G y})$ & $\mathbf{L}_{\text {diodo }}($ u.a) & $\begin{array}{c}\text { Fator } \\
\text { Calibração } \\
\left(\mathbf{c G y /} \mathbf{L}_{\text {diodo }}\right)\end{array}$ & CORR \\
\hline $21,50 \pm 0.05$ & $14,28 \pm 0,01$ & $24,4 \pm 0,1$ & $0,59 \pm 0,01$ & 12 \\
\hline \multicolumn{5}{|c|}{$D L L=45,00 \pm 0,05 \mathrm{~cm}$} \\
\hline $\begin{array}{c}\text { Ponto Presc. } \\
\text { Dose }(\mathbf{c m})\end{array}$ & $\mathbf{L}_{\text {C.I }}(\mathbf{c G y})$ & $\mathbf{L}_{\text {diodo }}($ u.a) & $\begin{array}{c}\text { Fator } \\
\text { Calibração } \\
\left(\mathbf{c G y /} \mathbf{L}_{\text {diodo }}\right)\end{array}$ & CORR \\
\hline $22,50 \pm 0.05$ & $13,78 \pm 0,01$ & $24,5 \pm 0,1$ & $0,56 \pm 0,01$ & 13 \\
\hline \multicolumn{5}{|c|}{ DLL $=47,00 \pm 0,05 \mathrm{~cm}$} \\
\hline $\begin{array}{c}\text { Ponto Presc. } \\
\text { Dose }(\mathrm{cm})\end{array}$ & $\mathbf{L}_{\text {C.I }}(\mathbf{c G y})$ & $\mathbf{L}_{\text {diodo }}(\mathbf{u} . \mathbf{a})$ & $\begin{array}{c}\text { Fator } \\
\text { Calibração } \\
\left(\mathbf{c G y /} \mathbf{L}_{\text {diodo }}\right)\end{array}$ & CORR \\
\hline $23,50 \pm 0.05$ & $13,78 \pm 0,01$ & $24,6 \pm 0,1$ & $0,54 \pm 0,01$ & 14 \\
\hline
\end{tabular}

Tabela 9- Fatores de calibração dos diodos semicondutores para dosimetria TBI

Os valores de leitura dos diodos foram obtidos de uma média de duas leituras por ponto de prescrição de dose. Nessa etapa foi utilizado apenas um diodo, pois os outros 2 canais de leitura do eletrômetro deixaram de funcionar e estavam em manutenção.

Os resultados da etapa de verificação de dose para os diodos fixados na região da cabeça são apresentados na Tabela 10.

\begin{tabular}{|c|c|c|c|c|}
\hline \multicolumn{5}{|c|}{$D L L=12,00 \pm 0,05 \mathrm{~cm}$} \\
\hline $\begin{array}{c}\text { Ponto Presc. } \\
\text { Dose }(\mathrm{cm})\end{array}$ & $\mathbf{L}_{\text {C.I }}(\mathbf{c G y})$ & $\mathbf{L}_{\text {diodo }}(\mathbf{c G y})$ & Dif \% & CORR \\
\hline $6,00 \pm 0.05$ & $9,00 \pm 0,01$ & $8,9 \pm 0,1$ & 1,1 & 16 \\
\hline \multicolumn{5}{|c|}{$D L L=18,00 \pm 0,05 \mathrm{~cm}$} \\
\hline $\begin{array}{c}\text { Ponto Presc. } \\
\text { Dose }(\mathrm{cm})\end{array}$ & $\mathbf{L}_{\text {C.I }}(\mathbf{c G y})$ & $\mathbf{L}_{\text {diodo }}(\mathbf{c G y})$ & Dif \% & CORR \\
\hline $9,00 \pm 0.05$ & $8,30 \pm 0,01$ & $8,1 \pm 0,1$ & 2,4 & 17 \\
\hline \multicolumn{5}{|c|}{$D L L=22,00 \pm 0,05 \mathrm{~cm}$} \\
\hline $\begin{array}{c}\text { Ponto Presc. } \\
\text { Dose }(\mathrm{cm})\end{array}$ & $\mathbf{L}_{\text {C.I }}(\mathbf{c G y})$ & $\mathbf{L}_{\text {diodo }}(\mathbf{c G y})$ & Dif $\%$ & CORR \\
\hline $11,00 \pm 0.05$ & $7,83 \pm 0,01$ & $7,6 \pm 0,1$ & 3,0 & 18 \\
\hline
\end{tabular}

Tabela 10- Diferença percentual de dose entre diodo e C.I, com diodo posicionado na cabeça do OSA

Pelos resultados da Tabela 10 conclui-se que a diferença percentual entre as leituras de dose com o diodo e com a câmara estão dentro do recomendado [ ${ }^{9}$ ]. Dessa 
forma, não foi necessária uma calibração adicional para a região da cabeça e os mesmo fatores de calibração obtidos com a calibração na região da pelve podem ser usados na dosimetria in vivo TBI, caso seja de interesse posicionar o diodo na cabeça do paciente.

\subsubsection{SIMULAÇÃO EM SETUP PARA TBI COM DIODOS}

Os resultados observados nessa etapa representam a validação do método de dosimetria para tratamento de TBI. Irradiou-se o OSA e o diodo com uma dose total de 50 cGy, calculada na profundidade de $15,50 \pm 0,05 \mathrm{~cm}$, já que o DLL do OSA na altura da pelve era de $31,00 \pm 0,05 \mathrm{~cm}$. A partir desses valores verifica-se pela Tabela 9 que o fator de correção a ser utilizado é o de número 6 (CORR 6). Dessa forma, para a dosimetria, selecionou-se o fator de correção número 6 no eletrômetro do sistema dosimétrico, e os fatores de calibração foram automaticamente selecionados. Após a irradiação verifica-se a dose obtida com o diodo e que é representada por:

$$
D_{\text {diodo }}=L_{\text {diodo }} * F_{C}
$$

Equação 19

Onde $D_{\text {diodo }}$ é a dose final obtida com o diodo, $L_{\text {diodo }}$ é leitura obtida com o diodo após irradiação e $F_{C}$ é o fator de calibração para o diodo, na profundidade em questão. Para este caso, $F_{C}$ era de 0,724 (Tabela 9).

\begin{tabular}{|c|c|}
\hline \multicolumn{2}{|c|}{ Validação do método de dosimetria } \\
\hline$D_{\text {diodo }}(\boldsymbol{c G y})$ & Dose prescrita $(\boldsymbol{c} G y)$ \\
\hline $48,70 \pm 0,14$ & 50 \\
\hline \multicolumn{2}{|c|}{ Diferença \%: $\mathbf{2 , 6}$} \\
\hline
\end{tabular}

Tabela 11- Valores de doses obtidas com o diodo na simulação do tratamento de TBI

Pelos resultados da Tabela 11, observa-se que os valores estão dentro do aceitável, ou seja, a diferença entre a dose prescrita e a dose efetivamente entregue durante o tratamento, foi menor que $5 \%$, conforme recomendada pela literatura $\left[{ }^{9}\right]$. Conclui-se que o método utilizado para simulação de um tratamento de TBI é válido e pode ser usado posteriormente na dosimetria in vivo.

Fatores de correção não foram usados nessa etapa uma vez que a dosimetria do diodo foi realizada nas mesmas condições da simulação do tratamento. Dessa forma, apenas o fator de calibração foi utilizado para encontrar a dose no diodo.

A partir desses resultados, verifica-se que os diodos semicondutores representam um método adequado para as medidas in vivo realizadas nesse trabalho. 


\subsubsection{CALIBRAÇÃO DOS TLD NAS CONDIÇÕES DE TBI}

Após serem caracterizados, os TLDs foram calibrados no setup de TBI, de acordo com as condições estabelecidas em 3.5. O objetivo de se calibrar os dosímetros no setup de TBI era para evitar que fatores de correção tivessem que ser determinados e aplicados na determinação da dose quando a dosimetria in vivo fosse realizada. Uma dose de 75 cGy nominal foi administrada com o objeto simulador sendo irradiado lateralmente. Posteriormente, girou-se a mesa $180^{\circ}$, mantendo-se o isocentro e irradiouse a outra lateral do OSA novamente com 75 cGy nominal. A Tabela 12 apresenta os TLDs utilizados para calibração.

\begin{tabular}{|c|c|c|c|}
\hline $\mathbf{N}^{\mathbf{0}} \mathbf{T L D}$ & Leitura $(\boldsymbol{\mu C})$ & $\mathbf{L}_{\text {corr }}(\boldsymbol{\mu C})$ & \multirow{2}{*}{$\mathbf{L}_{\text {Média }}(\boldsymbol{\mu C})$} \\
\cline { 1 - 3 } 58 & $14,24 \pm 1,00$ & $14,74 \pm 1,07$ & \\
\cline { 1 - 3 } 59 & $14,04 \pm 1,00$ & $13,77 \pm 1,02$ & \\
\cline { 1 - 3 } 60 & $15,23 \pm 1,00$ & $15,11 \pm 1,04$ & \multirow{2}{*}{$14,51 \pm 0,34$} \\
\cline { 1 - 3 } 61 & $14,83 \pm 1,00$ & $15,29 \pm 1,04$ & \\
\cline { 1 - 3 } 62 & $12,61 \pm 1,00$ & $13,64 \pm 1,15$ & \\
\hline
\end{tabular}

Tabela 12- Leitura de referência com TLDs posicionados ao lado da câmara de ionização

A partir dos valores da Tabela 12, que foram tomados como referência para o cálculo da dose, calculou-se o Fator de Calibração do grupo. Apesar de ter sido selecionada uma dose nominal total de 150 cGy, a câmara de ionização registrou uma

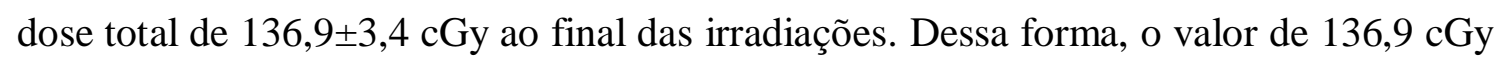
foi tomado como referência para determinação do fator de calibração.

$$
\mathrm{D}_{\mathrm{C} . \mathrm{I}}=136,9 \pm 3,4 \mathrm{cGy}
$$

O Fator de calibração encontrado, através da Equação 7, foi:

$$
F_{C}=9,43 \pm 0,32 c G y / \mu C
$$

Os valores de leitura em dose para os TLDs inseridos na capa de buildup e fixados na superfície de entrada do OSA são apresentados Tabela 13.

\begin{tabular}{|c|c|c|}
\hline $\mathbf{N}^{\mathbf{0}} \mathbf{T L D}$ & $\mathbf{L}_{\mathbf{c o r r}}(\boldsymbol{\mu} \mathbf{C})$ & \multirow{2}{*}{$\mathbf{L}_{\text {Média }}(\boldsymbol{\mu} \mathbf{C})$} \\
\cline { 1 - 2 } 17 & $14,80 \pm 1,27$ & \multirow{2}{*}{$14,52 \pm 0,12$} \\
\cline { 1 - 2 } 20 & $14,56 \pm 1,31$ & \\
\cline { 1 - 2 } 22 & $14,41 \pm 1,12$ & \\
\cline { 1 - 2 } 21 & $14,12 \pm 1,11$ & $14,72 \pm 1,15$ \\
\hline \multicolumn{2}{|c|}{18} & \multicolumn{2}{|c|}{ Tabela 13- Leitura do TLD na superfície de entrada do OSA } \\
\hline
\end{tabular}


Dessa forma, convertendo a leitura do TLD para leitura em dose, temos:

$$
L_{\text {Média }}=136,92 \pm 4,78 c G y
$$

Por outro lado, temos os resultados da leitura do diodo que estava posicionado na superfície de entrada do OSA, ao lado do TLD:

$$
L_{\text {diodo }}=138,1 \pm 1,2 c G y
$$

Verifica-se que a diferença percentual entre as leituras com TLD e diodo é de $0,8 \%$, demonstrando que a dosimetria termoluminescente é um método adequado para o controle de qualidade, uma vez que está de acordo com a dosimetria com diodos.

Optou-se, pela confiabilidade dos dados, o uso do diodo semicondutor para todas as medidas de dosimetria in vivo TBI, uma vez que a leitura em tempo real permite monitorar qualquer discrepância de dose efetivamente entregue, com aquela prescrita.

O uso de dosimetria TL é desejável para medidas intracavitárias, uma vez que um número muito grande de TLD pode ser inserido.

\subsubsection{SIMULAÇÃO EM SETUP PARA TBI COM TLD}

As posições selecionadas do OSA, bem como os TLDs utilizados em cada uma delas, estão especificadas na Tabela 14. Temperatura e pressão foram devidamente

\begin{tabular}{|c|c|c|c|c|}
\hline $\begin{array}{c}\text { Posicionamento no } \\
\text { OSA } \\
\end{array}$ & $\mathbf{N}^{\mathbf{0}}$ TLD & $L(\mu C)$ & $\mathrm{L}_{\text {corr }}(\mu \mathrm{C})$ & $\mathbf{L}_{\text {média }}(\mu \mathrm{C})$ \\
\hline \multirow{3}{*}{ Pescoço (Direita) } & 1 & 13,86 & 13,17 & \multirow{3}{*}{$14,35 \pm 0,68$} \\
\hline & 2 & 14,72 & 14,37 & \\
\hline & 3 & 16,71 & 15,51 & \\
\hline \multirow{3}{*}{ Pescoço (Centro) } & 4 & & & \multirow{3}{*}{$16,23 \pm 0,82$} \\
\hline & 6 & 16,63 & 17,04 & \\
\hline & 7 & 16,15 & 15,41 & \\
\hline \multirow{3}{*}{ Pescoço (Esquerda) } & 8 & 16,01 & 15,21 & \multirow{3}{*}{$14,42 \pm 0,78$} \\
\hline & 9 & & & \\
\hline & 10 & 14,75 & 13,64 & \\
\hline \multirow{3}{*}{ Cabeça (Direita) } & 11 & 15,91 & 16,11 & \multirow{3}{*}{$15,48 \pm 0,65$} \\
\hline & 12 & 14,45 & 14,79 & \\
\hline & 13 & 15,25 & 15,54 & \\
\hline \multirow[b]{2}{*}{ Cabeça (Centro) } & 14 & 15,21 & 15,68 & \multirow[b]{2}{*}{$15,96 \pm 0,65$} \\
\hline & 15 & 15,24 & 17,19 & \\
\hline
\end{tabular}
monitoradas e apresentaram valores respectivamente de $21,1^{0} \mathrm{C}$ e $94,29 \mathrm{kPa}$. 


\begin{tabular}{|c|c|c|c|c|}
\hline & 16 & 15,41 & 15,01 & \\
\hline \multirow{3}{*}{ Cabeça (Esquerda) } & 17 & 14,06 & 13,23 & \multirow{3}{*}{$15,42 \pm 1,11$} \\
\hline & 18 & 17,03 & 16,92 & \\
\hline & 19 & 16,35 & 16,11 & \\
\hline \multirow{3}{*}{$\begin{array}{l}\text { Tórax Superior } \\
\text { (Direita) }\end{array}$} & 26 & 19,77 & 20,82 & \multirow{3}{*}{$20,11 \pm 1,87$} \\
\hline & 27 & 19,78 & 22,94 & \\
\hline & 28 & 17,18 & 16,56 & \\
\hline \multirow{3}{*}{$\begin{array}{l}\text { Tórax Superior } \\
\quad(\text { Centro })\end{array}$} & 23 & & & \multirow{3}{*}{$17,81 \pm 1,74$} \\
\hline & 24 & 19,55 & 19,55 & \\
\hline & 25 & 17,13 & 16,07 & \\
\hline \multirow{3}{*}{$\begin{array}{l}\text { Tórax Superior } \\
\text { (Esquerda) }\end{array}$} & 20 & 19,06 & 21,06 & \multirow{3}{*}{$19,91 \pm 0,58$} \\
\hline & 21 & 19,64 & 19,23 & \\
\hline & 22 & 19,52 & 19,42 & \\
\hline \multirow{3}{*}{$\begin{array}{l}\text { Tórax Inferior } \\
\text { (Direita) }\end{array}$} & 35 & 16,77 & 16,39 & \multirow{3}{*}{$17,62 \pm 1,05$} \\
\hline & 36 & 17,21 & 16,77 & \\
\hline & 37 & 18,25 & 19,69 & \\
\hline \multirow{3}{*}{$\begin{array}{l}\text { Tórax Inferior } \\
\quad(\text { Centro })\end{array}$} & 32 & 17,97 & 19,55 & \multirow{3}{*}{$18,44 \pm 0,56$} \\
\hline & 33 & 17,64 & 18,01 & \\
\hline & 34 & 17,23 & 17,73 & \\
\hline \multirow{3}{*}{$\begin{array}{l}\text { Tórax Inferior } \\
\text { (Esquerda) }\end{array}$} & 29 & 18,84 & 18,53 & \multirow{3}{*}{$18,38 \pm 0,76$} \\
\hline & 30 & 17,75 & 16,99 & \\
\hline & 31 & 17,82 & 19,63 & \\
\hline \multirow{3}{*}{ Abdômen (Direita) } & 45 & 17,26 & 16,23 & \multirow{3}{*}{$17,09 \pm 0,86$} \\
\hline & 46 & & & \\
\hline & 47 & 17,13 & 17,95 & \\
\hline \multirow{3}{*}{ Abdômen (Centro) } & 41 & 16,26 & 15,77 & \multirow{3}{*}{$17,31 \pm 1,64$} \\
\hline & 43 & 16,02 & 15,55 & \\
\hline & 44 & 17,97 & 20,57 & \\
\hline \multirow{3}{*}{ Abdômen (Esquerda) } & 38 & & & \multirow{3}{*}{$16,22 \pm 0,55$} \\
\hline & 39 & 16,66 & 15,67 & \\
\hline & 40 & 16,37 & 16,77 & \\
\hline \multirow{3}{*}{ Pelve (Direita) } & 54 & 16,71 & 18,19 & \multirow{3}{*}{$16,72 \pm 0,81$} \\
\hline & 55 & 16,01 & 16,59 & \\
\hline & 57 & 15,98 & 15,38 & \\
\hline \multirow{3}{*}{ Pelve (Centro) } & 51 & 15,73 & 15,73 & \multirow{3}{*}{$16,52 \pm 0,39$} \\
\hline & 52 & 17,22 & 16,98 & \\
\hline & 53 & 16,32 & 16,86 & \\
\hline \multirow{2}{*}{ Pelve (Esquerda) } & 48 & 16,75 & 16,01 & \multirow[b]{2}{*}{$15,48 \pm 0,43$} \\
\hline & 49 & 15,27 & 15,81 & \\
\hline
\end{tabular}




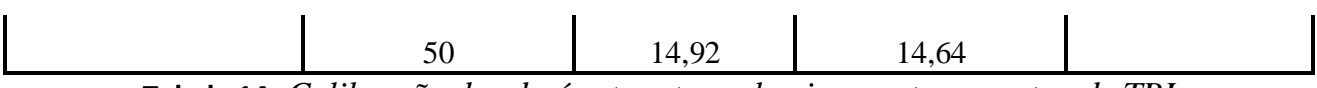

Tabela 14- Calibração dos dosímetros termoluminescentes no setup de TBI

A partir do fator de calibração do grupo calculado em 4.3.2, determinaram-se os valores de dose para cada região do OSA.

\begin{tabular}{|c|c|c|}
\hline $\begin{array}{c}\text { Posicionamento no } \\
\text { OSA }\end{array}$ & Média $(\mu \mathrm{C})$ & Dose (cGy) \\
\hline Pescoço (Direita) & $14,35 \pm 0,68$ & $135,46 \pm 10,86$ \\
\hline Pescoço (Centro) & $16,23 \pm 0,82$ & $153,05 \pm 12,76$ \\
\hline Pescoço (Esquerda) & $14,42 \pm 0,78$ & $135,98 \pm 11,82$ \\
\hline Cabeça (Direita) & $15,48 \pm 0,65$ & $145,97 \pm 10,93$ \\
\hline Cabeça (Centro) & $15,96 \pm 0,65$ & $150,51 \pm 11,07$ \\
\hline Cabeça (Esquerda) & $15,42 \pm 1,11$ & $145,41 \pm 15,25$ \\
\hline $\begin{array}{l}\text { Tórax Superior } \\
\text { (Direita) }\end{array}$ & $20,11 \pm 1,87$ & ט \\
\hline $\begin{array}{l}\text { Tórax Superior } \\
\quad(\text { Centro })\end{array}$ & $17,81 \pm 1,74$ & $167,95 \pm$ \\
\hline $\begin{array}{c}\text { Tórax Superior } \\
\text { (Esquerda) }\end{array}$ & $19,91 \pm 0,58$ &, $75 \pm 1$ \\
\hline $\begin{array}{l}\text { Tórax Inferior } \\
\text { (Direita) }\end{array}$ & $17,62 \pm 1,05$ & $66,16 \pm 15$ \\
\hline Tórax Inferior (Centro) & $18,44 \pm 0,56$ & $73,89 \pm 10,99$ \\
\hline $\begin{array}{c}\text { Tórax Inferior } \\
\text { (Esquerda) }\end{array}$ & $18,38 \pm 0,76$ & .32 \\
\hline
\end{tabular}




\begin{tabular}{|c|c|c|}
\hline Abdômen (Direita) & $17,09 \pm 0,86$ & $161,16 \pm 13,41$ \\
\hline Abdômen (Centro) & $17,31 \pm 1,64$ & $163,23 \pm 20,83$ \\
\hline Abdômen (Esquerda) & $16,22 \pm 0,55$ & $152,95 \pm 10,22$ \\
\hline Pelve (Direita) & $16,72 \pm 0,81$ & $157,67 \pm 12,82$ \\
\hline Pelve (Centro) & $16,52 \pm 0,39$ & $155,78 \pm 8,81$ \\
\hline & & \\
\hline & & $145,97 \pm 8,86$ \\
\hline & & \\
\hline & & \\
\hline
\end{tabular}

Tabela 15- Valores de Dose para simulação com TLD em setup de TBI

Os resultados apresentados na Tabela 15, são provenientes de uma média de 3 irradiações realizadas com os TLDS inseridos no OSA. Verifica-se que os valores se aproximaram, em média da dose nominal 150 cGy, mesmo levando-se em conta as incertezas. No entanto, regiões como do tórax superior e inferior (grafadas em vermelho), apresentaram valores de dose significativamente superiores, uma vez que nessa região o OSA simula a cavidade torácica, onde se aloja o pulmão e, dessa forma, ocorre uma maior absorção de dose pelos TLDs, devido à falta de material absorvedor do OSA. Vale ressaltar que, em tratamentos de TBI, a região do tórax deve ser blindada com uma espessura de chumbo suficiente para absorver parte da irradiação, uma vez que o excesso de dosagem pode sobrecarregar a área e levar ao desenvolvimento de pneumonite radio-induzida.

Dos resultados apresentados, conclui-se que, uma vez que o OSA não possui braços, ocorre um aumento na dose nas regiões do tórax superior e inferior. No entanto, na prática clínica, os cálculos de planejamento de entrega de dose levam em consideração a espessura do braço do paciente, que se localiza na frente do feixe de radiação e blinda, dessa forma, parte da energia incidente. Embora os braços do paciente possam compensar parte da dose entregue, seria adequado que a clínica utilizasse compensadores de dose na região do pulmão. Um estudo mais detalhado seria 
conveniente para comprovar quanto de radiação é blindada apenas com os braços do paciente na frente do feixe. Ainda, vale ressaltar que, na clínica, são colocados compensadores de dose nos joelhos, uma vez que essa região também recebe doses mais elevadas que no restante do corpo.

Os resultados demonstram a viabilidade na utilização dos dosímetros termoluminescentes para cálculo de doses em simulação de tratamento de TBI, uma vez que concordaram em média com a dose total nominal aplicada geralmente em TBI.

\subsubsection{SIMULAÇÃO TBI UTILIZANDO DIODOS E TLD}

As pastilhas de TLD foram inseridas nos orifícios do OSA, nas mesmas posições descritas na Tabela 14. O DLL do OSA foi medido e encontrou-se o valor de $16 \mathrm{~cm}$. Dessa forma, prescreveu-se uma dose de 150 cGy (75cGy em cada lateral) na profundidade de referência (linha média do $\mathrm{OSA}-15,5 \mathrm{~cm}$ ). A câmara de ionização não foi utilizada nessa etapa.

A fixação do diodo na região da cabeça se justifica, uma vez que essa região tem um DLL menor que da pelve e, por isso, pode receber doses maiores de radiação. Para compensar a variação de dose, blocos absorvedores de chumbo (4mm) devem ser fixados no gantry na altura da cabeça. Pela unidade de terapia, verificou-se que, com $4 \mathrm{~mm}$ de chumbo, a dose entregue a cabeça seria de 147cGy, ao invés de 150cGy (nominal).

As leituras dos TLDs encontram-se na Tabela 16.

\begin{tabular}{|c|c|c|}
\hline $\begin{array}{c}\text { Posicionamento } \boldsymbol{n o} \\
\text { OSA }\end{array}$ & $\mathbf{L}_{\text {Médiacorr }}(\boldsymbol{\mu} \mathbf{C})$ & Dose $(\mathbf{c G y})$ \\
\hline Pescoço & $14,35 \pm 0,68$ & $135,32 \pm 10,86$ \\
\hline Cabeça & $15,96 \pm 0,82$ & $150,51 \pm 12,76$ \\
\hline Tórax Superior & $18,91 \pm 0,78$ & $178,32 \pm 11,82$ \\
\hline Tórax Inferior & $18,30 \pm 0,65$ & $172,57 \pm 10,93$ \\
\hline
\end{tabular}




\begin{tabular}{|c|c|c|}
\hline Abdômen & $17,31 \pm 0,65$ & $163,23 \pm 11,07$ \\
\hline Pelve & $16,54 \pm 1,11$ & $155,97 \pm 15,25$ \\
\hline
\end{tabular}

Tabela 16-Leitura de dose dos TLD a partir da simulação TBI

Pela Tabela 16 verifica-se que os valores se aproximaram, em média da dose nominal $150 \mathrm{cGy}$, mesmo levando-se em conta as incertezas. No entanto, regiões como do tórax superior e inferior apresentaram valores de dose significativamente superiores, uma vez que nessa região o OSA simula a cavidade torácica, onde se aloja o pulmão e, dessa forma, ocorre uma maior absorção de dose pelos TLDs, devido à falta de material absorvedor do OSA. Vale ressaltar que, em tratamentos de TBI, a região do tórax deve ser blindada com uma espessura de chumbo suficiente para absorver parte da irradiação, uma vez que o excesso de dosagem pode sobrecarregar a área e levar ao desenvolvimento de pneumonite radio-induzida.

Os resultados da Tabela 16 concordam com aqueles da Tabela 15, demonstrando a viabilidade da dosimetria TL em aplicações em setup TBI.

\subsubsection{DOSIMETRIA IN VIVO TBI}

Utilizando os diodos previamente calibrados, realizou-se a dosimetria in vivo em 3 (três) pacientes que foram submetidos ao tratamento de TBI, até o presente momento, no Serviço de Radioterapia do HCFMRP. A Tabela 17 apresenta os parâmetros utilizados para os 3 tratamentos in vivo realizados. Vale ressaltar que a taxa de dose utilizada 7cGy/min - foi determinada clinicamente pelos médicos responsáveis do Setor de Radioterapia. Essa escolha baseou-se em estudos que comprovaram a diminuição de efeitos colaterais em taxas de dose menores. Embora a taxa de dose utilizada para calibração tenha sido de 12 cGy/min, os resultados mostrados na Tabela 4 indicam que o diodo não apresenta dependência significativa com a taxa de dose.

\section{Parâmetros utilizados no Tratamento}

Acelerador Oncor $6 \mathrm{MV}$

Campo : $40 \times 40 \mathrm{~cm}^{2}$

Gantry: $270^{\circ}$

Colimador: $45^{\circ}$

$\mathrm{DFS}=393 \mathrm{~cm}$

Dose total=1200cGy (4 frações diárias de 300 cGy) 
Taxa de Dose $=7 \mathrm{cGy} / \mathrm{min}$

Diodo utilizado: EDP-15 3G,4m DEC 712-2801 (Canal 1)

Tabela 17- Parâmetros do tratamento de dosimetria in vivo TBI.

\begin{tabular}{|c|c|c|c|}
\hline Paciente & $\begin{array}{c}\text { Fração Diária } \\
(\boldsymbol{c G} \boldsymbol{y})\end{array}$ & $\boldsymbol{L}_{\text {diodo }}(\boldsymbol{c G} \boldsymbol{G})$ & Dif $\%$ \\
\hline & 300 & $293,0 \pm 0,5$ & 2,3 \\
Paciente 1 & 300 & $292,0 \pm 0,5$ & 2,6 \\
DLL=20,0cm & 300 & $293,0 \pm 0,5$ & 2,3 \\
& 300 & $293,0 \pm 0,5$ & 2,3 \\
\hline & 300 & $298,0 \pm 4,5$ & 0,6 \\
Paciente 2 & 300 & $299,0 \pm 4,5$ & 0,3 \\
DLL=23,0cm & 300 & $289,0 \pm 4,5$ & 3,6 \\
& 300 & $294,0 \pm 4,5$ & 2,0 \\
\hline & 300 & $292,0 \pm 2,5$ & 2,7 \\
Paciente 3 & 300 & $294,0 \pm 2,5$ & 2,0 \\
DLL=22,0cm & 300 & $295,0 \pm 2,5$ & 1,7 \\
& 300 & $298,0 \pm 2,5$ & 0,7 \\
\hline
\end{tabular}

Tabela 18- Valores de dosimetria in vivo em pacientes em tratamento de TBI

Todos os resultados apresentados demonstram a viabilidade da técnica de dosimetria in vivo com o uso do diodo semicondutor, uma vez que todas as leituras diárias estão dentro do recomendado pelo ICRU.

Os resultados demonstram ainda a adequada calibração realizada para os diodos semicondutores, que apresentaram valores de dose correspondentes com o esperado, para a dosimetria in vivo. 
Capítulo 5 - Conclusões 


\section{CONCLUSÕES}

Os resultados apresentados na simulação do tratamento de irradiação de corpo inteiro estão de acordo com os valores recomendados pelo ICRU, uma vez que a diferença entre a dose determinada com o diodo e a dose prescrita foi de 2,6\%, conforme apresentado na Tabela 11. Dessa forma, conclui-se que o método utilizado para a simulação de um tratamento de TBI é válido podendo ser usado para dosimetria in vivo.

Conclui-se com os resultados deste trabalho que foi possível comprovar que o diodo mostrou-se adequado à aplicação in vivo para o Controle de Qualidade, principalmente devido à resposta imediata, ao fácil manuseio e a reduzida dispersão entre os valores obtidos e os nominais.

Em tratamentos de irradiação de corpo inteiro, onde o paciente está sendo preparado para um transplante de medula óssea, e o planejamento necessita de uma grande eficácia na distribuição de dose, a metodologia com aplicações de dosímetros semicondutores apresentou uma alternativa viável, precisa e de grande importância para o controle dosimétrico. Dessa forma, fica evidenciada a importância da utilização do diodo para o controle de qualidade, na avaliação da dose a ser ministrada ao paciente, pelo menos em toda primeira fração de tratamento de TBI.

O presente estudo testou a aplicabilidade dos dosímetros termoluminescente no OSA, demonstrando assim o valor desta dosimetria, como um sistema de verificação de dose e sua eficácia como parte de um programa de garantia de qualidade em Radioterapia. A caracterização realizada evidencia a possibilidade de aplicação da técnica TL em dosimetria in vivo.

Com o objetivo de documentar o procedimento foram elaboradas tabelas para a correta utilização do sistema dosimétrico, visando facilitar e garantir a rotina dos profissionais do Serviço de Radioterapia. Além disso, este trabalho é importante para a implantação de aplicações da dosimetria em serviços de radioterapia e fornece subsídios para a elaboração de procedimentos de controle de dose em técnicas de TBI. 
Capítulo 6 - Referências Bibliográficas 
${ }^{1}$ WILLIAMS, J.R.; THWAITES, D.I. Introduction. In: WILLIAMS, JR; THWAITES, DI. (Ed.). Radiotherapy physics: in practice. 2. ed. New York, NY: Oxford, 2000; 1-5.

${ }^{2}$ GALVIN, J.M. Total Body Irradiation. Dosimetry and Pratical Considerations. Thomaz Jefferson University Hospital. Kimmel Cancer Center. Philadelphia, PA, 1997.

${ }^{3}$ SARFARAZ, M.; YU, C.; CHEN, D.J.; et al. A translational couch technique for total body irradiation. Journal of Applied Clinical Medical Physics, 2001; 2.

${ }^{4}$ THOMAS, E.D.; BUCKNER, C.D.; BANAJI, M.; CLIFT, R.A.; FEFER, A.; FLOURNOY, N.; et al. One hundred patients with acute leukemia treated by chemotherapy, total body irradiation, and allogeneic marrow transplantation. Blood, 1977;49:511-33.

${ }^{5}$ COSSET, J.M; SOCIE, G.; DUBRAY, B.; GIRINSKY, T.; FOURQUET, A.; GLUCKMAN, E. Single dose versus fractionated total body irradiation before bone marrow transplantation: radiobiological and clinical considerations. Int J Radiat Oncol Biol Phys, 1994; 30:477-92.

6 SHANK, B.; CHU, F.C.; DINSMORE, R.; KAPOOR, N.; KIRKPATRICK, D.; TEITELBAUM, H.; et al. Hyperfrac- tionated total body irradiation for bone marrow transplantation. Results in seventy leukemia patients with allogeneic transplants. Int J Radiat Oncol Biol Phys, 1983;9:1607-11.

${ }^{7}$ QUAST, U. Total body irradiation-review of treat-ment techniques in Europe. Radiother Oncol, 1987; 9:91-106.

${ }^{8}$ AAPM REPORT No87. "Diode in vivo Dosimetry for Patients Receiving External Beam Radiation Therapy". 2005, American Association of Physicists in Medicine, USA.

${ }^{9}$ ICRU (International Commission on Radiation Units and Measurements), 1976. Determination of dose in patient irradiated by means of $\mathrm{X}$ or gamma rays in radiotherapy procedures. ICRU Report no. 24, ICRU, Bethesda.

${ }^{10}$ SAMPATH, S.; SCHULTHEISS, T.E.; WONG, J. Dose response and factors related to interstitial pneumonitis after bone marrow transplant. Int. J. Radiation Oncology Biol. Phys., 2005;63: 876-884.

${ }^{11}$ BUCHAL, A.; FEYER, P.; GROLL, J.; et al: Immediate toxicity during fractionated total 
body irradiation as conditioning for bone marrow transplantation. Radiotherapy and Oncology, 2000;54:157-162.

${ }^{12}$ LENNERNAS, B.; ROSENGREN, B.; RIKNER G.; et AL. Silicon diodes as detectors for backscatter radiation in photon fields. ONCOLOGY REPORTS, 2001;8:181-183.

${ }^{13}$ PALKOSKOVA, P.; HLAVATA, H.; DVORAK, P.; et al. In vivo thermoluminescence dosimetry for total body irradiation. RADIATION PROTECTION DOSIMETRY, 2002;101: 597-599.

${ }^{14}$ RAPAPORT, S.I. "Introdução à hematologia", Editora Harper e Row do Brasil LTDA, 1978.

${ }^{15}$ ERHART, E.A. "Elementos de Anatomia Humana”, Atheneu Editora SP, $8^{\circ}$ Edição, 1992.

${ }^{16}$ RAMOS JR, J. Oncologia Clínica. Sarvier Editora SP, $2{ }^{\circ}$ Edição, 1984.

${ }^{17}$ EDMANN, F.R.; OLIVEIRA, H.P.; MEDEIROS, M. "Hematologia Clínica", Atheneu Editora, RJ - SP, 1983.

${ }^{18}$ ARMITAGE, J.O. Bone Marrow Transplantation. N Engl J Med, 1994; 330: 827-38.

${ }^{19}$ OSGOOD, E.E.; RIDDLE, M.C.; MATHEWA, T.J. Aplastic anemia treated with daily transfusions and intravenous marrow; case report. Ann Intern Med, 1939; 13:357-367.

${ }^{20}$ LORENZ, E.; UPHOFF, D.; REID, T.R.; SHELTON, E. Modification of irradiation injury in mice and guinea-pigs by bone marrow injections. J Natl Cancer Inst, 1951; 12:197-201.

${ }^{21}$ EPSTEINS, R.B.; BRYANT, J.; THOMAZ, E.D. Cytogenetic demonstration of permanent tolerance in adult outbred dogs. Transplantation, 1967; 5:267-72.

22 THOMAS, E.D.; COLLINS, J.A.; HERNAN JR, E.C.; FERREBEE, J.W. Marrow transplantations in lethally irradiated dogs given methotrexate. Blood, 1962; 19: 217-28.

${ }^{23}$ THOMAZ, E.D.; STORB, R.; CLIFT, R.A.; FEFER, A.; JOHNSON, F.L.; NEIMAN, P.E.; et al. Bone marrow transplantation. N Engl J Med, 1975; 292: 832-43. 
${ }^{24}$ KARP, G. Biologia Celular e Molecular-Conceitos e Experimentos. Manole Editora, $3^{\circ}$ Edição, 2007.

${ }^{25}$ THOMAZ, E.D.; STORB, R. Technique for human marrow grafting. Blood, 1970; 36:507-15

${ }^{26}$ SHANK, B.; SIMPSON, L. The Role of Total Body Irradiation in Bone Marrow Transplantation for Leukemia. Radiation Therapy Department. Medical Physics Department. Memorial Sloan-Kettering Cancer Center. New York, 1982;58.

${ }^{27}$ SZÉKELY, J.; FÁBRY, L.; FORGÁCS, G.; et al: Total body irradiation before bone marrow transplantation, Technique and cute toxicity. Strahlentherapie und Onkologie, 1999; 175:16061610.

${ }^{28}$ GOPAL, R.; HA, C.S.; TUCKER, S.L.; et al.: Comparison of two total body irradiation fractionation regimens with respect to acute and late pulmonary toxicity. Cancer, 2001;92:19491958.

${ }^{29}$ CARRUTHERS, S.A.; WALLINGTON, M.M. Total body irradiation and pneumonitis risk: a review of outcomes. British Journal of Cancer, 2004; 90:2080-2084.

${ }^{30}$ LANSON, J.H.; et al. In vivo dosimetry during conformal radiotherapy: requirements for and findings of a routine procedure. Radiotherapy and Oncology, 1999; 52:51-59.

${ }^{31}$ BLANCO, S.; LOPEZBOTE, M.A.; DESCO, M.Quality assurance in radiation therapy: systematic evaluation of errors during the treatment execution. Radiotherapy and Oncology, 1987; 8: 253-261.

${ }^{32}$ LEUNENS, G.; et al. Human errors in data transfer during the preparation and delivery of radiation treatment affecting the final result - garbage in, garbage out. Radiotherapy and Oncology, 1992; 23:217-222.

${ }^{33}$ LEUNENS, G.; et al. Quality assurance in radiotherapy by in vivo dosimetry. 2. Determination of the target absorbed dose. Radiotherapy and Oncology, 1990;19:73-87.

${ }^{34}$ HEUKELOM, S.; LANSON, J.H.; MIJNHEER, B. J. In vivo dosimetry during pelvic 
treatment. Radiotherapy and Oncology, 1992;25:111-120.

${ }^{35}$ TERRON, J.A.; et al. Midline dose algorithm for in vivo dosimetry. Medical Dosimetry, 1994;19:263-267.

${ }^{36}$ GRIESSBACH, I.; et al. "Dosimetric characteristics of a new unshielded silicon diode and its application in clinical photon and electron beams. Medical Physics, 2005; 32:3750-3754.

${ }^{37}$ AMERICAN ASSOCIATION OF PHYSICISTS IN MEDICINE. The physical aspects of total and half body irradiation. AAPM Report No. 17. New York, N.Y.: American Institute of Physics, 1986.

${ }^{38}$ IAEA-TECDOC-1151. Aspectos Físicos da Garantia de Qualidade em Radioterapia: Protocolo de Controle de Qualidade. OIEA, Viena, 2000.

${ }^{39}$ TRS-398, Absorbed Dose Determination in External Beam Radiotherapy: An Internacional Code of Practice for Dosimetry Based on Standards of Absorbed Dose to Water. Vienna: International Atomic Energy Agency, IAEA, 2000

${ }^{40}$ JOHNS, H.E., CUNNINGHAM, J.R. "The Physics of Radiology”. Fourth Edition, 1983. Charles C Thomas Publisher, Springfield, USA.

${ }^{41}$ ATTIX, F.H. "Introduction to Radiological Physics and Radiation Dosimetry", 1986, New York, USA, John Wiley \& Sons, Inc.

42 VIEGAS, C.C.B., Dosimetria in vivo com uso de Detectores Semicondutores $e$ Termoluminescentes Aplicada ao Tratamento de Câncer de Cabeça e Pescoço- COPPE / INCA, Rio de Janeiro, 2003.

${ }^{43}$ HEUKELOM, S.; LANSON, J.H.; MIJNHEER, B.J. Comparison of entrance and exit dose measurements using ionization chambers and silicon diodes. Physics in Medicine and Biology, 1991;36:47-59.

${ }^{44}$ LARIN, F. Radiation Efects in Semiconductor Devices. New York: Wiley, 1968 
${ }^{45}$ HUYSKENS, D; BOGAERTS, R; VERSTRAETE, J; LÖÖF, M; NYSTRÖM, H.; et al. Practical Guidelines for the Implementation of In Vivo Dosimetry With Diodes in external radiotherapy with photon beams (entrance dose). Physics for Clinical Radiotherapy. Booklet No 5.

${ }^{46}$ RIKNER, G.; GRUSELL, E. Patient dose measurements in photon fields by means of silicon semiconductor detectors. Medical Physics, 1987;14: 870-873.

47 CAMERON, J. R.; SUNTHARALINGAM, N.; KENNEY, G. N. Thermoluminescent dosimetry, University of Wisconsin Press, Madison, 1968.

48 DRISCOLL, C.M.H.; et al. Annealing procedures for commonly used radiothermoluminescent materials. Radiation Protection Dosimetry, 1986; 14:17-32.

${ }^{49}$ MAYLES, W.P.M.; HEISIG, S.; MAYLES, H.M.O. Treatment verification and in vivo dosimetry. In: Williams, J.R.,Thwaites, D.I. Radiotherapy Physics: In Practice. Oxford, New York, 2000;220-246.

${ }^{50}$ RIKNER, G.; GRUSELL, E. General specifications for silicon semiconductors for use in radiation dosimetry. Physics in Medicine and Biology, 1987; 32:1109-1117.

51 JORNET, N.; RIBAS, M.; EUDALDO, T. Calibration of semiconductor detectors for dose assessment in total body irradiation. Radiotherapy and Oncology, 1996; 38:247-251. 


\section{APÊNDICES}

\subsection{LEITURAS DOS TLDS}

\subsubsection{PRIMEIRA LEITURA}

\begin{tabular}{|c|c|c|c|c|c|}
\hline $\mathbf{N}^{0}$ TLD & $\begin{array}{c}\mathbf{L} 1 \\
(\mu \mathrm{C})\end{array}$ & $\mathrm{L}_{0} 1(\mu \mathrm{C})$ & $\begin{array}{c}\mathrm{L1-L_{0 } 1} \\
(\mu \mathrm{C})\end{array}$ & $\mathbf{S}_{\mathbf{i}}$ & $\Delta_{\max }$ \\
\hline 1 & 11,93 & 0,0003766 & 11,9296234 & 0,963449756 & \multirow[t]{34}{*}{$26,18 \%$} \\
\hline 2 & 11,71 & 0,0005923 & 11,7094077 & 0,981569098 & \\
\hline 3 & 12,21 & 0,001021 & 12,208979 & 0,941404908 & \\
\hline 6 & 11,17 & 0,0004327 & 11,1695673 & 1,029009669 & \\
\hline 8 & 11,98 & 0,0004584 & 11,9795416 & 0,959435105 & \\
\hline 10 & 10,88 & 0,001071 & 10,878929 & 1,056500392 & \\
\hline 11 & 12,11 & 0,0004709 & 12,1095291 & 0,949136226 & \\
\hline 12 & 11,21 & 0,0008806 & 11,2091194 & 1,025378742 & \\
\hline 14 & 10,91 & 0,0006362 & 10,9093638 & 1,053552981 & \\
\hline 15 & 11,34 & 0,001393 & 11,338607 & 1,013668853 & \\
\hline 16 & 11,29 & 0,0005923 & 11,2894077 & 1,018086427 & \\
\hline 17 & 10,36 & 0,0005467 & 10,3594533 & 1,109478697 & \\
\hline 18 & 11,61 & 0,0005128 & 11,6094872 & 0,990017264 & \\
\hline 19 & 12,51 & 0,001407 & 12,508593 & 0,918855762 & \\
\hline 20 & 11,98 & 0,0006466 & 11,9793534 & 0,959450178 & \\
\hline 21 & 11,62 & 0,0008715 & 11,6191285 & 0,989195769 & \\
\hline 22 & 10,59 & 0,001699 & 10,588301 & 1,085499246 & \\
\hline 24 & 12,41 & 0,0004511 & 12,4095489 & 0,926189408 & \\
\hline 25 & 11,33 & 0,002112 & 11,327888 & 1,014628036 & \\
\hline 26 & 11,48 & 0,0009584 & 11,4790416 & 1,001267628 & \\
\hline 27 & 12,45 & 0,002417 & 12,447583 & 0,923359398 & \\
\hline 28 & 10,43 & 0,0006856 & 10,4293144 & 1,102046818 & \\
\hline 29 & 12,01 & 0,001593 & 12,008407 & 0,957128847 & \\
\hline 30 & 11,68 & 0,0008706 & 11,6791294 & 0,984113829 & \\
\hline 31 & 11,76 & 0,0005479 & 11,7594521 & 0,977391859 & \\
\hline 32 & 11,87 & 0,002255 & 11,867745 & 0,968473181 & \\
\hline 33 & 10,8 & 0,001614 & 10,798386 & 1,064380617 & \\
\hline 34 & 10,08 & 0,0005551 & 10,0794449 & 1,140300172 & \\
\hline 35 & 11,13 & 0,0008681 & 11,1291319 & 1,032748363 & \\
\hline 36 & 11,21 & 0,001322 & 11,208678 & 1,025419122 & \\
\hline 37 & 11,79 & 0,001122 & 11,788878 & 0,974952218 & \\
\hline 39 & 10,71 & 0,0006653 & 10,7093347 & 1,073231258 & \\
\hline 40 & 12,18 & 0,0008018 & 12,1791982 & 0,943706848 & \\
\hline 41 & 11,27 & 0,001412 & 11,268588 & 1,019967431 & \\
\hline
\end{tabular}




\begin{tabular}{|c|c|c|c|c|}
\hline 43 & 10,82 & 0,0006773 & 10,8193227 & 1,062320911 \\
\hline 44 & 11,94 & 0,0008552 & 11,9391448 & 0,96268141 \\
\hline 45 & 11,53 & 0,0009987 & 11,5290013 & 0,996928741 \\
\hline 47 & 12,06 & 0,001771 & 12,058229 & 0,953174197 \\
\hline 48 & 11,75 & 0,00104 & 11,74896 & 0,978264693 \\
\hline 49 & 11,59 & 0,00147 & 11,58853 & 0,991807654 \\
\hline 50 & 10,25 & 0,0008138 & 10,2491862 & 1,121415157 \\
\hline 51 & 10,76 & 0,0008655 & 10,7591345 & 1,068263693 \\
\hline 52 & 11,64 & 0,001255 & 11,638745 & 0,987528531 \\
\hline 53 & 11,51 & 0,001757 & 11,508243 & 0,998726978 \\
\hline 54 & 12,05 & 0,001087 & 12,048913 & 0,953911174 \\
\hline 55 & 10,76 & 0,0009253 & 10,7590747 & 1,06826963 \\
\hline 57 & 11,47 & 0,001383 & 11,468617 & 1,002177747 \\
\hline 58 & 10,74 & 0,001551 & 10,738449 & 1,070321491 \\
\hline 59 & 12,26 & 0,001938 & 12,258062 & 0,93763539 \\
\hline 60 & 11,08 & 0,002162 & 11,077838 & 1,037530315 \\
\hline 61 & 11,03 & 0,0009545 & 11,0290455 & 1,042120349 \\
\hline 62 & 11,01 & 0,0008053 & 11,0091947 & 1,043999408 \\
\hline 63 & 12,36 & 0,0008358 & 12,3591642 & 0,929965212 \\
\hline 64 & 11,57 & 0,0009261 & 11,5690739 & 0,99347561 \\
\hline 65 & 10,84 & 0,0009246 & 10,8390754 & 1,06038498 \\
\hline 66 & 11,25 & 0,0009773 & 11,2490227 & 1,021741449 \\
\hline 67 & 11,63 & 0,000848 & 11,629152 & 0,988343153 \\
\hline 68 & 11,42 & 0,001743 & 11,418257 & 1,006597833 \\
\hline 69 & 12,67 & 0,001448 & 12,668552 & 0,907253864 \\
\hline 70 & & 0,0008761 & & \\
\hline 71 & 12,35 & 0,003373 & 12,346627 & 0,930909531 \\
\hline 72 & 10,83 & 0,0007104 & 10,8292896 & 1,061343188 \\
\hline 73 & 11,38 & 0,003428 & 11,376572 & 1,010286117 \\
\hline 74 & 12,21 & 0,001452 & 12,208548 & 0,941438142 \\
\hline 75 & 12,06 & 0,001988 & 12,058012 & 0,953191351 \\
\hline Média & 11,48 & & & \\
\hline Desvio Padrão & 0,61 & & & \\
\hline$C V(\%)$ & 5,32 & & & \\
\hline
\end{tabular}

Tabela 19- Primeira Leitura dos TLDs

\subsubsection{SEGUNDA LEITURA}

\begin{tabular}{|c|c|c|c|c|c|}
\hline $\mathbf{N}^{\mathbf{0}} \mathbf{T L D}$ & $\mathbf{L} \mathbf{2}(\boldsymbol{\mu C})$ & $\mathbf{L}_{\mathbf{0}} \mathbf{2}(\boldsymbol{\mu} \mathbf{C})$ & $\mathbf{L}_{-} \mathbf{L}_{\mathbf{0}}(\boldsymbol{\mu} \mathbf{C})$ & $\mathbf{S}_{\mathbf{i}}$ & \multirow{2}{*}{$\Delta_{\max }$} \\
\hline 1 & 11,97 & 0,0007886 & 11,9692114 & 0,896298404 & \multirow{2}{*}{$28,97 \%$} \\
\cline { 1 - 5 } 2 & 11,58 & 0,001313 & 11,578687 & 0,926528637 & \\
\cline { 1 - 5 } 3 & 11,88 & 0,0009008 & 11,8790992 & 0,903097524 & \\
\cline { 1 - 5 } 6 & 10,65 & 0,001108 & 10,648892 & 1,007427353 & \\
\hline
\end{tabular}




\begin{tabular}{|c|c|c|c|c|}
\hline 8 & 11,67 & 0,0007791 & 11,6692209 & 0,919340303 \\
\hline 10 & 10,34 & 0,0005425 & 10,3394575 & 1,037577173 \\
\hline 11 & 12,02 & 0,002028 & 12,017972 & 0,892661847 \\
\hline 12 & 10,63 & 0,0008341 & 10,6291659 & 1,009296984 \\
\hline 14 & & 0,001212 & & \\
\hline 15 & 10,55 & 0,0005444 & 10,5494556 & 1,016923099 \\
\hline 16 & 10,26 & 0,0007777 & 10,2592223 & 1,045691844 \\
\hline 17 & 9,43 & 0,0005956 & 9,4294044 & 1,137716087 \\
\hline 18 & 11,17 & 0,0009876 & 11,1690124 & 0,960513311 \\
\hline 19 & 11,21 & 0,0008286 & 11,2091714 & 0,957072088 \\
\hline 20 & 10,61 & 0,002191 & 10,607809 & 1,01132902 \\
\hline 21 & 10,91 & 0,0005366 & 10,9094634 & 0,983365055 \\
\hline 22 & 10,08 & 0,0007151 & 10,0792849 & 1,064359742 \\
\hline 24 & 10,87 & 0,001633 & 10,868367 & 0,987083439 \\
\hline 25 & 9,93 & 0,001503 & 9,928497 & 1,080524583 \\
\hline 26 & 10,69 & 0,002205 & 10,687795 & 1,003760372 \\
\hline 27 & 11,21 & 0,001307 & 11,208693 & 0,957112937 \\
\hline 28 & 9,43 & 0,001548 & 9,428452 & 1,137831012 \\
\hline 29 & 10,53 & 0,001881 & 10,528119 & 1,018984026 \\
\hline 30 & 10,75 & 0,0007646 & 10,7492354 & 0,998023085 \\
\hline 31 & 11,11 & 0,0008019 & 11,1091981 & 0,96568492 \\
\hline 32 & 10,76 & 0,002716 & 10,757284 & 0,997276365 \\
\hline 33 & 9,78 & 0,002116 & 9,777884 & 1,097168373 \\
\hline 34 & 9,61 & 0,0005697 & 9,6094303 & 1,116401779 \\
\hline 35 & 10,49 & 0,001843 & 10,488157 & 1,022866561 \\
\hline 36 & 10,12 & 0,0006128 & 10,1193872 & 1,060141772 \\
\hline 37 & 10,91 & 0,001285 & 10,908715 & 0,98343252 \\
\hline 39 & 9,45 & 0,001746 & 9,448254 & 1,135446304 \\
\hline 40 & 11,41 & 0,001725 & 11,408275 & 0,940368731 \\
\hline 41 & 9,32 & 0,002147 & 9,317853 & 1,151336588 \\
\hline 43 & 10,38 & 0,002241 & 10,377759 & 1,033747756 \\
\hline 44 & & 0,001716 & & \\
\hline 45 & 10,97 & 0,001949 & 10,968051 & 0,978112253 \\
\hline 47 & 10,99 & 0,0006706 & 10,9893294 & 0,976218356 \\
\hline 48 & 11,72 & 0,001627 & 11,718373 & 0,915484179 \\
\hline 49 & 10,38 & 0,0007016 & 10,3792984 & 1,033594436 \\
\hline 50 & 10,07 & 0,0007853 & 10,0692147 & 1,065424206 \\
\hline 51 & 10,59 & 0,0006786 & 10,5893214 & 1,013094671 \\
\hline 52 & 11,41 & 0,0008347 & 11,4091653 & 0,94029535 \\
\hline 53 & 10,65 & 0,0008318 & 10,6491682 & 1,007401224 \\
\hline 54 & 10,85 & 0,001671 & 10,848329 & 0,988906686 \\
\hline 55 & 10,61 & 0,001273 & 10,608727 & 1,011241507 \\
\hline 57 & 11,72 & 0,002018 & 11,717982 & 0,915514726 \\
\hline
\end{tabular}




\begin{tabular}{|c|c|c|c|c|}
\hline 58 & 10,39 & 0,001296 & 10,388704 & 1,032658653 \\
\hline 59 & 10,62 & 0,00356 & 10,61644 & 1,010506825 \\
\hline 60 & 10,94 & 0,0009018 & 10,9390982 & 0,980701049 \\
\hline 61 & 10,51 & 0,001006 & 10,508994 & 1,020838444 \\
\hline 62 & 10,15 & 0,0006966 & 10,1493034 & 1,057016886 \\
\hline 63 & 11,46 & 0,0007919 & 11,4592081 & 0,936189044 \\
\hline 64 & 10,15 & 0,0006916 & 10,1493084 & 1,057016366 \\
\hline 65 & 10,38 & 0,0006583 & 10,3793417 & 1,033590125 \\
\hline 66 & 10,91 & 0,002121 & 10,907879 & 0,983507892 \\
\hline 67 & 11,08 & 0,0008172 & 11,0791828 & 0,968301117 \\
\hline 68 & 11,12 & 0,000714 & 11,119286 & 0,964808809 \\
\hline 69 & 11,49 & 0,00196 & 11,48804 & 0,933839461 \\
\hline 70 & 10,73 & 0,0008528 & 10,7291472 & 0,999891686 \\
\hline 71 & 11,38 & 0,002437 & 11,377563 & 0,942907113 \\
\hline 72 & 9,95 & 0,001238 & 9,948762 & 1,078323623 \\
\hline 73 & 11,21 & 0,001401 & 11,208599 & 0,957120964 \\
\hline 74 & 11,42 & 0,000869 & 11,419131 & 0,939474736 \\
\hline 75 & 10,18 & 0,0008335 & 10,1791665 & 1,053915866 \\
\hline Média & 10,73 & & & \\
\hline $\begin{array}{l}\text { Desvio } \\
\text { Padrão }\end{array}$ & 0,67 & & & \\
\hline$C V(\%)$ & 6,29 & & & \\
\hline
\end{tabular}

Tabela 20-- Segunda Leitura dos TLDs

\subsubsection{TERCEIRA LEITURA}

\begin{tabular}{|c|c|c|c|c|c|}
\hline $\mathbf{N}^{\mathbf{0}} \mathbf{T L D}$ & $\mathbf{L} \mathbf{3}(\boldsymbol{\mu C})$ & $\mathbf{L}_{\mathbf{0}} \mathbf{3}(\boldsymbol{\mu} \mathbf{C})$ & $\mathbf{L}-\mathbf{L}_{\mathbf{0}}(\boldsymbol{\mu} \mathbf{C})$ & $\mathbf{S}_{\mathbf{i}}$ & $\Delta_{\max }$ \\
\hline 1 & 10,98 & 0,0006945 & 10,9793055 & 0,990942144 & $26,29 \%$ \\
\hline 2 & 10,64 & 0,0005475 & 10,6394525 & 1,022595526 \\
\hline 3 & 11,58 & 0,0005833 & 11,5794167 & 0,939585889 \\
\hline 6 & 10,47 & 0,0004796 & 10,4695204 & 1,039193403 \\
\hline 8 & 11,05 & 0,0005837 & 11,0494163 & 0,984654414 \\
\hline 10 & 10,29 & 0,0004828 & 10,2895172 & 1,057372889 \\
\hline 11 & 11,66 & 0,000505 & 11,659495 & 0,933132741 \\
\hline 12 & 10,84 & 0,0005124 & 10,8394876 & 1,003724247 \\
\hline 14 & 10,95 & 0,0004693 & 10,9495307 & 0,993636789 \\
\hline 15 & 10,59 & 0,000496 & 10,589504 & 1,027418898 \\
\hline 16 & 10,57 & 0,0005745 & 10,5694255 & 1,029370663 \\
\hline 17 & 9,57 & 0,0004503 & 9,5695497 & 1,136924607 \\
\hline 18 & 11,21 & 0,0006206 & 11,2093794 & 0,970602934 \\
\hline 19 & 11,48 & 0,001065 & 11,478935 & 0,947810623 \\
\hline 20 & 10,78 & 0,000958 & 10,779042 & 1,009352828 \\
\hline 21 & 11,08 & 0,0006816 & 11,0793184 & 0,981996919 \\
\hline
\end{tabular}




\begin{tabular}{|c|c|c|c|c|}
\hline 22 & 10,77 & 0,0005186 & 10,7694814 & 1,010248881 \\
\hline 24 & 11,11 & 0,0005036 & 11,1094964 & 0,979329408 \\
\hline 25 & 10,05 & 0,0004257 & 10,0495743 & 1,082618647 \\
\hline 26 & 10,93 & 0,0007593 & 10,9292407 & 0,995481464 \\
\hline 27 & 11,64 & 0,0007055 & 11,6392945 & 0,934752233 \\
\hline 28 & 10,11 & 0,000518 & 10,109482 & 1,076203166 \\
\hline 29 & 11,31 & 0,0008099 & 11,3091901 & 0,962036754 \\
\hline 30 & 10,85 & 0,000842 & 10,849158 & 1,002829577 \\
\hline 31 & 10,99 & 0,0009478 & 10,9890522 & 0,990063231 \\
\hline 32 & 11,36 & 0,0005795 & 11,3594205 & 0,957782708 \\
\hline 33 & 10,11 & 0,0006348 & 10,1093652 & 1,0762156 \\
\hline 34 & 10,79 & 0,000679 & 10,789321 & 1,008391217 \\
\hline 35 & 10,79 & 0,0005071 & 10,7894929 & 1,008375151 \\
\hline 36 & 10,86 & 0,0005724 & 10,8594276 & 1,001881216 \\
\hline 37 & 10,96 & 0,000662 & 10,959338 & 0,992747603 \\
\hline 39 & 9,93 & 0,0006536 & 9,9293464 & 1,095727361 \\
\hline 40 & 11,61 & 0,0006972 & 11,6093028 & 0,937167091 \\
\hline 41 & 10,21 & 0,0005289 & 10,2094711 & 1,065663091 \\
\hline 43 & & 0,000231 & & \\
\hline 44 & 11,13 & 0,0008187 & 11,1291813 & 0,977597205 \\
\hline 45 & 11,59 & 0,0005437 & 11,5894563 & 0,938771953 \\
\hline 47 & 10,87 & 0,0007382 & 10,8692618 & 1,000974742 \\
\hline 48 & 11,72 & 0,0007194 & 11,7192806 & 0,928372389 \\
\hline 49 & 10,37 & 0,0004851 & 10,3695149 & 1,049215574 \\
\hline 50 & 10,07 & 0,0005353 & 10,0694647 & 1,08048013 \\
\hline 51 & 10,58 & 0,000651 & 10,579349 & 1,028405106 \\
\hline 52 & 11,33 & 0,00122 & 11,32878 & 0,960373185 \\
\hline 53 & 10,93 & 0,000213 & 10,929787 & 0,995431707 \\
\hline 54 & 10,71 & 0,0008088 & 10,7091912 & 1,015936342 \\
\hline 55 & 10,67 & 0,001048 & 10,668952 & 1,019768064 \\
\hline 57 & 11,45 & 0,001596 & 11,448404 & 0,950338277 \\
\hline 58 & 10,85 & 0,0006575 & 10,8493425 & 1,002812523 \\
\hline 59 & 10,93 & 0,000998 & 10,929002 & 0,995503206 \\
\hline 60 & 11,37 & 0,0006396 & 11,3693604 & 0,956945347 \\
\hline 61 & 10,55 & 0,001755 & 10,548245 & 1,031437602 \\
\hline 62 & 9,511 & 0,00103 & 9,50997 & 1,144047408 \\
\hline 63 & 11,61 & 0,0006316 & 11,6093684 & 0,937161795 \\
\hline 64 & 10,62 & 0,0007088 & 10,6192912 & 1,024536979 \\
\hline 65 & 10,29 & 0,0007491 & 10,2892509 & 1,057400255 \\
\hline 66 & 11,08 & 0,000111 & 11,079889 & 0,981946347 \\
\hline 67 & 10,96 & 0,0006289 & 10,9593711 & 0,992744605 \\
\hline 68 & 11,63 & 0,0008853 & 11,6291147 & 0,935570489 \\
\hline 69 & 11,72 & 0,001211 & 11,718789 & 0,928411334 \\
\hline
\end{tabular}




\begin{tabular}{|c|c|c|c|c|}
\hline 70 & 10,92 & 0,001202 & 10,918798 & 0,996433539 \\
\hline 71 & 11,85 & 0,001269 & 11,848731 & 0,918229685 \\
\hline 72 & 10,19 & 0,0006635 & 10,1893365 & 1,067768891 \\
\hline 73 & 11,25 & 0,0009543 & 11,2490457 & 0,967180401 \\
\hline 74 & 11,24 & 0,001015 & 11,238985 & 0,968046183 \\
\hline 75 & 10,38 & 0,0006744 & 10,3793256 & 1,048223839 \\
\hline Média & 10,88 & & & \\
\hline $\begin{array}{l}\text { Desvio } \\
\text { Padrão } \\
\end{array}$ & 0,57 & & & \\
\hline$C V(\%)$ & 5,25 & & & \\
\hline
\end{tabular}

Tabela 21-- Terceira Leitura dos TLDs

\subsection{FATORES DE CORREÇÃO INDIVIDUAL}

\begin{tabular}{|c|c|}
\hline $\mathbf{N}^{\mathbf{0}} \mathbf{T L D}$ & $\mathbf{S}_{\text {i.médio }}$ \\
\hline 1 & $0,95 \pm 0,02$ \\
\hline 2 & $0,97 \pm 0,03$ \\
\hline 3 & $0,93 \pm 0,01$ \\
\hline 6 & $1,03 \pm 0,01$ \\
\hline 8 & $0,95 \pm 0,02$ \\
\hline 10 & $1,05 \pm 0,01$ \\
\hline 11 & $0,92 \pm 0,02$ \\
\hline 12 & $1,01 \pm 0,01$ \\
\hline 14 & $1,02 \pm 0,02$ \\
\hline 15 & $1,02 \pm 0,01$ \\
\hline 16 & $1,03 \pm 0,01$ \\
\hline 17 & $1,13 \pm 0,01$ \\
\hline 18 & $0,97 \pm 0,01$ \\
\hline 19 & $0,94 \pm 0,02$ \\
\hline 20 & $0,99 \pm 0,02$ \\
\hline 21 & $0,98 \pm 0,01$ \\
\hline 22 & $1,05 \pm 0,02$ \\
\hline 24 & $0,96 \pm 0,02$ \\
\hline 25 & $1,06 \pm 0,02$ \\
\hline 26 & $1,01 \pm 0,01$ \\
\hline 27 & $0,94 \pm 0,01$ \\
\hline 28 & $1,11 \pm 0,02$ \\
\hline 29 & $0,98 \pm 0,02$ \\
\hline 30 & $0,99 \pm 0,01$ \\
\hline 33 & $0,97 \pm 0,01$ \\
\hline & $0,97 \pm 0,02$ \\
\hline 32 & $1,08 \pm 0,01$ \\
\hline
\end{tabular}




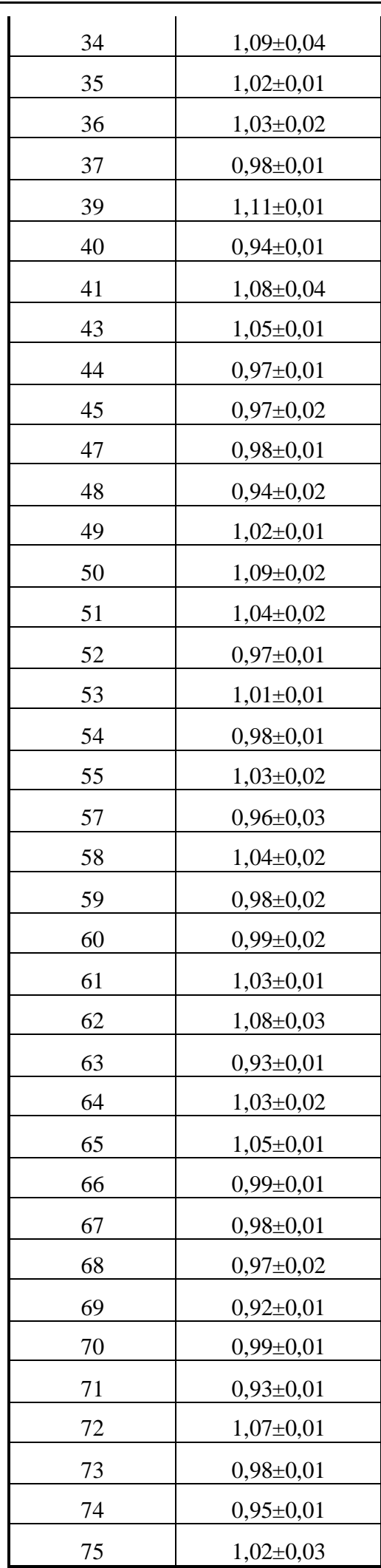

Tabela 22- Fatores de correção individual para cada TLD

\begin{tabular}{|c|c|c|c|c|c|c|}
\hline${ }^{0}$ TLD & $\mathbf{L}(\boldsymbol{\mu} \mathbf{C})$ & $\begin{array}{c}\text { D }_{\text {nominal }} \\
\text { (Gy) }\end{array}$ & $\mathbf{L}_{\text {corr }}(\boldsymbol{\mu} \mathbf{C})$ & $\begin{array}{c}\mathbf{L}_{\text {corr,média }} \\
(\mu \mathrm{C})\end{array}$ & $\mathrm{C}_{\text {supra }}$ & $\begin{array}{c}\mathbf{L}_{\text {corr, supra }} \\
(\mu \mathrm{C})\end{array}$ \\
\hline 1 & 1,88 & & 1,79 & \multirow[t]{2}{*}{1,77} & \multirow[t]{2}{*}{1} & \multirow[t]{2}{*}{1,77} \\
\hline 2 & 1,80 & & 1,76 & & & \\
\hline
\end{tabular}




\begin{tabular}{|c|c|c|c|c|c|c|}
\hline 3 & 1,89 & \multirow[t]{3}{*}{0,25} & 1,76 & & & \\
\hline 4 & & & & & & \\
\hline 6 & 1,75 & & 1,79 & & & \\
\hline 8 & 3,44 & \multirow{5}{*}{0,5} & 3,28 & \multirow[t]{5}{*}{3,48} & \multirow[t]{5}{*}{1} & \multirow[t]{5}{*}{3,48} \\
\hline \multicolumn{2}{|l|}{9} & & & & & \\
\hline 10 & 3,43 & & 3,61 & & & \\
\hline 11 & 3,72 & & 3,44 & & & \\
\hline 12 & 3,55 & & 3,59 & & & \\
\hline 14 & 5,05 & \multirow{5}{*}{0,75} & 5,17 & \multirow[t]{5}{*}{5,36} & \multirow[t]{5}{*}{1} & \multirow[t]{5}{*}{5,36} \\
\hline 15 & 5,55 & & 5,66 & & & \\
\hline 16 & 5,31 & & 5,47 & & & \\
\hline 17 & 4,87 & & 5,49 & & & \\
\hline 18 & 5,13 & & 4,99 & & & \\
\hline 19 & 8,16 & \multirow{5}{*}{1} & 7,68 & \multirow[t]{5}{*}{7,40} & \multirow[t]{5}{*}{1} & \multirow[t]{5}{*}{7,40} \\
\hline 20 & 7,69 & & 7,65 & & & \\
\hline 21 & 7,25 & & 7,14 & & & \\
\hline 22 & 6,76 & & 7,13 & & & \\
\hline 23 & & & & & & \\
\hline 24 & 9,96 & \multirow{5}{*}{1,25} & 9,61 & \multirow[t]{5}{*}{9,97} & \multirow[t]{5}{*}{0,996948403} & \multirow[t]{5}{*}{9,94} \\
\hline 25 & 9,51 & & 10,07 & & & \\
\hline 26 & 9,53 & & 9,52 & & & \\
\hline 27 & 10,38 & & 9,74 & & & \\
\hline 28 & 9,87 & & 10,91 & & & \\
\hline 29 & 11,69 & \multirow{5}{*}{1,5} & 11,45 & \multirow[t]{5}{*}{11,29} & \multirow[t]{5}{*}{0,996438976} & \multirow[t]{5}{*}{11,25} \\
\hline 30 & 11,23 & & 11,17 & & & \\
\hline 31 & 10,67 & & 10,43 & & & \\
\hline 32 & 11,97 & & 11,66 & & & \\
\hline 33 & 10,88 & & 11,74 & & & \\
\hline 34 & 13,25 & & 14,42 & 13,97 & 0,995962927 & 13,91 \\
\hline 35 & 12,72 & & 12,99 & & & \\
\hline 36 & 13,34 & 1,75 & 13,72 & & & \\
\hline 37 & 14,98 & & 14,74 & & & \\
\hline 38 & & & & & & \\
\hline 39 & 14,54 & & 16,02 & 16,29 & 0,995520159 & 16,22 \\
\hline 40 & 18,57 & & 17,46 & & & \\
\hline 41 & 14,51 & 2 & 15,64 & & & \\
\hline 43 & 15,54 & & 16,28 & & & \\
\hline 44 & 16,56 & & 16,06 & & & \\
\hline 45 & 16,64 & & 16,16 & 17,12 & 0,995110586 & 17,03 \\
\hline 46 & & & & & & \\
\hline 47 & 17,18 & 2,25 & 16,78 & & & \\
\hline 48 & 18,29 & & 17,21 & & & \\
\hline 49 & 17,87 & & 18,31 & & & \\
\hline 50 & 17,77 & & 19,35 & 19,88 & 0,994734126 & 19,77 \\
\hline 51 & 19,96 & & 20,69 & & & \\
\hline 52 & 20,55 & 2,5 & 19,78 & & & \\
\hline 53 & 19,57 & & 19,58 & & & \\
\hline
\end{tabular}




\begin{tabular}{|c|c|c|c|c|c|c|}
\hline 54 & 20,27 & & 19,99 & & & \\
\hline 55 & 20,74 & \multirow{5}{*}{2,75} & 21,43 & \multirow[t]{5}{*}{21,71} & \multirow[t]{5}{*}{0,994390704} & \multirow[t]{5}{*}{21,59} \\
\hline 57 & 22,39 & & 21,41 & & & \\
\hline 58 & 20,88 & & 21,62 & & & \\
\hline 59 & 23,79 & & 23,34 & & & \\
\hline 60 & 20,97 & & 20,79 & & & \\
\hline 61 & 24,73 & \multirow{5}{*}{3} & 25,51 & \multirow[t]{5}{*}{25,17} & \multirow[t]{5}{*}{0,994080252} & \multirow[t]{5}{*}{25,02} \\
\hline 62 & 23,41 & & 25,32 & & & \\
\hline 63 & 26,83 & & 25,07 & & & \\
\hline 64 & 24,47 & & 25,08 & & & \\
\hline 65 & 23,69 & & 24,89 & & & \\
\hline
\end{tabular}

Tabela 23- Análise da linearidade dos dosímetros termoluminescentes 